Aus dem Institut für Neuropathologie

(Prof. Dr. med. W. Brück)

der Medizinischen Fakultät der Universität Göttingen

\title{
Der Einfluss oraler Vitamin-D-Gabe auf das Immunsystem der Maus bei der experimentellen E.-coli-Meningitis
}

\author{
INAUGURAL-DISSERTATION \\ zur Erlangung des Doktorgrades \\ (für Zahnheilkunde) \\ der Medizinischen Fakultät der \\ Georg-August-Universität zu Göttingen
}

vorgelegt von

Nadine Margarete Sostmann

aus

Lingen (Ems)

Göttingen 2017 
Dekan:

Referentin:

Ko-Referent:
Prof. Dr. rer. nat. H. K. Kroemer

PD Dr. med. M. Djukic

PD Dr. rer. nat. F. Lühder

Datum der mündlichen Prüfung: 05.03.2018 
Hiermit erkläre ich, die Dissertation mit dem Titel "Der Einfluss oraler Vitamin-D-Gabe auf das Immunsystem der Maus bei der experimentellen E.-coli-Meningitis" eigenständig angefertigt und keine anderen als die von mir angegebenen Quellen und Hilfsmittel verwendet zu haben.

Göttingen, den 


\section{Inhaltsverzeichnis}

$1 \quad$ Einleitung

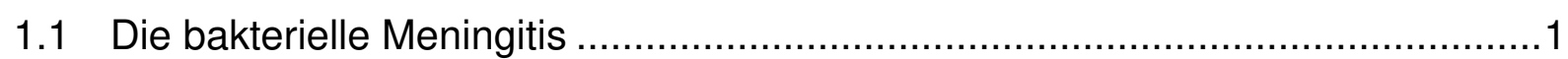

1.2 Escherichia coli K1 als Pathogen der bakteriellen Meningitis ............................3

1.3 Zytokine und Chemokine als Entzündungsmediatoren .....................................

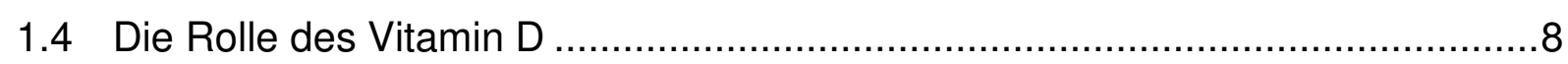

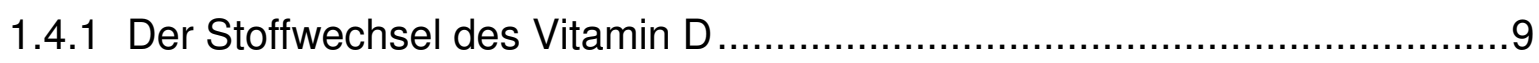

1.4.2 Vitamin D und das Immunsystem.......................................................

1.4.3 Ursachen und Konsequenzen eines Vitamin-D-Mangels ..........................13

1.5 Gegenstand und Zielsetzung dieser Arbeit .................................................15

$\begin{array}{lll}2 & \text { Material und Methode } & 17\end{array}$

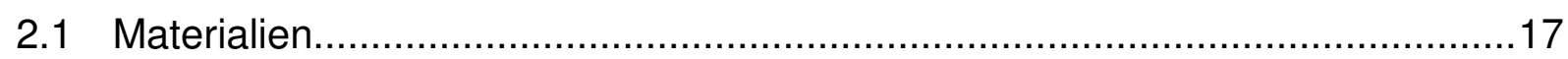

2.1.1 Geräte .................................................................................. 17

2.1.2 Verbrauchsmaterialien und spezielles Material .......................................18

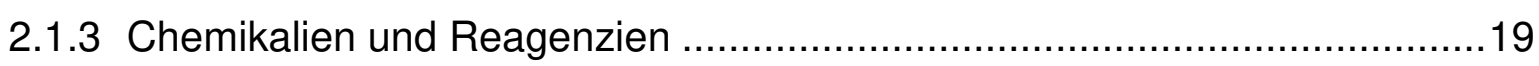

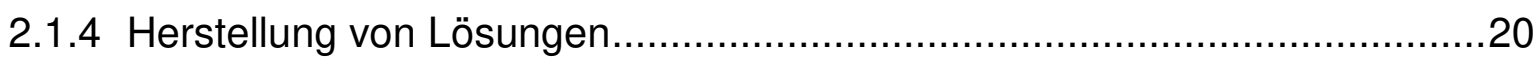

2.1.4.1 Herstellung von 70\%igem Alkohol ................................................20

2.1.4.2 Herstellung von phosphate-buffered saline (PBS).............................20

2.1.4.3 Herstellung von tris-buffered saline (TBS) .......................................20

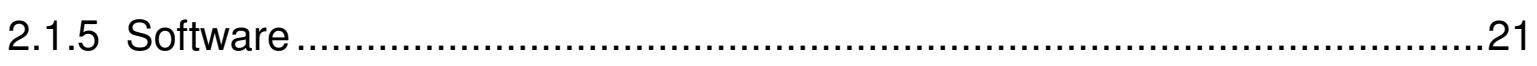

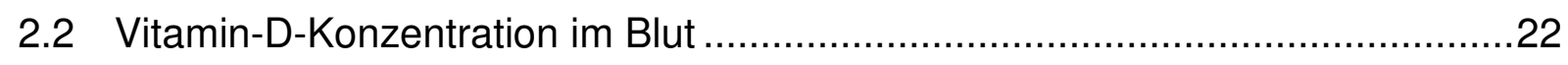

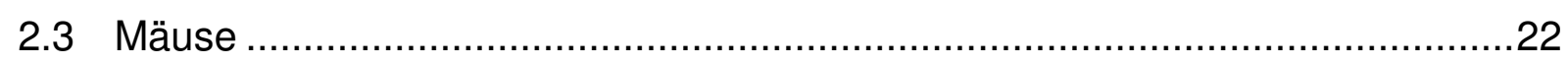

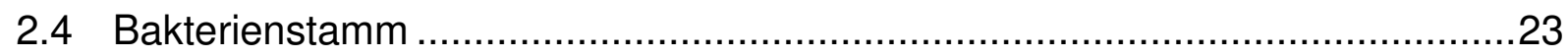

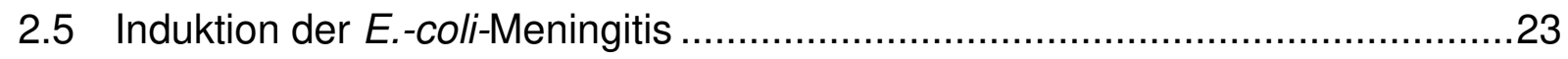

2.6 Gewebepräparation und Gewinnung von Blutserum ..................................25

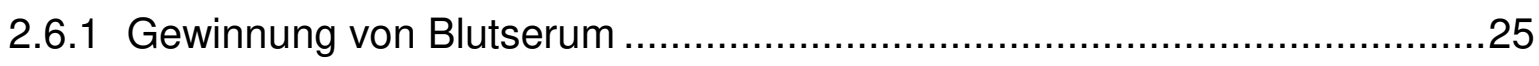

2.6.2 Präparation und Homogenisierung der Milz ..........................................25

2.6.3 Präparation und Homogenisierung des Gehirns .....................................25

2.6.4 Ausplattierung und bakterielle Titer ...................................................26

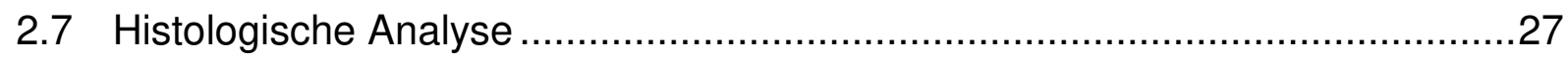

2.7.1 Entparaffinierung und Chloracetatesterase(CAE)-Färbung.......................27 
2.7.2 Mikroskopische Auswertung der Präparate ...........................................28

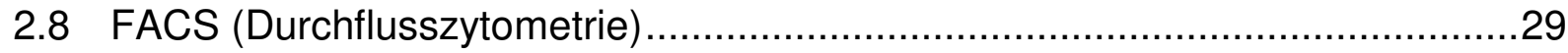

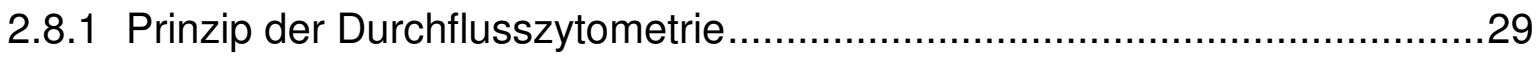

2.8.2 Ansetzen der Proben ................................................................29

2.8.3 Auswertung der Ergebnisse der Durchflusszytometrie............................30

2.9 Enzyme-Linked Immunosorbent Assay (ELISA) ....................................31

2.9.1 Prinzip der Enzym-gekoppelten Immunreaktion ................................31

2.9.2 ELISA zur Bestimmung von Zytokinen und Chemokinen ..........................31

2.9.3 Auswertung der Ergebnisse des ELISA ............................................

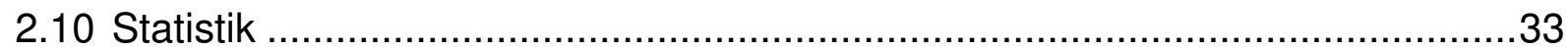

$3 \quad$ Ergebnisse $\quad 34$

3.1 Die Konzentration von Vitamin D im Blutserum war abhängig von der jeweiligen Vitamin-D-Ernährung.

3.2 Ein Vitamin-D-Mangel verursachte eine erhöhte Sterblichkeit der Mäuse bei einer E.-coli-Meningitis 35

3.3 Vitamin D hatte keinen Einfluss auf die bakteriellen Titer in Kleinhirn, Milz und Blut

3.4 Eine hohe Vitamin-D-Konzentration führte zu einer besseren Eliminierung von Bakterien in Mäusen, die die Infektion überlebten

3.5 Die verschiedenen Vitamin-D-Ernährungen beeinflussten nicht die Leukozyteninfiltration in die Meningen $20 \mathrm{~h}$ nach einer E.-coli-Infektion

3.6 VitD-Supplementierung inhibierte die Produktion des proinflammatorischen IL-6 und förderte die Produktion des antiinflammatorischen IL-10.

4.1 Der Zusammenhang zwischen einem Vitamin-D-Mangel und der erhöhten Sterblichkeit der Mäuse bei einer E.-coli-Meningitis .55

4.2 Die geringe antibakterielle Funktion des Vitamin $D$..................................56

4.3 Vitamin D und die meningeale Leukozyteninfiltration ..................................58

4.4 Vitamin D und dessen Wirkung auf die Ausschüttung von Zytokinen und Chemokinen 


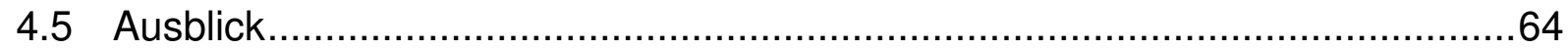

$5 \quad$ Zusammenfassung 


\section{Abbildungsverzeichnis}

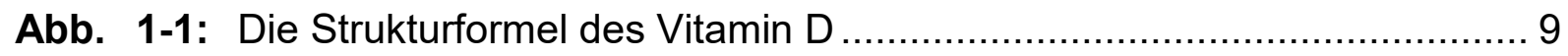

Abb. 1-2: Der Stoffwechsel des Vitamin D ............................................... 10

Abb. 1-3: Die Wirkung des 1,25VitD auf die Zellen des angeborenen und adaptiven Immunsystems................................................... 11

Abb. 2-1: Gewebepräparation von Gehirn und Milz sowie Gewinnung von Blutserum 26

Abb. 2-2: Leukozyteninfiltration und Scores .................................................. 28

Abb. 2-3: Prinzip der Auswertung der Ergebnisse einer FACS-Analyse ............... 30

Abb. 3-1: 25-OH-Vitamin-D-Konzentration im Blutserum................................ 34

Abb. 3-2: Überlebensrate (\%) in Abhängigkeit von der Zeit (Stunden nach

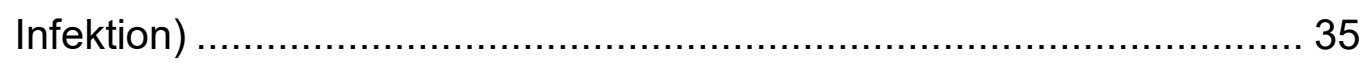

Abb. 3-3: Gewichtsverlust in g $24 \mathrm{~h}$ nach der Infektion bei S-VitD, N-VitD und $\mathrm{H}-\mathrm{VitD}$ 36

Abb. 3-4: Klinischer Score 24 h nach der Infektion ..................................... 37

Abb. 3-5: Bakterientiter von Kleinhirn (A) und Milz (B) im Überlebensversuch ..... 38

Abb. 3-6: Bakterielle Titer von Kleinhirn, Milz und Blut im 20 h-Versuch ............. 40

Abb. 3-7: Leukozytenanzahl der 3 VitD-Gruppen .................................... 42

Abb. 3-8: Meningeale Leukozyteninfiltration mit CAE-Färbung ….................... 43

Abb. 3-9: Zytokine IL-6 (A), IL-10 (B) und Chemokine KC (C), MIP-2 (D) des Kleinhirns der verstorbenen und getöteten Mäuse im Überlebensversuch

Abb. 3-10: Zytokine IL-6 (A), IL-10 (B) und Chemokine KC (C), MIP-2 (D) der Milz der verstorbenen und getöteten Mäuse im Überlebensversuch..... 48 Abb. 3-11: Zytokine IL-6 (A), IL-10 (B) und Chemokine KC (C), MIP-2 (D) des Kleinhirns $20 \mathrm{~h}$ post infectionem ........................................... 50

Abb. 3-12: Zytokine IL-6 (A), IL-10 (B) und Chemokine KC (C), MIP-2 (D) der Milz $20 \mathrm{~h}$ post infectionem

Abb. 3-13: Konzentration des Zytokins IFN-y in Kleinhirn und Milz im 20 hVersuch. 


\section{Tabellenverzeichnis}

Tab. 1-1: VitD-Zufuhr über die Ernährung und geschätzte Angaben zur zusätzlichen Aufnahme bei fehlender endogener Synthese durch das

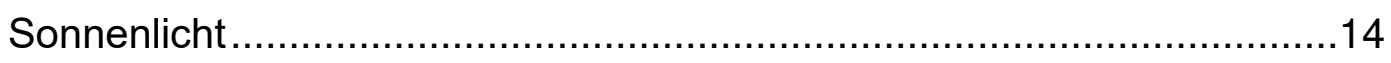

Tab. 2-1: Vitamin-D-Konzentration im Futter................................................22

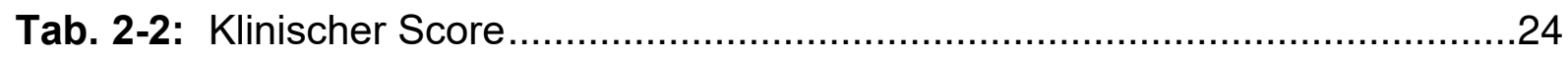

Tab. 2-3: Entparaffinierung der Großhirnpräparate ........................................27

Tab. 3-1: Bakterienlast der Kleinhirnhomogenate von Mäusen, die 14 Tage nach der Infektion getötet wurden.............................................. 41

Tab. 3-2: Die Daten der FACS-Analyse ......................................................44 


\section{Abkürzungsverzeichnis}

1,25VitD

25VitD

$\mathrm{Ag}$

Ak

ANOVA

APC

BHS

BLS

BSA

CAE

CCR2

CD

CFU

DMEM

E. coli

ELISA

FACS

FGF

FoxP3

FSC

H. influenzae

HBMEC
$1,25(\mathrm{OH})_{2}$ VitaminD $_{3}$, Calcitriol

$25(\mathrm{OH})_{2}$ VitaminD $_{3}$, Calcidiol

Antigen

Antikörper

analysis of variance

antigen-presenting cell

Blut-Hirn-Schranke

Blut-Liquor-Schranke

bovine serum albumin

Chloracetatesterase

c-c chemokine receptor type 2

cluster of differentiation

colony forming unit

Dulbecco's Modified Eagle Medium

Escherichia coli

enzyme-linked immunosorbent assay

fluorescence-activated cell sorting

fibroblast-growth factor

forkhead box protein 3

forward scatter

Haemophilus influenzae

human brain microvascular endothelial cells 
HRP

IFN

IL

IE

$\mathrm{KC}$

Ly6C

MAPK

$\mathrm{MHC}$

MIP

MMP

M. tuberculosis

n

$\mathrm{N}$

$\mathrm{NaCl}$

N. meningitidis

$\mathrm{p}$

p. $i$.

PBS

$\mathrm{pH}$

PRRs

RT

SD

SSC

S. pneumoniae

TBS horseradish peroxidase

Interferon

Interleukin

internationale Einheiten

kreatinocyte-derived chemokine

lymphocyte antigen 6C

mitogen-activated protein kinase

major histocompatibility complex

macrophage inflammatory protein

Matrix-Metalloproteinase

Mycobacterium tuberculosis

Anzahl; Nano-

Teilchenanzahl

Natriumchlorid

Neisseria meningitidis

Irrtumswahrscheinlichkeit

post infectionem

phosphate-buffered saline

negativer dekadischer Logarithmus der

Protonenkonzentration

pattern-recognition receptors

Raumtemperatur

Standardabweichung

side scatter

Streptococcus pneumoniae

tris-buffered saline 
TLR

TNF

VDR

ZNS
Toll-like-Rezeptor

Tumornekrose-Faktor

Vitamin-D-Rezeptor

Zentrales Nervensystem 


\section{Einleitung}

\subsection{Die bakterielle Meningitis}

Die bakterielle Meningitis, die eine Infektion des Zentralnervensystems (ZNS) darstellt, wird von Pathogenen wie Neisseria meningitidis ( $N$. meningitidis), Streptococcus pneumoniae (S. pneumoniae), Haemophilus influenzae $(H$. influenzae) Typ b und Escherichia coli (E. coli) K1 ausgelöst und infiltriert die Hirnhäute (Meningen), die sowohl das Gehirn als auch das Rückenmark umgeben (Doran et al. 2016). Die Meningen setzen sich von außen nach innen zusammen aus der Pachymeninx, welche die Dura mater enthält und der aus Arachnoidea und Pia mater bestehenden Leptomeninx. Zwischen Arachnoidea und Pia mater liegt der Subarachnoidalraum, der mit Liquor cerebrospinalis gefüllt ist und das Gehirn umschließt. Der Liquor cerebrospinalis füllt zu etwa $2 / 3$ alle vier miteinander in Verbindung stehenden Ventrikel des Gehirns aus und wird vom Plexus choroideus, welcher aus kapillarreichem Bindegewebe besteht, gebildet. Um das Gehirn vor dem unkontrollierten Eintritt schädlicher Pathogene zu schützen, gibt es die Blut-HirnSchranke (BHS) und die Blut-Liquor-Schranke (BLS). Die Tight Junctions ihrer Epithelzellen stellen eine relativ dichte Barriere dar (Lüllmann-Rauch 2009). Pathogene können diese Schranken jedoch transzellulär, parazellulär oder über infizierte Phagozyten passieren (Pulzova et al. 2009). Die Erreger erreichen das ZNS hierbei nicht nur über den hämatogenen Weg infolge einer Bakteriämie, welche als das Vorhandensein von Bakterien im Blut definiert wird, sondern häufiger auch per continuitatem nach einer Mastoiditis, Otitis oder Sinusitis (Doran et al. 2016; Isenberg 1993). Die Höhe einer Bakteriämie korreliert direkt mit dem Auftreten einer bakteriellen Meningitis (Kim 2002). Als Folge einer Infektion wird eine Immunantwort nach dem Kontakt mit dem Erreger oder seinen Zellwandbestandteilen ausgelöst. Hierbei kommt es insbesondere zu einer vermehrten Einwanderung von Leukozyten in das ZNS. In Studien zur bakteriellen Meningitis mit dem Erreger S. pneumoniae wurde festgestellt, dass bereits $12 \mathrm{~h}$ nach der bakteriellen Infektion einer Maus eine vermehrte Einwanderung von Granulozyten und Monozyten im ZNS stattfand (Mildner et al. 2008).

Trotz geeigneter Antibiotika und der adjuvanten Gabe des Kortikosteroids Dexamethason ist die bakterielle Meningitis mit einer Letalität von $20 \%$ in Industriestaaten immer noch eine lebensbedrohliche Erkrankung (Adriani et al. 2015). 
Die positiven Effekte des Kortikosteroids Dexamethason waren auch nur in Ländern mit einem hohen medizinischen Standard wirksam. In Entwicklungsländern (z. B. Malawi) zeigten sich keine Vorteile bei der Behandlung einer bakteriellen Meningitis, was vermutlich mit der zu späten ärztlichen Versorgung und Behandlung sowie mit dem bereits bei Erstvorstellung fortgeschrittenen Krankheitsstadium zusammenhing (DGN 2016). Bei bis zu $70 \%$ der Überlebenden treten neurologische oder neuropsychologische Spätschäden auf (van de Beek et al. 2004). Nachfolgende neuronale Zellschäden entstehen hierbei $u$. a. durch toxische Bakterienprodukte oder aufgrund der Immunantwort, die durch den Wirt ausgelöst wird (Doran et al. 2016). In einer klinischen Studie von Schmidt et al. (2006) wurden die Spätfolgen bei der bakteriellen und der viralen Meningitis (Erwachsene $<70$ Jahre, 1-12 Jahre nach Gesundung) untersucht und in Bezug zu einer gesunden Kontrollgruppe gesetzt, wobei Alter, Geschlecht und Schulbildung berücksichtigt wurden. Bei den an einer bakteriellen Meningitis erkrankten Patienten zeigte sich, dass 4 von 59 durch die Folgen der Erkrankung in den vorzeitigen Ruhestand gehen mussten. Die Spätfolgen der bakteriellen Meningitis äußerten sich u. a. bei 58,6\% der Studienteilnehmer (Kontrollgruppe: 15,4 \%) in Schwierigkeiten beim Kurzzeit- und Arbeitsgedächtnis.

Prinzipiell kann jeder an einer bakteriellen Meningitis erkranken, Früh- und Neugeborene, ältere und immunsupprimierte Patienten sind jedoch besonders oft betroffen (Russo und Johnson 2000). Neugeborene besitzen ein noch unreifes Immunsystem und können sich nicht adäquat gegen die Erreger wehren (Vergnano et al. 2016). Bei Älteren steigt dagegen die Häufigkeit bakterieller Infektionen aufgrund einer Infektabwehrschwäche im Alter an (Ptaszynski et al. 2007). Es werden weniger Antikörper gegen Epitope der Pathogene produziert, die Antikörperspezifität sowie die Proliferation der B- und T-Lymphozyten sind herabgesetzt. Des Weiteren ist die Produktion der Zytokine und Chemokine und die intrazelluläre Tötung von Pathogenen durch Granulozyten und Makrophagen im Alter beeinträchtigt (Schütze et al. 2014). Schuchat und Kollegen (1997) zeigten z. B., dass die Inzidenz der Pneumokokkenmeningitis bei Personen, die älter als 60 Jahre alt sind, ca. viermal höher ist als bei Personen zwischen 2 und 29 Jahren. 
Aufgrund des signifikanten Anstiegs multiresistenter Stämme, u. a. von E. coli, wird nach neuen Therapiemöglichkeiten gesucht (Pouillot et al. 2012).

Zur Prävention der bakteriellen Meningitis wäre eine Impfung, auch gegen multiresistente Stämme, sinnvoll. Jedoch liegen bisher keine effektiven Impfstoffe gegen $E$. coli vor, sondern nur gegen $H$. influenzae Typ b, S. pneumoniae und $N$. meningitidis Serogruppen A, C, W, Y und B (Allocati et al. 2013; Nau et al. 2015; Robert Koch-Institut 2016).

\subsection{Escherichia coli K1 als Pathogen der bakteriellen Meningitis}

Das zur Gruppe der Enterobacteriaceae gehörende gramnegative Bakterium Escherichia coli ist ein fakultativ anaerobes Stäbchen und ist Bestandteil der physiologischen Darmflora des Menschen und der Säugetiere (Schwerk et al. 2015).

Es kann jedoch zu extraintestinalen Infektionen (Harnwege, Abdomen und Lunge) kommen, wenn die Erreger an andere Stellen des Körpers gelangen. Ohne antibiotische Therapie führen diese Infektionen zur Sepsis und hierdurch zur bakteriellen Meningitis (Russo und Johnson 2000).

Es gibt verschiedene Subtypen des E. coli: Besonders pathogen ist der E.-coli-K1Stamm. Aufgrund seiner Kapsel erschwert er die Phagozytose durch die Mikrogliazellen, welche die residenten Phagozyten des ZNS darstellen (Ribes et al. 2009). Um in das ZNS zu gelangen, muss das $E$. coli $\mathrm{K} 1$ jedoch zunächst die BlutHirn-Schranke (BHS) überwinden (Doran et al. 2016). Die Kapillaren der BHS werden, wie zuvor beschrieben, von Endothelzellen hermetisch durch Tight Junctions abgedichtet (Pulzova et al. 2009). Der E.-coli-K1-Stamm umgeht aber diese Schutzmechanismen der mikrovaskulären Hirnendothelzellen (HBMEC, human brain microvascular endothelial cells) mit Hilfe von Strukturen wie dem outer membrane protein A (OmpA), dem lbe (IQGAP1-binding effector) protein, den cytotoxic necrotising factor 1 (CNF-1), der K1-Kapsel und seiner Fimbrien (Kim 2002; Doran et al. 2016; Wang et al. 2016). Außerdem kann das Bakterium durch den Schutz seiner Kapsel und aufgrund seines Überlebens in Granulozyten und Makrophagen eine hämatogene Ausbreitung sichern. Die durch die Pathogene in Form einer Immunantwort ausgelöste Inflammation, die neuronale Apoptose und die erhöhte Durchlässigkeit der BHS führen zu einem ausgeprägten Zellschaden (Doran et al. 2016). 
E. coli $\mathrm{K} 1$ ist der häufigste Erreger der frühen neonatalen Meningitis, welche sich durch ein hohes Letalitätsrisiko sowie bleibende Schäden charakterisieren lässt. Akute Komplikationen können intraventrikuläre Blutungen, Hirnblutungen, Hydrozephalus oder Krampfanfälle sein. Dagegen erkranken Erwachsene an einer bakteriellen E.-coli-K1-Meningitis, wenn sie im fortgeschrittenen Alter oder immunsupprimiert sind. Außerdem stellen neurochirurgische Operationen und Unfälle ein hohes Risiko für diese Erkrankung dar (Mofredj et al. 2000). Erste Symptome äußern sich bei innen durch hohes Fieber, Kopfschmerzen, Nackensteifigkeit und Bewusstseinsstörungen (Petersen et al. 2014). Van de Beek und Kollegen (2004) untersuchten zwischen 1998 und 2002 in den Niederlanden, wie häufig diese Symptome bei erwachsenen Patienten, die an einer akuten bakteriellen Meningitis erkrankt waren, vorkamen. Bei $44 \%$ der 696 Patienten war die klassische Trias aus Fieber, Nackensteifigkeit und Bewusstseinsstörungen feststellbar. Dagegen hatten $95 \%$ zumindest 2 der 4 Symptome (Kopfschmerz, Fieber, Nackensteifigkeit, Bewusstseinsstörungen). Zusätzlich zu den sichtbaren Symptomen können intrakranielle Komplikationen wie Ischämien, Hydrozephalus, Zerebritis, subdurale Empyeme, Sinusthrombose oder Abszesse auftreten (DGN 2016).

Bei Verdacht auf eine ambulant erworbene bakterielle Meningitis bei Erwachsenen, die keine Bewusstseinsstörung, keine epileptischen Anfälle u. a. zeigen, empfiehlt die DGN in ihrer Leitlinie (2016) die Gabe von $10 \mathrm{mg}$ Dexamethason, wenn zuvor eine klinische Untersuchung, eine lumbale Liquorentnahme und eine Abnahme von Blutkulturen stattgefunden hat. Unmittelbar nach Gabe des Kortikosteroids sollte das jeweilige Antibiotikum intravenös injiziert werden. Geeignete Antibiotika bei gramnegativen Enterobacteriaceae wie E. coli sind hierbei u. a. Ceftriaxon, Meropenem oder Cefepim. Eine Verzögerung um mehr als 3 Stunden nach Aufnahme im Krankenhaus soll unbedingt vermieden werden. In einer retrospektiven Datenanalyse (Erwachsene $\geq 16$ Jahren mit einer bakteriellen Meningitis) zeigte sich, dass Patienten ein 8,4-fach höheres Letalitätsrisiko hatten, wenn das jeweilige Antibiotikum erst $\geq 6$ Stunden nach Krankenhausaufnahme gegeben wurde (Proulx et al. 2005). 


\subsection{Zytokine und Chemokine als Entzündungsmediatoren}

Das Immunsystem ist essentiell für die Gesundheit und das Überleben jedes einzelnen Individuums (Lang und Aspinall 2015). Es besteht aus den lymphatischen Organen, verschiedenen lymphatischen Zellen und zahlreichen spezialisierten Molekülen, die für die Abwehr von Pathogenen und für die Signalübertragung zwischen den einzelnen Immunzellen verantwortlich sind (Lüllmann-Rauch 2009). Um Mikroorganismen abzuwehren, gibt es bei höheren Vertebraten zum einen das angeborene Immunsystem, bestehend aus Makrophagen, dendritischen Zellen, Granulozyten und natürlichen Killerzellen, und zum anderen das erworbene hochspezifische Immunsystem, welches aus im Knochenmark gereiften B-Zellen und im Thymus gereiften T-Lymphozyten zusammengesetzt ist (Lang und Aspinall 2015). B-Lymphozyten sind als Vorläufer der Plasmazellen bei der humoralen Immunantwort beteiligt, indem sie für die Antikörperbildung verantwortlich sind. TZellen, die zur zellvermittelten Immunantwort gehören, lassen sich weiter in T-HelferZellen und in zytotoxische T-Zellen unterteilen. Die nach einer erfolgten Immunreaktion übrig gebliebenen Plasmazellen und B-Gedächtniszellen sind für das immunologische Gedächtnis, also für den Zweitkontakt mit dem spezifischen Antigen, wichtig und gehören der erworbenen Immunität an (Lüllmann-Rauch 2009).

Bei einer E.-coli-Meningitis treffen die Pathogene zunächst auf die Schleimhäute des Intestinaltraktes: Das Darmepithel besitzt eine natürliche Barriere gegen Erreger, indem die in inm vorhandenen Becherzellen Muzine produzieren (Lüllmann-Rauch 2009). Um diese Barriere zu durchdringen, schüttet E. coli das hek protein aus, welches die Adhärenz an das Epithel vermittelt. Durch Bindung an das Heparansulfat-Proteoglykan der extrazellulären Matrix gelangen die Pathogene anschließend durch die Mukosa. Die folgende hämatogene Streuung führt zu einer Bakteriämie, was die Voraussetzung für die Invasion der Pathogene über die BHS oder BLS in das ZNS darstellt (Fagan et al. 2008; Nau et al. 2015). Die Zellen des angeborenen Immunsystems lösen infolgedessen eine Immunreaktion aus, welche sich durch Komplementaktivierung, Bakteriolyse und Präsentation für andere Immunzellen kennzeichnen lässt (Doran et al. 2016). Aufgrund seiner Kapsel erschwert das E. coli K1 jedoch nach dem Erstkontakt die Phagozytose durch Mikrogliazellen und behindert durch Bindung an das $C 4 b$-binding protein über sein OmpA eine suffiziente Komplementaktivierung (Ribes et al. 2009; Mittal et al. 2010). 
Zudem wird bei Neugeborenen durch deren unreifes Immunsystem und bei älteren und immunsupprimierten Patienten durch deren erhöhte Infektanfälligkeit eine adäquate Immunreaktion des Wirts erschwert (Nau et al. 2014; Russo und Johnson 2000; Vergnano et al. 2016; Ptaszynski et al. 2007; Leib und Täuber 2000). Bei einer Immunreaktion werden vermehrt Leukozyten in das ZNS gelockt, wenn u. a. die Mikrogliazellen in Kontakt zu den Pathogenen treten (Nau et al. 2014). Dies geschieht, indem die mustererkennenden Rezeptoren (pattern-recognition receptors, PRRs) auf den Oberflächen der Immunzellen Pathogen-assoziierte molekulare Muster (pathogen-associated molecular patterns, PAMPs) auf den Oberflächen der Antigene, also den Erregerbestandteilen, erkennen (Zeiser 2015; Muniz et al. 2012). $\mathrm{Zu}$ den PRRs gehören auch die Toll-Like-Rezeptoren (TLR), die während einer Inflammation, welche zuvor durch eine bakterielle Meningitis ausgelöst wurde, im ZNS eine wichtige Rolle spielen und von Mikrogliazellen ausgeschüttet werden (Hanamsagar et al. 2012; Ribes et al. 2009). Wenn eine kritische Konzentration an Pathogenen im ZNS erreicht ist, setzt die Entzündungsreaktion ein, indem u. a. Zytokine, Chemokine, Stickstoffmonoxid (NO) oder Matrix-Metalloproteasen (MMP) freigesetzt werden (Leib und Täuber 2000; lliev et al. 2004). Das NO ist toxisch und kann somit auch die Wirtszelle bis zum Zelltod schädigen (Iliev et al. 2004). Hohe Konzentration des MMP-9 sind nach einer bakteriellen Meningitis für neurologische Spätfolgen verantwortlich (Nau et al. 2015). Der neuronale Schaden entsteht hierbei zum einen durch die Vermehrung von Bakterien und deren Produkten im Liquor cerebrospinalis sowie zum anderen durch die Immunantwort des Gehirns, indem es zu einer Einwanderung von Granulozyten und Makrophagen aus dem Blut in den Subarachnoidalraum kommt (Nau et al. 2015; Leib und Täuber 2000).

Zytokine und Chemokine, die sowohl im angeborenen als auch im adaptiven Immunsystem vorzufinden sind, agieren bei der Immunabwehr unterstützend als Entzündungsmediatoren, können jedoch auch einen Neuronenschaden hervorrufen (Leib und Täuber 2000). Nach dem Kontakt zwischen Erreger und Immunzellen werden in der Initialphase einer bakteriellen Pneumokokken-Meningitis z. B. die proinflammatorischen Zytokine IL-1, TNF- $\alpha$ und IL-6 produziert. Diese sorgen für eine Erhöhung der Adhäsionsfaktoren am Kapillarendothel, indem das intracellular adhesion molecule 1 (ICAM-1) auf der BHS sezerniert wird. Somit werden weitere Leukozyten aus dem Blut in den Liquorraum gelockt (Mook-Kanamori et al. 2011; Doran et al. 2016). 
IL-6 wird von Monozyten und Makrophagen produziert. Es ist eines der wichtigsten Zytokine der Akute-Phase-Reaktion zu Beginn einer bakteriellen Infektion. Eine erhöhte Konzentration an IL-6 führt zu einer Inflammation des gesamten Organismus, was sich u. a. durch Fieber äußert (Adam et al. 2004). Je nach Kontext kann IL-6 jedoch auch neurotrophe und neuroprotektive Funktionen beinhalten. Es wirkt somit sowohl pro- als auch antiinflammatorisch (Albrecht et al. 2016). In den Versuchen zu dieser Arbeit wurden die proinflammatorischen Eigenschaften des IL-6 untersucht. Ein weiteres proinflammatorisches Zytokin, das IFN- $\gamma$, ist eines der wichtigsten Zytokine im T-Helferzellen-Signalweg bei der bakteriellen Meningitis. Bei der Pneumokokken-Meningitis war dessen Konzentration im Liquor erhöht (MookKanamori et al. 2011).

Es ist äußerst wichtig, dass die Zytokin- und Chemokinproduktion reguliert abläuft, da es auch zu überschießenden Reaktionen kommen kann, wodurch Krankheiten entstehen können (Kishimoto 2006). Deshalb gibt es für die Regulation der proinflammatorischen Zytokine u. a. das antiinflammatorische Zytokin IL-10 (Zwijnenburg et al. 2003). Bei der bakteriellen E.-coli-Meningitis sichert die Produktion des IL-10 das Überleben des Wirts und die Kontrolle über die Pathogene mit Hilfe seiner antiinflammatorischen Eigenschaften (Mittal et al. 2010). Es verringert u. a. die Produktion des IL-6 und KC und somit die Pleozytose im Liquor cerebrospinalis (Mook-Kanamori et al. 2011). Außerdem erschwert es die Leukozyten-Endothelzelleninteraktion und Leukozytenemigration in das ZNS. Des Weiteren werden reaktive Sauerstoffspezies, reaktive Stickstoffintermediate und Matrix-Metalloproteinasen gehemmt (Adam et al. 2004).

Die Ausschüttung des zu den Chemokinen gehörenden MIP-2 (macrophage inflammatory protein) durch Immunzellen des Gehirns führte zu einer Zerstörung der BHS-Barriere, einem Hirnödem und einer Liquor-Leukozytose im Kaninchenmodell der S.-pneumoniae-Meningitis. Während der akuten Phase der bakteriellen Infektion lockt MIP-2 Monozyten und Neutrophile aus dem Blut in das ZNS. (Mook-Kanamori et al. 2011). Auch das Chemokin KC, welches vermehrt bei der PneumokokkenMeningitis produziert wurde, hat diese Funktion (Ribes et al. 2013; Ramesh et al. 2013). Um die Wirkung beider Chemokine bei der experimentellen bakteriellen Meningitis zu überprüfen, injizierten Zwijnenburg et al. (2006) MIP-2 und KC, zuerst jeweils einzeln und anschließend zusammen, in die Gehirne adulter Ratten. 
Es stellte sich heraus, dass MIP-2 mehr an der Rekrutierung von Leukozyten beteiligt war als KC. Wenn beide zusammen gegeben wurden, waren die größten Effekte nachweisbar, was bedeutet, dass MIP-2 und KC synergistisch zusammenarbeiten.

\subsection{Die Rolle des Vitamin D}

Das zur Gruppe der Secosteroide und fettlöslichen Hormone gehörende Vitamin $D_{3}$ (im Folgenden vereinfacht als Vitamin D oder VitD bezeichnet), auch Cholecalciferol genannt, wurde erstmals 1932 durch Goldblatt und Soames identifiziert und charakterisiert (Windaus et al. 1932). Es wird in der Haut durch UV(ultraviolett)-BStrahlung aus 7-Dehydrocholesterol gebildet (Schlögl und Holick 2014; Holick 2008). VitD kann auch in geringen Mengen durch den Verzehr von Fisch und Eiern über die Nahrung aufgenommen werden (Balvers et al. 2015).

Zum klassischen Wirkungsgebiet des VitD gehören die Regulation der Kalziumhomöostase und des Knochenstoffwechsels. Dies wird deutlich, wenn sich durch einen VitD-Mangel die Gefahr von Knochenfrakturen erhöht. Bereits im 17. Jahrhundert wurde die Krankheit der Rachitis beschrieben, die eine Störung des Kalzium- und Phosphathaushaltes aufgrund eines Vitamin-D-Mangels darstellt (Balvers et al. 2015). In den letzten Jahrzehnten fanden Forscher heraus, dass ein Vitamin-D-Mangel nicht nur ein höheres Risiko für das Entstehen von skelettalen Erkrankungen bereithält, sondern auch für Krebs, Herz-und Kreislauferkrankungen, Diabetes, Parkinson, Multiple Sklerose, Arthritis und kognitive Krankheiten (Spiro und Buttriss 2014). Aufgrund der individuellen Unterschiede, die durch Alter, Sonnenexposition, Krankheiten und Ernährung auftreten, variiert die Vitamin-DKonzentration von Mensch zu Mensch. Trotzdem ist bekannt, dass ein Mangel des durch den im Blutplasma zirkulierenden VitD-Metaboliten $25(\mathrm{OH})_{2}$ VitaminD $_{3}(25 \mathrm{VitD}$, Calcidiol) schon bei $<30 \mathrm{ng} / \mathrm{ml}$ gekennzeichnet ist (Chowdhury et al. 2014). Bei Serumspiegeln > $150 \mathrm{ng} / \mathrm{ml}$ kann VitD selten jedoch auch toxisch wirken (Özkan et al. 2012). Es können Nierenbeschwerden bis hin zu einer Insuffizienz resultieren sowie Krankheiten des Gastrointestinaltraktes und Bluthochdruck (Hemachandar et al. 2014). Präventiv kann eine ausreichende VitD-Aufnahme durch Aufhalten im Freien erreicht werden. Zu den Risikogruppen eines Mangels gehören zum einen ältere bettlägerige Patienten, aber auch diejenigen, die durch längere Arbeitszeiten und durch das Aufhalten in Bürogebäuden keinem Sonnenlicht ausgesetzt sind (Spiro und Buttriss 2014). 


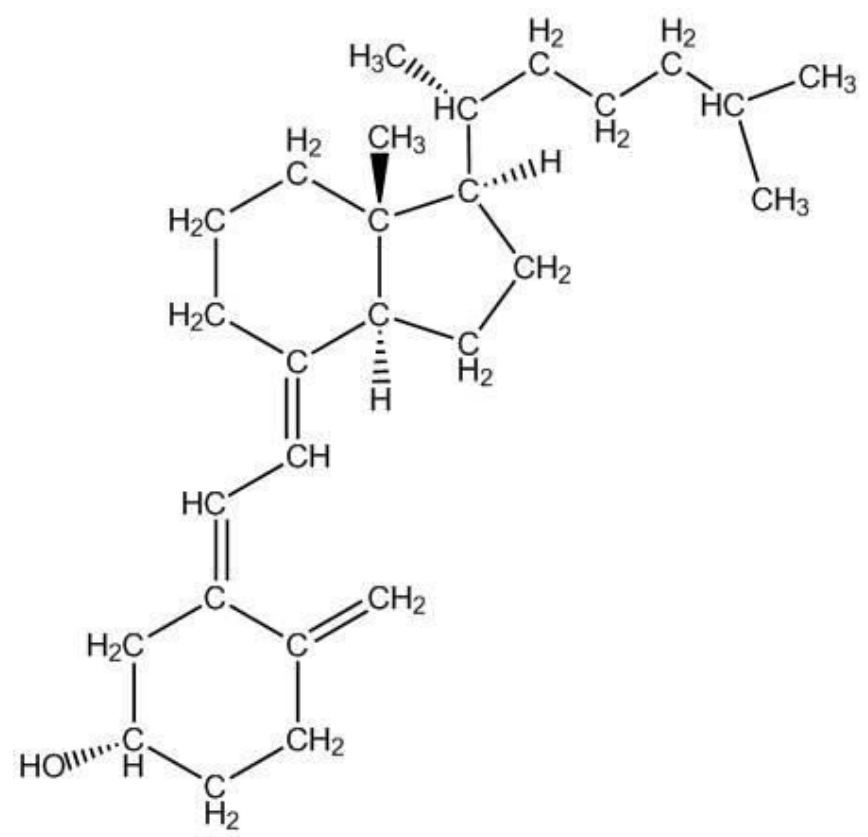

Abbildung 1-1 Die Strukturformel des Vitamin D (nach Adolf Windaus, erstellt mit ChemDraw®)

\subsubsection{Der Stoffwechsel des Vitamin D}

Zuerst wird das Cholesterin-Abbauprodukt 7-Dehydrocholesterol durch das Sonnenlicht (UV-B-Strahlung: 290-315 nm) in der Plasmamembran von Keratinozyten und Fibroblasten in das Prä-VitD konvertiert (s. Abb. 1-2; Schlögl und Holick 2014; Holick 2008). Diese photochemische Reaktion ist zum einen abhängig von individuellen Faktoren wie der Sonnencreme, der Hautpigmentierung und der Hautalterung und zum anderen vom Einstrahlungswinkel der Sonne sowie der Tages- und Jahreszeit (Holick 2008). Das Prä-VitD wird anschließend temperaturabhängig zum VitD isomerisiert und in den extrazellulären Raum entlassen (Dusso et al. 2005; Holick 2008). Hier binden sowohl das VitD aus der Haut als auch das VitD aus der Nahrung an das Vitamin-D-bindende Protein (DBP) (Holick 2008). In der Leber entsteht nun mit Hilfe des Enzyms CYP2R1, einer 25Hydroxylase, das 25VitD durch eine Hydroxylierung an der C-25-Position beider VitD. Diese Hydroxylierung ist kaum reguliert. Mit steigender VitD-Aufnahme steigt auch die Konzentration an 25VitD, wodurch sich letzterer Metabolit als Indikator zur VitDAufnahme eignet. In einem nächsten Schritt wird dieser in der Niere durch das Enzym CYP27B1, einer 1a-Hydroxylase, zum 1,25(OH $)_{2} V_{\text {itaminD }}$ (1,25VitD; Calcitriol) konvertiert (Dusso et al. 2005; Schlögl und Holick 2014). 


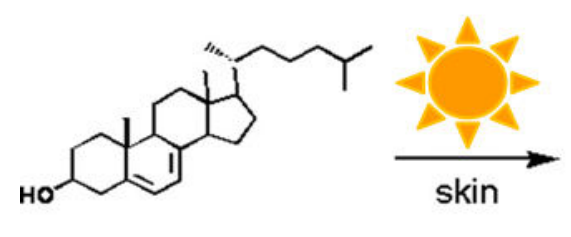

7,8-dehydrocholesterol

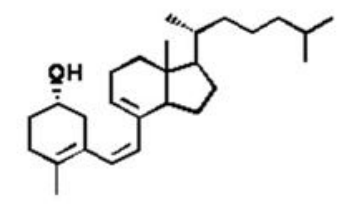

pre-vitamin $\mathrm{D}_{3}$

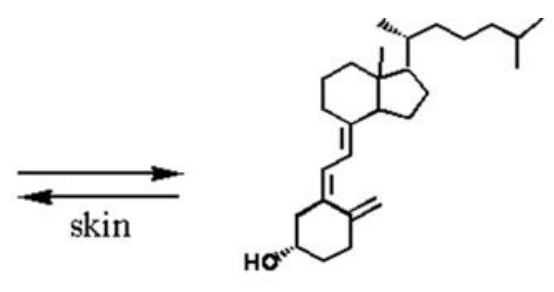

vitamin $\mathrm{D}_{3}$

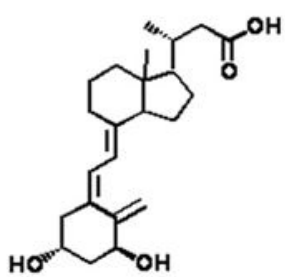

calcitroic acid

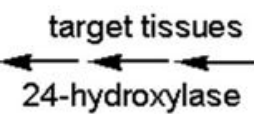

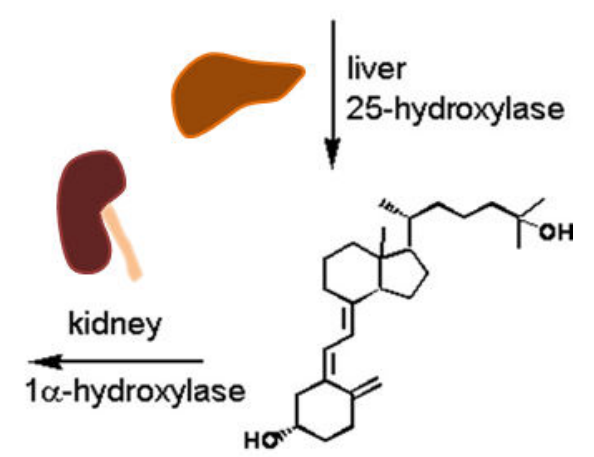

25-hydroxyvitamin $D_{3}$

Abbildung 1-2 Der Stoffwechsel des Vitamin D (modifiziert nach Dusso et al. 2005, S. 9)

Das Verhältnis zwischen 25VitD- und 1,25VitD-Konzentration im Serum liegt bei ungefähr 1000:1 (Johal und Levin 2009). Das 1,25VitD besitzt zwar eine 100- bis 1000-fach höhere biologische Aktivität als andere natürliche VitD-Metabolite (Linseisen et al. 2011), hat jedoch mit ungefähr 4-6 Stunden eine deutlich kürzere Halbwertszeit als 25VitD, welches eine Halbwertszeit von bis zu 3 Wochen hat (Johal und Levin 2009). Die Konzentration im Blut ist durch negative Rückkopplung reguliert, indem 1,25VitD das Enzym CYP24A1 induziert, welches wiederum 25VitD und wiederum 1,25VitD durch Hydroxylierung inaktiviert (Deluca 2004). 1,25VitD wird durch diese Hydroxylierung zu dem biologisch schwachen Metaboliten 24,25Dihydroxycholecalciferol (Calcitroinsäure) umgewandelt (Deluca 2004; Linseisen et al. 2011). Die Konzentration von 1,25VitD wird außerdem durch das Parathormon, Kalzium, den fibroblast growth factor 23 (FGF-23) und die Zytokine IFN-Y und TNF- $\alpha$ reguliert (Schlögl und Holick 2014). Das 1,25VitD ist an der Kalziumhomöostase beteiligt. Wenn der Kalziumspiegel sinkt, wird dies zum einen durch eine Erhöhung der intestinalen Kalziumabsorption ausgeglichen und zum anderen durch Aktivierung von Osteoklasten, die Kalzium aus dem Knochen lösen (Holick 2008). 


\subsubsection{Vitamin D und das Immunsystem}

Die klassische endokrine Wirkung des VitD als wesentliche Komponente in der Kalziumhomöostase und im Knochen- und Mineralstoffwechsel ist seit langer Zeit bekannt (Schwalfenberg 2011). VitD beeinflusst jedoch auch das angeborene und das erworbene Immunsystem (Mora et al. 2008). Studien der letzten Jahre zeigen, dass die Vitamin-D-Signal-Kaskade als ein Schlüsselregulator bei der Immunität des Menschen agiert (Schwalfenberg 2011). Das VitD besitzt sowohl eine antibakterielle als auch eine antivirale Funktion (Bikle 2008; Beard et al. 2011).

Der antibakterielle Effekt von VitD wurde bereits 1986 in kultivierten menschlichen Monozyten nachgewiesen. Hierbei begrenzte die aktive Form 1,25VitD das Wachstum vom Mycobacterium tuberculosis (M. tuberculosis) (Rook et al. 1986). Die Wirkung des VitD erfolgt durch Bindung an den Vitamin-D-Rezeptor (VDR), welcher zu den nukleären Hormonrezeptoren gehört (Lee und Song 2015). In-vitro-Versuche und Studien an nephrektomierten Patienten zeigten, dass der VDR und das Enzym CYP27B1, welches die Produktion von 1,25VitD aus 25VitD katalysiert, nicht nur in den Nierentubuli enthalten sind, sondern auch in zahlreichen anderen Zellen, wie z. B. extrarenalen Keratinozyten, Monozyten, Makrophagen, Osteoblasten, Prostataund Kolonzellen (Lang und Aspinall 2015; Schlögl und Holick 2014; Linseisen et al. 2011).

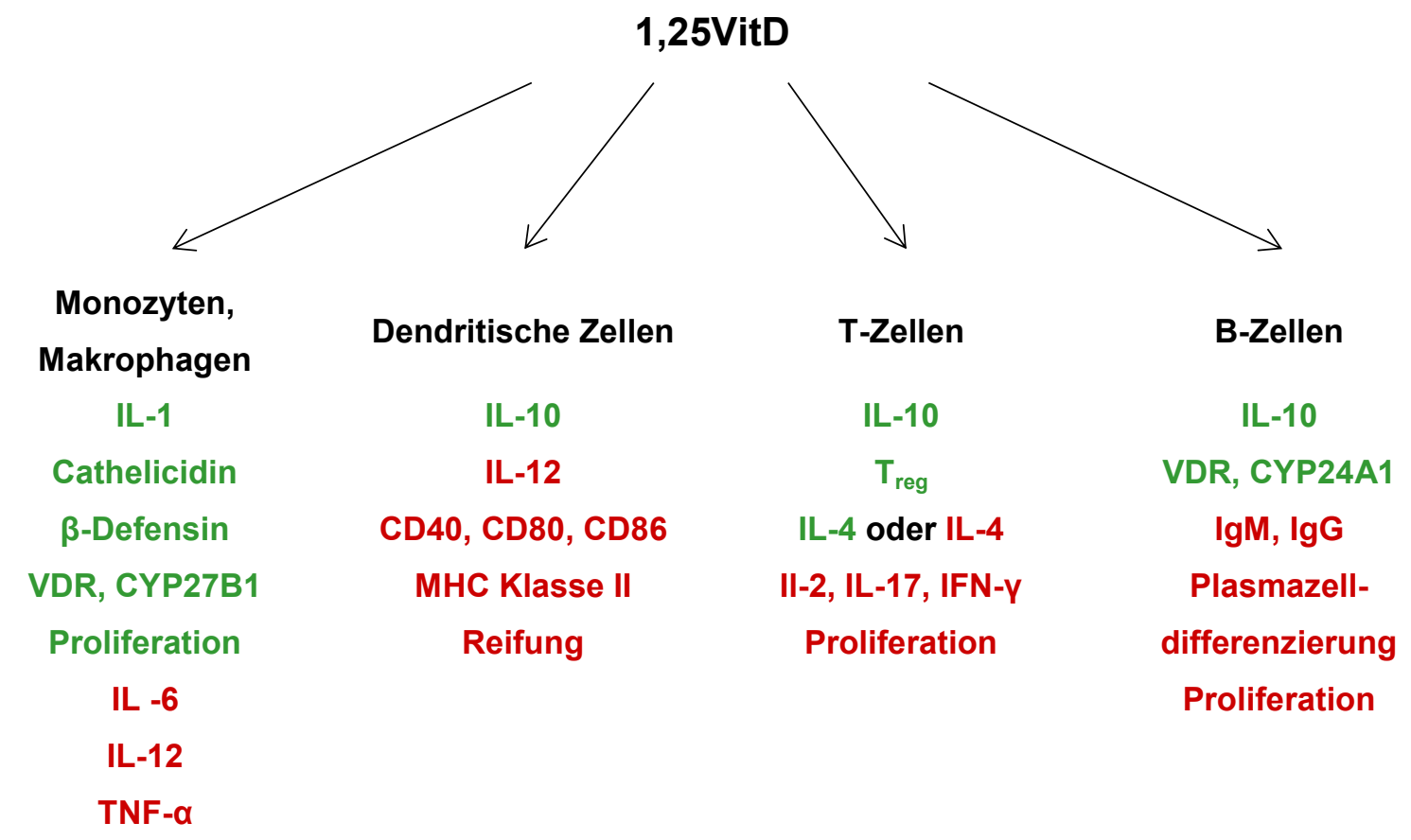

Abbildung 1-3 Die Wirkung des 1,25VitD auf die Zellen des angeborenen und adaptiven Immunsystems, grün = Induktion, rot $=$ Hemmung (nach Mora et al. 2008 und De Castro Kroner et al. 2015) 
Auch im menschlichen Gehirn, z. B. im Hippocampus, präfrontalen Kortex, Thalamus und Cerebellum, sind der VDR und das Enzym CYP27B1 vorhanden (Schlögl und Holick 2014). Keratozyten, dendritische Zellen und Makrophagen exprimieren sowohl CYP27B1 als auch CYP2R1 und können somit auch extrarenal 1,25VitD direkt aus dem VitD produzieren, wodurch das Vitamin $D$ auch extrarenale Funktionen übernimmt (s. Abb. 1-3; Mora et al. 2008).

Des Weiteren besteht die Vermutung, dass 1,25VitD die Genexpression antimikrobieller Proteine unterstützt und bei der Regulation anti- und proinflammatorischer Zytokine mitwirkt (Bergman et al. 2015). Proinflammatorische Zytokine sind wichtig für die Immunantwort, jedoch führt eine überschießende Reaktion zu einer unkontrollierten Inflammation. Regulierend wirkt hier die mitogenactivated protein kinase (MAP-Kinase), die durch die in der Zellwand gramnegativer Bakterien enthaltenen Lipopolysaccharide (LPS) aktiviert wird. Die MAPK reguliert proinflammatorische Zytokine wie IL-6 und TNF- $\alpha$ (Zhang et al. 2012). In einer Studie von Zhang et al. (2012) wurde untersucht wie sich VitD u. a. auf die Produktion des Zytokins IL-6 auswirkte. Hierfür wurden menschliche Zellen (peripheral blood mononuclear cells, PBMC) für 24 Stunden mit VitD vorbehandelt und anschließend mit LPS stimuliert. Es wurde gezeigt, dass VitD u. a. die durch LPS induzierte Produktion des IL-6 verringerte.

VitD wirkt des Weiteren antiinflammatorisch auf das erworbene Immunsystem durch Stimulierung der IL-10-Sezernierung dendritischer Zellen, durch Regulation der proinflammatorischen Zytokine und durch Erhöhung immunregulatorischer T-Zellen (Bergman et al. 2015; De Castro Kroner et al. 2015). Den Zusammenhang zwischen VitD und dem Zytokin IFN-y zeigten Fabri et al. (2011) in einer Studie an menschlichen Monozyten mit dem Erreger Mycobacterium tuberculosis. Es wurde überprüft, ob VitD Einfluss auf die antimikrobielle Aktivität des IFN-y hatte. Hierfür wurden menschliche Monozyten mit $M$. tuberculosis infiziert und anschließend mit IFN-y behandelt. Eine hohe VitD-Serumkonzentration führte hierbei zu einer signifikanten Verringerung des Wachstums des M. tuberculosis. Eine niedrige VitDKonzentration hatte jedoch keinen bzw. nur einen geringen Effekt.

Ryynänen und Carlberg (2013) bewiesen in ihrer in-vitro-Studie an menschlichen Monozyten, dass eine Inkubation mit 1,25VitD zu einer Hochregulierung des Chemokins KC führte und somit einer Immunantwort förderlich war. 
Denn bei der akuten bakteriellen Meningitis haben u. a. KC und MIP-2 die Funktion, Monozyten und Neutrophile aus dem Blutstrom in das ZNS zu locken (Prinz et al. 1999). Somit beeinflusst VitD nicht nur den klassischen Weg, die Kalziumhomöostase und den Mineralstoffwechsel, sondern besitzt auch immunmodulatorische Aufgaben, wodurch es eine wichtige Rolle bei Infektionen einnimmt (Lagishetty et al. 2011).

\subsubsection{Ursachen und Konsequenzen eines Vitamin-D-Mangels}

Wie zuvor beschrieben wird Vitamin D hauptsächlich über die UV-B-Strahlung des Sonnenlichts aufgenommen. Im Winter kann jedoch durch die fehlende Sonnenstrahlung nicht genügend VitD synthetisiert werden und auch über die Nahrung ist es nicht möglich die benötigte Menge aufzunehmen (Spiro und Buttriss 2014; Balvers et al. 2015). Der empfohlene Richtwert für die VitD-Aufnahme variiert von Mensch zu Mensch. Es ist jedoch bekannt, dass der im Blutplasma zirkulierende VitD-Metabolit 25VitD den Wert von $30 \mathrm{ng} / \mathrm{ml}$ nicht unterschreiten sollte (Chowdhury et al. 2014). Laut Schätzungen sind weltweit 1 Milliarde Menschen von einem VitDMangel betroffen (Zhang et al. 2012).

Studien von Linseisen und Kollegen (2011), die in Deutschland durchgeführt wurden, ergaben bei Kindern und Jugendlichen eine mediane 25VitD-Serumkonzentration von $16,72 \mathrm{ng} / \mathrm{ml}$, wohingegen bei Erwachsenen der Wert bei 17,96 $\mathrm{ng} / \mathrm{ml}$ war. Eine Konzentration von $10 \mathrm{ng} / \mathrm{ml}$ und weniger hatten $19 \%$ der Jungen und Mädchen sowie $16 \%$ der Männer und $17 \%$ der Frauen. Es gab jedoch saisonale Unterschiede. Ein Wert von $10 \mathrm{ng} / \mathrm{ml}$ oder weniger trat häufiger im Winter (31\%) als im Sommer (23\%) bei 65-79-jährigen Frauen auf. Bei multimorbiden geriatrischen Patienten (mittleres Alter $83 \pm 5$ Jahre) lagen die medianen Serumwerte bei 10,96 $\mathrm{ng} / \mathrm{ml}$, wobei $<10 \mathrm{ng} / \mathrm{ml}$ bei $45 \%$ der Patienten im Gegensatz $\mathrm{zu}<20 \mathrm{ng} / \mathrm{ml}(79 \%)$ und $>30 \mathrm{ng} / \mathrm{ml}(8 \%)$ vorlagen (Linseisen et al. 2011). Durch die verringerte VitDSyntheseleistung der Haut im Alter und durch weniger Bewegung im Freien gibt es eine besonders hohe Prävalenz bei älteren Menschen, die in Pflegeheimen wohnen (> $80 \%$ ), aber auch bei denjenigen, die noch zu Hause wohnen (> $50 \%$ ) zeigt sich ein solcher Mangel (Gloth et al. 1995; Holick 2006; Holick 2007; Flicker et al. 2005; Spiro und Buttriss 2014). 
Die folgende Tabelle 1-1 zeigt die jeweilige Zufuhr von Vitamin D in Bezug zum Lebensalter und nennt einen Richtwert für die tägliche Vitamin-D-Aufnahme ohne endogene Synthese des Sonnenlichts. Die DGE (Deutsche Gesellschaft für Ernährung), ÖGE (Österreichische Gesellschaft für Ernährung), SGE (Schweizerische Gesellschaft für Ernährungsforschung) und SVE (Schweizerische Vereinigung für Ernährung) veröffentlichten 2015 Referenzwerte für die Nährstoffzufuhr des Vitamin D. Sie empfehlen bei > 65-Jährigen die zusätzliche VitDGabe von 800-1000 IE/Tag und bei Säuglingen 400 IE/Tag.

\begin{tabular}{lllll}
\hline & Säuglinge & Kinder & Erwachsene & Senioren \\
& $0-12$ Monate & 1-15 Jahre & 15-65 Jahre & >5 Jahre \\
\hline Zufuhr Ernährung & $0,3-1,5^{\text {a }}$ & $1-2$ & $2-4$ & $2,9-3,6^{\mathrm{b}}$ \\
benötigt (ohne endogene Synthese) & 10 & 20 & 20 & 20 \\
& & & & (Angaben in $\mu \mathrm{g} / \mathrm{Tag}$ VitD) \\
\hline
\end{tabular}

Tabelle 1-1 VitD-Zufuhr über die Ernährung und geschätzte Angaben zur zusätzlichen Aufnahme bei fehlender endogener Synthese durch das Sonnenlicht. Die Werte sind in $\mu g / T a g$ VitD angegeben. $40 \mathrm{IE} / \mathrm{Tag} \hat{=} 1 \mathrm{\mu g} / \mathrm{Tag} \mathrm{VitD} \triangleq 1 \mathrm{ng} / \mathrm{ml}$ VitD $\triangleq 2,5 \mathrm{nmol} / \mathrm{l}$ VitD (Referenzwerte nach DGE, ÖGE, SGE/SVE 2015). 'Dieser Wert bezieht sich auf die VitD-Menge in der Muttermilch (Wabitsch et al. 2011). 'Werte aus einer Studie „Ernährung ab 65“ entnommen: 583 Männer: 3,6 $\mu$ g/Tag VitD, 789 Frauen: 2,9 $\mu \mathrm{g} / \mathrm{Tag}$ VitD, mediane VitD-Zufuhr (Stehle et al. 2000)

Ein VitD-Mangel ist assoziiert mit einem verstärkten Vorkommen von Erkrankungen wie Osteoporose, Osteogenesis imperfecta und Myasthenie (Spiro und Buttriss 2014). Natürlicherweise nehmen mit zunehmendem Lebensalter sowohl Muskelkraft als auch Muskelmasse ab (Linseisen et al. 2011). Es kann sich jedoch auch ein Abbau der Muskelmasse über das normale Maß hinaus entwickeln. Dies wird als Sarkopenie bezeichnet und führt zu einer verstärkten Fragilität und außerdem zu einer erhöhten Mortalität (Kob et al. 2014). Überdies gibt es eine Verbindung zwischen Vitamin D und zahlreichen bakteriellen Infektionen. Anlehnend an die Arbeit von Rook und Kollegen zum M. tuberculosis (1986) führte eine Substitution hoher Vitamin-D-Dosen in einer klinischen Untersuchung bei Patienten mit einer pulmonalen Tuberkulose bereits nach 12 Wochen zu einer Verbesserung der klinischen und bildgebenden Befunde (Salahuddin et al. 2013).

In experimentellen Arbeiten zu den Konsequenzen eines Vitamin-D-Mangels bei der E.-coli-Meningitis zeigten Djukic et al. (2014), dass ein VitD-Mangel bei Mikrogliakulturen den Widerstand des Gehirns gegenüber bakteriellen Infektionen beeinträchtigen konnte. 
In dieser Studie wurden Primärkulturen von Mikrogliazellen aus den Gehirnen neugeborener Mäuse präpariert, deren Eltern zuvor entweder eine defiziente oder eine normale VitD-Ernährung erhalten haben. Die murinen Mikrogliazellkulturen wurden anschließend mit den Agonisten diverser Toll-Like-Rezeptoren stimuliert. Das Resultat war, dass die Vitamin-D-defiziente Gruppe eine geringere Phagozytoserate sowie eine geringere intrazelluläre Abtötung des $E$. coli aufwies.

Weitere Effekte des VitD zeigten sich in einem bakteriellen in-vivo-Rattenmodell von Møller und Kollegen (2007): Eine tägliche subkutane 1,25VitD-Injektion (100 ng/kg) übte einen positiven Verlauf nach einer durch E. coli ausgelösten Sepsis aus. Die Sepsis wurde u. a. durch eine abdominale Operation oder durch Injektion von Lipopolyasacchariden des $E$. coli hervorgerufen.

Diese Daten vermitteln die überaus wichtige Rolle des Vitamin $D$ bei der Bekämpfung von Infektionen und Eindämmung von Entzündungen durch die körpereigenen Immunzellen.

\subsection{Gegenstand und Zielsetzung dieser Arbeit}

Obwohl Fortschritte in der Reduktion der Mortalität und Morbidität durch Gabe von geeigneten Antibiotika und dem Adjuvans Dexamethason feststellbar sind, liegt noch immer eine hohe Letalität bei der bakteriellen Meningitis und Sepsis vor (Russo und Johnson 2000). Auch wenn Patienten eine bakterielle Meningitis überleben, treten häufig Residualschäden auf (Adriani et al. 2015). Hinzufügend erschwert die zunehmende Resistenzentwicklung von Bakterien gegenüber Antibiotika die Therapie, wodurch neue Ansätze gefunden werden müssen (Pouillot et al. 2012). Präventiv erscheint eine Impfung sinnvoll. Jedoch liegen aktuell keine Impfstoffe gegen $E$. coli vor, sondern nur gegen $H$. influenzae Typ b, S. pneumoniae und $N$. meningitidis Serogruppen $\mathrm{A}, \mathrm{C}, \mathrm{W}, \mathrm{Y}$ und $\mathrm{B}$, sofern es für die jeweilige Altersklasse zugelassen ist (Robert Koch-Institut 2016; Nau et al. 2015; Allocati et al. 2013).

Die bisher publizierten Studien konnten zeigen, dass das Vitamin $D$ eine wichtige Rolle bei der Infektionsbekämpfung hat und Entzündungsreaktionen von Immunzellen kontrollieren kann (Bikle 2008; Beard et al. 2011). Wenn VitD in ausreichender Konzentration vorliegt, kann die Resistenz des Gehirns gegenüber $E$. coli im in-vitro-Modell der bakteriellen Meningitis erhöht werden (Djukic et al. 2014). Außerdem kann durch Beeinflussung des oxidativen Stresses eine protektive Rolle auf den Neuronenschaden erzielt werden (Ibi et al. 2001). 
Allerdings ist der genaue Einfluss von VitD bei der E.-coli-Meningitis im ZNS bisher noch nicht bekannt. Im Rahmen dieser Arbeit soll in einem intrazerebralen Mausmodell der experimentellen bakteriellen Meningitis die funktionelle Rolle des VitD untersucht werden. Dabei sollen insbesondere folgende Fragen geklärt werden: Verändert VitD die Infektionsresistenz des Gehirns während einer E.-coli-Meningitis? Wie beeinflusst VitD nach intrazerebraler Infektion mit E. coli den klinischen Verlauf der Infektion, die Bakterientiter, die meningeale Leukozyteninfiltration sowie die Entzündungsreaktion? Verändert VitD die Ausschüttung von Zytokinen und Chemokinen während einer inflammatorischen Reaktion?

Diesbezüglich wurden für die Experimente drei unterschiedliche Gruppen gebildet: Mäuse, die an einem Vitamin-D-Mangel litten, normal Vitamin-D-ernährte Mäuse und Mäuse, die Futter mit einer hohen Vitamin-D-Konzentration erhielten. Die Hypothese war, dass Mäuse, die mit Vitamin D angereichertes oder normales Futter bekamen, während der E.-coli-Meningitis eine höhere Infektionsresistenz gegenüber Mäusen mit einem VitD-Mangel zeigen werden. 


\section{Material und Methode}

Die Länderangaben sind nach ISO 3166-1 kodiert.

\subsection{Materialien}

\subsubsection{Geräte}

AB Sciex API 4000LC/MS/MS System

Absaugsystem VACUSAFE comfort

Brutschrank Heraeus B12

ELISA-Reader Rainbow Spectra

Eppendorf Research ${ }^{\circledR}$ Pipetten

FACSCanto II

Gentle MACS Dissociator

HPLC

Infrarotlampe Philips

Kühltruhe Siemens

MACS Rotator

MassChrom 25-OH Vitamin $\mathrm{D}_{3} / \mathrm{D}_{2}$

LC-MS/MS Kit

Mikroskop-Kamera DP71

Präzisionswaage Sartorius excellence

E 12000 S

Reagenzglasschüttler Reax top

Schüttelplatte „rotomix”

Tischautoklav DX-23

Wärmeschrank
AB Sciex (Darmstadt, DE)

Integra Biosciences (Fernwald, DE)

Thermo Fisher Scientific

(Langenselbold, DE)

Tecan Deutschland (Crailsheim, DE)

Eppendorf (Hamburg, DE)

BD Biosciences (Heidelberg, DE)

Miltenyi Biotec (Bergisch Gladbach, DE)

Shimadzu (Duisburg, DE)

Philips DAP BV (Drachten, NL)

Siemens (München, DE)

Miltenyi Biotec (Bergisch Gladbach, DE)

Chromsystems (München, DE)

Olympus (Tokio, JP)

Sartorius (Göttingen, DE)

Heidolph Instruments (Schwabach, DE)

Zeipel (Bovenden, DE)

Systec (Wettenberg, DE)

Heraeus (Hanau, DE) 


\subsubsection{Verbrauchsmaterialien und spezielles Material}

96-Loch-Gewebekulturplatten

(mit F-Boden)

BD Eclipse ${ }^{\mathrm{TM}}$ Needle

Columbia-Blutagarplatten mit $5 \%$

Schafblut

Duoset $^{\circledR}$ ELISA Development Systems

Einmalskalpelle

Futter der S/N/H-VitD-Gruppen

Nylonfiltersieb

Objektträger $3 \times 1$ Zoll, geputzt/gebrauchsfertig

Omnifix ${ }^{\circledR}$ Insulineinmalspritzen

Percoll Gradient

Pipettenspitzen $(1000 \mu \mathrm{l}, 200 \mu \mathrm{l})$

Präparierbesteck (Schere, Pinzetten)

Reaktionsgefäße 1,5 ml

Röhren 15 ml

Schraubbecher $100 \mathrm{ml}$

Sterican ${ }^{\circledR}$ Kanülen

Venofix ${ }^{\circledR}$ Venenpunktionsbesteck
Greiner Bio-One (Frickenhausen, DE)

BD (Franklin Lakes, NJ, USA)

bioMérieux Deutschland (Nürtingen, DE)

R\&D Systems (Wiesbaden, DE)

Dahlhausen (Köln, DE)

ssniff Spezialdiäten GmbH (Soest, DE)

BD Biosciences (Franklin Lakes, NJ, USA)

Waldemar Knittel, Glasbearbeitungsgesellschaft (Braunschweig, DE)

B. Braun Melsungen (Melsungen, DE)

GE Healthcare (Chalfont St Giles, Buckinghamshire, UK)

Sarstedt (Nümbrecht, DE)

Hermle Labortechnik (Wehingen, DE)

Sarstedt (Nümbrecht, DE)

Sarstedt (Nümbrecht, DE)

Sarstedt (Nümbrecht, DE)

B. Braun Melsungen (Melsungen, DE)

B. Braun Melsungen (Melsungen, DE) 


\subsubsection{Chemikalien und Reagenzien}

Aqua bidestillata

Aqua destillata

Aqua Tex

CCR2

CD3, CD25, CD19, NK1.1, FoxP3

CD45, CD4, CD27, CD11b, Ly6C

DePeX Einbettmedium für Histologie

Desoxyribonuklease I (DNase I, 2 mg/ml)

DMEM, High Glucose, GlutaMAX ${ }^{\mathrm{TM}_{-}}$I

(4,5 g/l Glukose, ohne Pyruvat)

Fast Red Violet LB Standardlösung

Formaldehyd

HRP Conjugate

Isopropanol

Isotone Natriumchloridlösung 0,9\%

Ketamin $10 \%$

KIT Sigma \# 91-C

Kollagenase D $(2,5 \mathrm{mg} / \mathrm{ml})$

Ly6G

Mayers Hämalaunlösung für Mikroskopie

Mouse IL6, IL10, KC, INF-y, MIP-2

ELISA Kit

Mouse TNF- $\alpha$ ELISA Kit
SG Wasseraufbereitung $u$.

Regenerierstation GmbH (Barsbüttel, $\mathrm{DE})$

B. Braun Melsungen (Melsungen, DE)

Merck (Darmstadt, DE)

R\&D Systems (Minneapolis, MN, USA)

eBioscience (San Diego, CA, USA)

Biolegend (San Diego, CA, USA)

Serva Electrophoresis (Heidelberg, DE)

Roche Diagnostics (Mannheim, DE)

Gibco (Paisley, Schottland, GB)

Sigma-Aldrich (St. Louis, MO, USA)

Merck (Darmstadt, DE)

BioSource International (Camarillo, CA, USA)

Merck (Darmstadt, DE)

B. Braun Melsungen (Melsungen, DE)

WDT (Garbsen, DE)

Sigma-Aldrich (St. Louis, MO, USA)

Roche Diagnostics (Mannheim, DE)

BD Pharmigen (Franklin Lakes, NJ, USA)

Merck (Darmstadt, DE)

R\&D Systems (Minneapolis, MN, USA)

Biolegend (San Diego, CA, USA) 
Naphthol-AS-D-Chloracetat-Lösung

Natriumnitrit-Lösung

PBS

TRIZMAL-Puffer

Tween-20

Xylazin $2 \%$

Xylol

Tris-(hydroxymethyl)-aminomethan
Sigma-Aldrich (St. Louis, MO, USA)

Sigma-Aldrich (St. Louis, MO, USA)

Biochrom (Berlin, DE)

Sigma-Aldrich (St. Louis, MO, USA)

Roth (Karlsruhe, DE)

Riemser Arzneimittel AG (Greifswald, $\mathrm{DE})$

Merck (Darmstadt, DE)

Roth (Karlsruhe, DE)

\subsubsection{Herstellung von Lösungen}

\subsubsection{Herstellung von $\mathbf{7 0} \%$ igem Alkohol}

Die Herstellung erfolgte durch Vermischung von $700 \mathrm{ml}$ 99\%igem Ethylalkohol mit $300 \mathrm{ml}$ destilliertem Wasser.

\subsubsection{Herstellung von phosphate-buffered saline (PBS)}

Auf einem Magnetrührer wurden 9,55 g PBS-Pulver in 1 I $\mathrm{H}_{2} \mathrm{O}$ destilliertes Wasser (aqua destillata) gelöst. Darauffolgend wurde die Lösung autoklaviert und bei Raumtemperatur (RT) aufbewahrt.

\subsubsection{Herstellung von tris-buffered saline (TBS)}

Es wurden $50 \mathrm{mM}$ Tris-(hydroxymethyl)-aminomethan mit $150 \mathrm{mM} \mathrm{NaCl}$ vermischt $(\mathrm{pH}=7,5)$. 


\subsubsection{Software}

Graph Pad Prism 5

GraphPad Software (La Jolla, CA, USA)

Microsoft Excel 2010 für Windows

Microsoft Corp. (Redmond, WA, USA)

Excel-Programmierung

Hanisch AG (Göttingen, DE)

"Template“ (Zytokinanalyse)

ChemDraw ${ }^{\circledR}$

PerkinElmer (Waltham, MA, USA)

cellSens Dimension 1.6

Olympus (Tokio, JP)

FlowJo Software (Version 8.8)

Tree Star (Ashland, OR, USA) 


\subsection{Vitamin-D-Konzentration im Blut}

Um zu untersuchen, welche Auswirkungen das VitD auf die Mäuse hat, wurden drei Gruppen mit jeweils 15 Mäusen gebildet und jede Gruppe erhielt zunächst sechs Wochen lang ein spezielles Futter mit folgenden Vitamin-D-Konzentrationen:

\begin{tabular}{lll}
\hline Gruppe & Vitamin-D-Konzentration des Futters & $\begin{array}{l}\text { Kalzium- und Phosphatkonzentration } \\
\text { des Futters }\end{array}$ \\
\hline S-VitD & $1500 \mathrm{IE} / \mathrm{kg}$ Futter & normal \\
N-VitD & unterhalb der Nachweisgrenze & normal \\
H-VitD & $7500 \mathrm{IE} / \mathrm{kg}$ Futter & normal \\
\hline
\end{tabular}

Tabelle 2-1 Vitamin-D-Konzentration im Futter. S-VitD: Standard-Vitamin-D-Konzentration, N-VitD: Niedrige Vitamin-D-Konzentration, H-VitD: Hohe Vitamin-D-Konzentration (ssniff Spezialdiäten GmbH), $\mathrm{IE}$ : internationale Einheiten $\triangleq \mathrm{IU}$ : international unit, kg: Kilogramm

Anschließend wurden nach sechs Wochen die 25VitD-Konzentrationen im Blutserum mit Hilfe der Flüssigchromatographie mit Massenspektrometrie-Kopplung ermittelt, um zu überprüfen, ob das Vitamin D vom Tier aufgenommen wurde. Hierfür wurden aus dem retroorbitalen Venengeflecht der Maus $50 \mu$ Blutserum entnommen, mit dem MassChrom ${ }^{\circledR} 25-\mathrm{OH}$ Vitamin $\mathrm{D}_{3} / \mathrm{D}_{2}$ LC-MS/MS Kit erfasst und mit dem AB Sciex API 4000LC/MS/MS System dargestellt. Die Analyse der VitD-Konzentrationen im Blut wurde in der klinischen Chemie des Klinikums Nürnberg in Kooperation mit Herrn Prof. Dr. med. Thomas Bertsch durchgeführt.

\subsection{Mäuse}

Die Tierversuche wurden von der Tierschutzkommission der Medizinischen Fakultät der Universitätsmedizin Göttingen und vom Niedersächsischen Landesamt für Verbraucherschutz und Lebensmittelsicherheit (LAVES, Braunschweig, DE, (Genehmigungsnummer: 33.9-42502-04-12/0772) bewilligt. Die Mäuse vom Wildtyp C57BI/6J (weiblich, 2 bis 3 Monate alt, 20-30 g schwer, Charles River Laboratory, Deutschland) wurden in Gemeinschaftskäfigen (maximal fünf Tiere) bei konstanten $20{ }^{\circ} \mathrm{C}$ Raumtemperatur, einer relativen Luftfeuchtigkeit von $55 \%$ sowie einem Tag/Nacht-Zyklus (12 h Licht, $12 \mathrm{~h}$ kein Licht) gehalten. Wasser und Futter waren ausreichend und frei zugänglich vorhanden. Alle Versuche wurden unter Aufsicht und Anleitung von Frau PD Dr. med. Marija Djukic durchgeführt. 


\subsection{Bakterienstamm}

Alle Infektionen wurden mit dem Bakterium E.-coli-K1 (Serotyp 018:K1:H7) durchgeführt, welches ursprünglich aus dem Liquor cerebrospinalis eines an Meningitis erkrankten Kindes isoliert wurde. Die Bakterien-Stammlösung, die zur Herstellung des Inokulums diente, ist ein Geschenk von Dr. Gregor Zysk (Institut für medizinische Mikrobiologie, Düsseldorf, DE). Die Proben wurden in 0,9\% $\mathrm{NaCl}$ (Natriumclorid) bei $-80{ }^{\circ} \mathrm{C}$ gelagert und erst kurz vor der Infektion aufgetaut.

Zur Herstellung des Inokulums wurden 10- $\mu$-Bakterien-Stammlösung in $5 \mathrm{ml} \mathrm{NaCl}$ pipettiert und nach Protokoll 1:10 weiter verdünnt. Zur Kontrolle der CFU (colony forming unit) wurde am Tag der Infektion das Inokulum in fünf Verdünnungsstufen $(1: 10,1: 100, \ldots)$ auf eine Blutagarplatte pipettiert und nach $24 \mathrm{~h}$ im Brutschrank bei $37^{\circ} \mathrm{C}$ abgelesen. Die Endkonzentration betrug im Mittel $10^{6} \mathrm{CFU} / \mathrm{ml}$.

\subsection{Induktion der E.-coli-Meningitis}

Der erste Versuch untersuchte die Auswirkungen der oben genannten unterschiedlichen VitD-Diäten auf das Überleben der Mäuse während der experimentellen bakteriellen Meningitis. Die Mäuse erhielten hierbei kein Antibiotikum. Zunächst wurde eine intraperitoneale Anästhesie mit Ketamin (100 mg/kg Körpergewicht) und Xylazin (10 mg/kg Körpergewicht) durchgeführt. Die Induktion der E.-coli-Meningitis fand anschließend durch langsame Injektion von 4000 CFU E. coli K1 mit Hilfe einer 27-Gauge(G)-Kanüle intrazerebral auf Höhe des rechten Vorderhirns statt (ausgeführt durch Frau PD Dr. med. Marija Djukic). Zur exakten Bestimmung der Injektionsstelle wurde der Abstand zwischen dem rechten Auge und dem äußeren Gehörgang gedrittelt und hierbei der Punkt zwischen dem vorderen und mittleren Drittel gewählt. Um die Bakterien in die Nähe des Subarachnoidalraumes zu injizieren, wurde die Kanüle bei jedem Versuch mittels eines Platzhalters exakt $2 \mathrm{~mm}$ tief eingeführt.

Anschließend wurden die Tiere in ihre Käfige zurückgelegt, mit einer Rotlichtlampe warm gehalten und die Vitalfunktionen bis zum Aufwachen überprüft. Alle Mäuse verhielten sich normal nach dem Aufwachen. Die Tiere wurden hiernach 14 Tage lang klinisch untersucht, und zwar alle $12 \mathrm{~h}$ in der akuten Infektionsphase (0-96 $\mathrm{h}$ post infectionem, p. i.) und an den Tagen 7, 10, 13 und 14. 
Es wurden Gewicht, klinischer Score (Gerber et al. 2001, s. Tabelle 2-2) und motorische Fähigkeiten protokolliert. Dieser erste Versuch endete nach 14 Tagen, indem die Mäuse, die überlebten, durch einen Genickbruch getötet und deren Gehirn, Milz und Blut im Hinblick auf E.-coli-Kolonien untersucht wurden.

\begin{tabular}{ll}
\hline Score & Klinisches Erscheinungsbild \\
\hline 0 & gesund \\
1 & leichte Lethargie \\
2 & deutliche Lethargie \\
3 & schwer lethargisch, unfähig zu laufen \\
4 & tot \\
\hline
\end{tabular}

Tabelle 2-2 Klinischer Score (modifiziert nach Gerber et al. 2001)

Während des Versuches führten folgende Faktoren aus ethischen Gründen zum Abbruch, somit zur Tötung der Maus durch einen Genickbruch: Zum einen, wenn die Maus unfähig war zu gehen (Klinischer Score 3), und zum anderen, wenn die Infektion zu einer ungenügenden Futter- und Trinkwasseraufnahme führte. Dies äußerte sich in einem Gewichtsverlust > $20 \%$ des Gewichts im Vergleich zum Zeitpunkt der Infektion. Anschließend wurden die Bakterienkonzentrationen in Gehirn und Milz ausgewertet, um sicherzustellen, dass die Infektion der Grund für den Tod war.

In dem darauffolgenden Versuch wurde nach intraperitonealer Anästhesie eine langsame Injektion von $9000 \mathrm{CFU}$ E. coli K1 in $10 \mu \mathrm{l}$ 0,9 \% NaCl mit Hilfe einer 27-GKanüle intrazerebral auf Höhe des rechten Vorderhirns (wie oben beschrieben, durch Frau PD Dr. med. Marija Djukic) durchgeführt. Anschließend wurden alle Mäuse nach $20 \mathrm{~h}$ und nach Anästhesie durch eine kardiale Blutabnahme und anschließendem Genickbruch getötet und die Bakterienkonzentrationen in Gehirn, Milz und Blut analysiert. In allen Versuchen dienten als Kontrolle fünf Mäuse, denen $10 \mu \mathrm{l}$ 0,9\% NaCl intrazerebral injiziert wurde. 


\subsection{Gewebepräparation und Gewinnung von Blutserum}

Die nachfolgenden Versuche wurden mit Hilfe von Frau Marianne Mecke und Frau Dr. med. Anja Manig (AG Nau) durchgeführt, um bei einer so hohen Anzahl an Versuchstieren verfälschte Ergebnisse aufgrund von zeitlichen Verzögerungen zu minimieren.

\subsubsection{Gewinnung von Blutserum}

Unter Narkose erfolgte eine kardiale Blutabnahme, wobei jeweils $10 \mu$ des Blutes in $90 \mu \mathrm{l}$ isotoner Kochsalzlösung gegeben wurden. Das restliche Blut wurde für 30 min bei $4{ }^{\circ} \mathrm{C}$ gelagert und anschließend bei $3000 \times \mathrm{g}$ für $10 \mathrm{~min}$ bei $4{ }^{\circ} \mathrm{C}$ zentrifugiert. Das Serum wurde in ein weiteres Gefäß gegeben und bei $-20^{\circ} \mathrm{C}$ bis zur nächsten Analyse eingefroren.

\subsubsection{Präparation und Homogenisierung der Milz}

Nachdem durch einen Genickbruch sichergestellt worden war, dass die Mäuse tot waren, wurde als Erstes die Bauchhöhle mit einer Schere eröffnet und die Milz als Ganzes herauspräpariert. Danach wurde sie mit einem Skalpell halbiert und die eine Hälfte in einem Reagiergefäß bei $-20^{\circ} \mathrm{C}$ eingefroren, die andere Hälfte in ein Reagiergefäß mit $500 \mu$ isotoner Kochsalzlösung überführt.

\subsubsection{Präparation und Homogenisierung des Gehirns}

Zuerst wurde das Gehirn zervikal vom Rest des Körpers abgetrennt. Die Haut und der Knochen wurden entfernt, indem mit einem Skalpell an der Mittellinie dieser durchtrennt und vorsichtig zu beiden Seiten aufgeklappt wurde. Anschließend wurde das Gehirn als Ganzes herauspräpariert, das Großhirn vom Kleinhirn getrennt und letzteres vom Hirnstamm. Das Großhirn wurde in 4 \%iges Paraformaldehyd gegeben, daraufhin in Paraffin für histologische Schnitte fixiert und das Kleinhirn in ein Reagiergefäß mit $500 \mu$ isotoner Kochsalzlösung überführt. 


\subsubsection{Ausplattierung und bakterielle Titer}

Das Kleinhirn und die Milz waren jeweils in $500 \mu \mathrm{l}$ isotoner Kochsalzlösung. Mit einem Stößel wurden beide Stammlösungen homogenisiert. Das Blutserum (10 $\mu \mathrm{l})$ war in $90 \mu \mathrm{l}$ isotoner Kochsalzlösung. Anschließend wurde eine Verdünnungsreihe mit sechs Verdünnungsstufen erstellt, wobei in jedem Reagiergefäß $450 \mu \mathrm{l}$ 0,9\%ige $\mathrm{NaCl}$-Lösung waren. Von der Stammlösung wurde $50 \mu \mathrm{l}$ in das erste Gefäß pipettiert (1:10), in das zweite wieder $50 \mu \mathrm{l}(1: 100)$ und weiter bis zur sechsten Verdünnungsstufe. Von dieser ausgehend wurden nun rückläufig jeweils $10 \mu \mathrm{l}$ jeder Lösung auf eine Schafsblut-Agarplatte gegeben, wobei die unverdünnte Ausgangslösung in die Mitte kam. Anschließend wurden die Platten für $24 \mathrm{~h}$ bei $37^{\circ} \mathrm{C}$ inkubiert und die in der jeweils höchsten Verdünnungsstufe sichtbaren Bakterienkolonien gezählt (CFU/ml). Das Detektionslimit lag bei dieser quantitativen Ausplattierung bei $100 \mathrm{CFU} / \mathrm{ml}$.

Die unverdünnten Stammlösungen wurden bei $-20^{\circ} \mathrm{C}$ eingefroren.

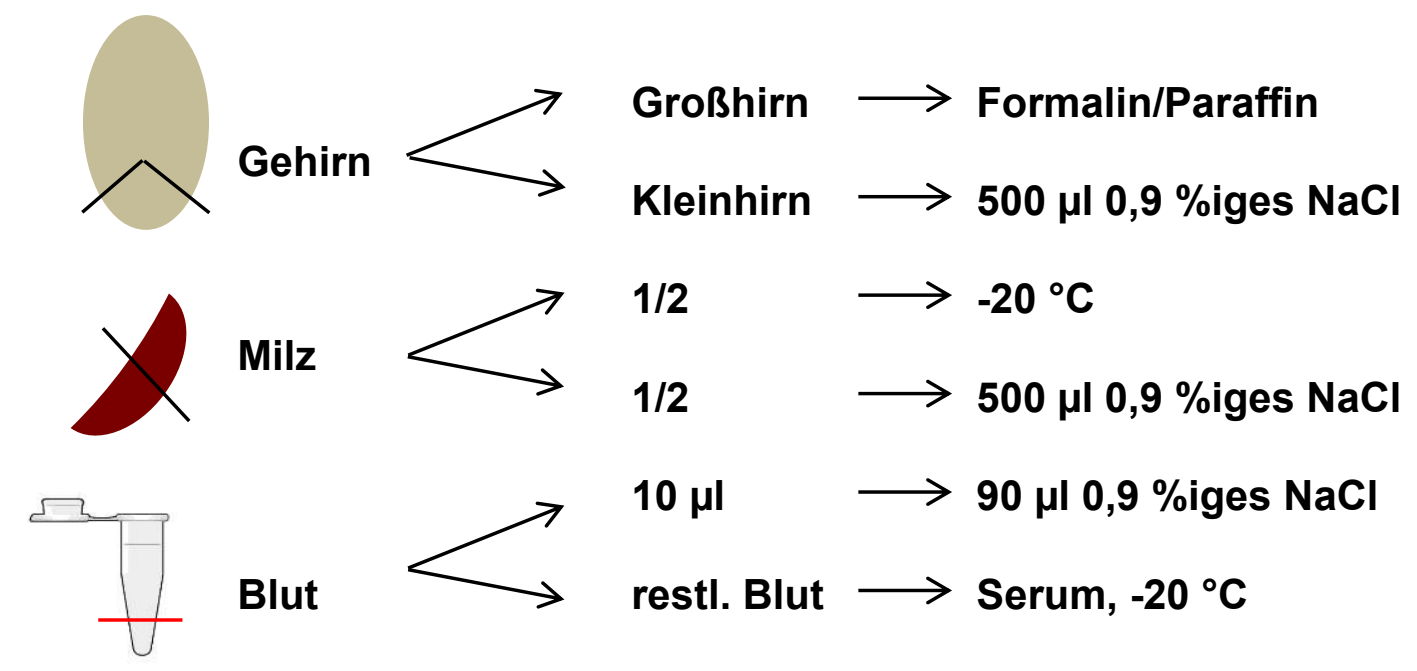

Abbildung 2-1 Gewebepräparation von Gehirn und Milz sowie Gewinnung von Blutserum (eigene Darstellung) 


\subsection{Histologische Analyse}

\subsubsection{Entparaffinierung und Chloracetatesterase(CAE)-Färbung}

Nachdem die Großhirne der Mäuse aus dem Überlebensversuch und der Versuche, in denen die Mäuse $20 \mathrm{~h}$ nach der Infektion getötet wurden, in $4 \%$ iges Paraformaldehyd gegeben und in Paraffin fixiert worden waren, wurden $2 \mu \mathrm{m}$ dicke Frontalschnitte des Gehirns angefertigt, um die meningeale Leukozyteninfiltration mikroskopisch beurteilen zu können $(n=17)$. Diese wurden vor der immunhistochemischen Färbung mit Chloracetatesterase entparaffiniert und rehydratisiert, da eine mangelhafte Entfernung von Paraffin Störungen im Färbemuster der nachfolgenden Immunreaktion verursacht (alle Arbeitsschritte in Zusammenarbeit mit Frau Stephanie Bunkowski). Für die Entparaffinierung wurde folgendes Protokoll durchgeführt, welches hier tabellarisch dargestellt wird:

Zuletzt wurden die Schnitte noch in aqua destillata gespült.

\begin{tabular}{lll}
\hline Menge & Reagenz & Zeit in Minuten (jeweils) \\
\hline $3 \mathrm{x}$ & Xylol & 10 \\
$1 \mathrm{x}$ & Gemisch aus Xylol und Isopropanol & 1 \\
$2 \mathrm{x}$ & 100\%iges Isopropanol & 3 \\
$1 \mathrm{x}$ & $96 \%$ iges Isopropanol & 3 \\
$1 \mathrm{x}$ & $70 \%$ iges Isopropanol & 3 \\
$1 \mathrm{x}$ & $50 \%$ iges Isopropanol & 3 \\
\hline
\end{tabular}

Tabelle 2-3 Entparaffinierung der Großhirnpräparate (Protokoll nach Stephanie Bunkowski, AG Nau, Universitätsmedizin Göttingen)

Die anschließende Färbung mit Chloracetatesterase dient einer Markierung der Neutrophilen, Monozyten und Makrophagen, um diese mikroskopisch quantitativ analysieren zu können.

Zur Vorbereitung wurden die entparaffinierten Schnitte $30-60$ min bei $37^{\circ} \mathrm{C}$ in $40 \mathrm{ml}$ aqua bidestillata vorinkubiert. Hiernach wurden $1 \mathrm{ml}$ Natriumnitritlösung mit $1 \mathrm{ml}$ Fast Red Violet LB Standardlösung vermengt und zu $40 \mathrm{ml}$ aqua bidestillata (vorgewärmt bei $37^{\circ} \mathrm{C}$ ) hinzugegeben. Anschließend wurden $5 \mathrm{ml}$ TRIZMAL-Puffer beigefügt und vermischt sowie $1 \mathrm{ml}$ Naphthol-AS-D-Chloracetat-Lösung hinzugefügt und vermischt. Die Rotfärbung dieser Lösung zeigt ein korrektes Vorgehen an. Die Inkubation der Schnitte fand daraufhin für $60-80$ min bei $37^{\circ} \mathrm{C}$ statt. 
Nach dem Spülen in aqua destillata wurde eine Kernfärbung mit Hämalaun ausgeführt und mit Aqua Tex eingedeckelt. Die fixierten und gefärbten Schnitte konnten nun histologisch auf Leukozyteninfiltration in den Meningen untersucht werden.

\subsubsection{Mikroskopische Auswertung der Präparate}

Alle Präparate wurden nach der gleichen Vorgehensweise ausgewertet: Die linke Hemisphäre wurde in vier Bereiche unterteilt, zusätzlich noch die Hippocampusfissur hinzugezogen und aus diesen fünf Werten ein Mittelwert gebildet, der in einen Leukozytenscore umgewandelt wurde (Ribes et al. 2013). Es wurde zunächst die linke Hemisphäre betrachtet und das Mikroskop auf eine 10-fache Vergrößerung eingestellt. Hiernach wurde in 40-facher Vergrößerung die Hippocampusfissur dargestellt (Bereich 5). Anschließend wurde solange nach oben bis zum Rand des Präparates geschoben, bis $50 \%$ des Mikroskopbildes das Präparat zeigten (Bereich 1) sowie anschließend ganz nach unten (Bereich 2), nach rechts (Bereich 3 ) und von hieraus nach oben (Bereich 4). Wenn in einem Bereich nichts sichtbar war, wurde auf die andere Hemisphäre gewechselt oder dieser Bereich ausgelassen. Der Mittelwert wurde nun in einen Score umgewandelt.

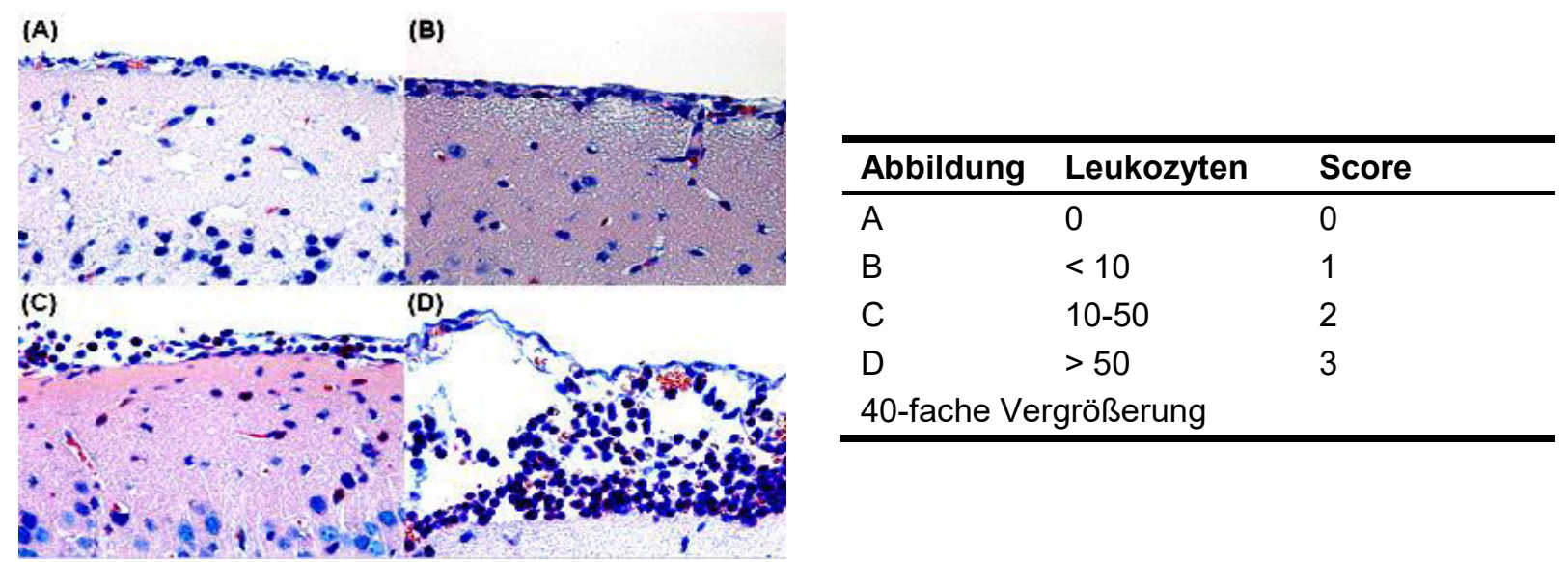

Abbildung 2-2 Leukozyteninfiltration und Scores (Die Verwendung der Abbildung und des Leukozytenscores erfolgt mit freundlicher Genehmigung von Frau PD Dr. rer. nat. Sandra Ribes, Ribes et al. 2013). 


\subsection{FACS (Durchflusszytometrie)}

\subsubsection{Prinzip der Durchflusszytometrie}

Mit Hilfe der Durchflusszytometrie können Proben durch Fluoreszenz und Lichtstreuung analysiert werden, indem sie durch ein optisches Messsystem geschickt werden. Die Zellen sind umgeben von Trägerflüssigkeit und passieren einzeln durch die hydrodynamische Fokussierung den Lichtstrahl. Dieser wird durch die Zellgröße (forward scatter, FSC) und durch die Zellgranularität (side scatter, SSC) gebrochen, was als $x$-und $y$-Achse in einem zweidimensionalen Koordinatensystem dargestellt wird. Um bestimmte Antigene sichtbarer zu machen, werden Antikörper, an die fluoreszierende Farbstoffe gekoppelt sind, hinzugefügt.

\subsubsection{Ansetzen der Proben}

Durch die Durchflusszytometrie wurden in dem Versuchsmodell zu dieser Dissertation die Leukozyten im Gehirn der Mäuse erfasst. Die Mäuse wurden $20 \mathrm{~h}$ nach der Infektion unter Narkose transkardial mit PBS (phosphate-buffered saline) perfundiert. Anschließend wurde das gesamte Gehirn herauspräpariert und mit einem Stößel und DMEM (Dulbecco's Modified Eagle Medium) durch ein $70 \mu \mathrm{m}$ feines Filtersieb aus Nylon gepresst. Bis zur Weiterverarbeitung wurden die Proben in Röhren auf Eis gelegt.

Die folgenden Arbeitsschritte wurden in Zusammenarbeit mit Herrn Dr. med. Stefan Nessler durchgeführt: Das Gehirn wurde nun durch Kollagenase D und DNase I und im Gentle MACS Dissociator verdaut und homogenisiert. Diese Proben rotierten anschließend auf dem MACS Rotator und wurden durch ein $70 \mu \mathrm{m}$ feines Filtersieb aus Nylon gepresst. Die Leukozyten wurden durch einen 37/70 \% Percoll Gradienten voneinander getrennt. Die einzelnen Zellen wurden mit folgenden Antikörpern angefärbt: CD45 (30-F11), CD4 (RM4-5), CD27 (LG.3A10), CD11b (M1/70), Ly6C (HK1.4), CD3 (145-2C11), CD25 (PC61.5), CD19 (eBio1D3), NK1.1 (PK136), FoxP3 (FJK-16 s), Ly6G und CCR2. Mindestens 50.000 events wurden aufgenommen, mit dem FACSCanto II analysiert und mit der FlowJo Software ausgewertet. 


\subsubsection{Auswertung der Ergebnisse der Durchflusszytometrie}

Die Ergebnisse wurden mit der FlowJo Software in einem Koordinatensystem (FSCA vs. SSC-A) ausgewertet. Ein Punkt entsprach jeweils einer Zelle. Durch unterschiedliche Lokalisation konnten u. a. Lymphozyten, Monozyten und Granulozyten ausgewertet werden, indem sie durch Gates (s. rote Rahmen in Abb. 2-3) weiter eingegrenzt wurden. Die erste Abbildung (A) zeigt alle Zellen, die in der Probe (Gehirn) enthalten waren, wobei rechts im Koordinatensystem die Leukozyten durch ein Gate eingegrenzt wurden. Durch einen Doppelklick auf dieses wurde ein zweites System geöffnet (B). Der Rahmen zeigt eine genauere Eingrenzung der Leukozyten, der $C D 45^{+}$-Zellen. Oben rechts befinden sich hier die neutrophilen Granulozyten. Diese wurden anschließend noch weiter eingegrenzt (C, D). Die Ergebnisse wurden tabellarisch in Prozentzahlen dargestellt und anschließend mit Graph Pad Prism 5 ausgewertet.

(A)

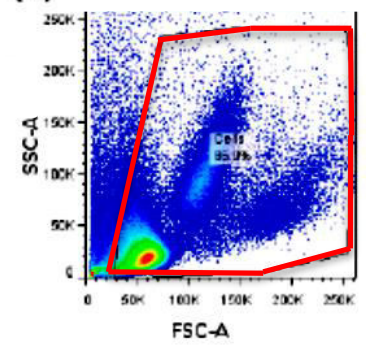

(B)

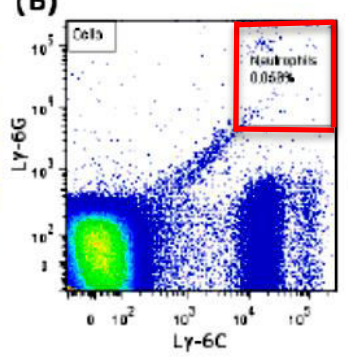

(C)

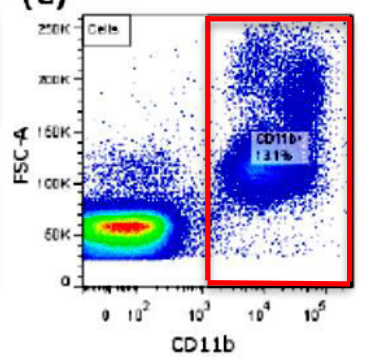

(D)

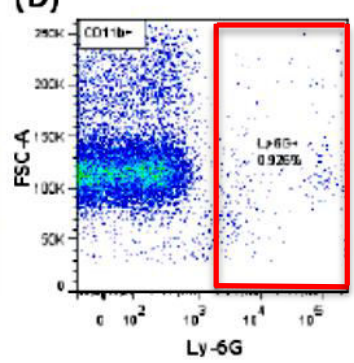

Abbildung 2-3 Prinzip der Auswertung der Ergebnisse einer FACS-Analyse (modifiziert nach Meister 2013, S. 30) 


\subsection{Enzyme-Linked Immunosorbent Assay (ELISA)}

\subsubsection{Prinzip der Enzym-gekoppelten Immunreaktion}

Mit Hilfe des ELISA kann durch eine enzymatische Farbreaktion ein spezifisches Antigen quantitativ nachgewiesen werden. Antigene, die bestimmt werden können, sind z. B. Zytokine wie IL-6 oder Chemokine wie KC. Zur Bestimmung wird ein capture-Antikörper (Ak) benötigt, welcher auf einer 96-Well-Mikrotiterplatte befestigt ist und spezifisch an das Epitop des Antigens ( $\mathrm{Ag}$ ) bindet, wenn die zu untersuchende Probe hinzugefügt wird. Anschließend bindet der detection-Ak, welcher am Ende mit einem Enzym konjugiert ist, an ein zweites Epitop des Ag. Es bildet sich ein Antikörper-Antigen-Antikörper-Komplex (Sandwich-ELISA). Anschließend wird ein chromogenes Substrat hinzugefügt, welches von dem Enzym zu einem Produkt umgesetzt wird. Dabei entsteht ein Farbumschlag. Die Intensität der Farbe ist proportional zu der Konzentration des entstandenen Produkts und somit auch zu der Konzentration des zu bestimmenden Antigens in der Probe. Zur Detektion der Menge an gebundenem Antigen wird eine Fotometrie bei $450 \mathrm{~nm}$ durchgeführt.

\subsubsection{ELISA zur Bestimmung von Zytokinen und Chemokinen}

Für die Zytokin/Chemokin-Messungen wurden jeweils die Homogenate von Kleinhirn und Milz aus dem ersten Überlebensversuch und aus den Versuchen, bei denen die Mäuse $20 \mathrm{~h}$ nach Infektion getötet wurden, verwendet. Die Homogenate stammten sowohl von infizierten Mäusen als auch von denjenigen, die eine intrazerebrale Injektion mit 0,9\% NaCl als Kontrollgruppe erhielten.

Mit Hilfe des DuoSet ${ }^{\circledR}$ ELISA Development Kits wurde in Zusammenarbeit mit Frau Stephanie Bunkowski die Menge an den für eine bakterielle Meningitis typischen Zytokinen und Chemokinen IL-6, IL-10, KC, IFN-y und MIP-2 in den Proben wie folgt bestimmt: Zur Vorbereitung der Well-Platten, wurden für jedes Zytokin/Chemokin jeweils 27,5 $\mathrm{ll}$ capture-Ak laut Vorschrift des ELISA Kits angesetzt und mit $5 \mathrm{ml}$ PBS verdünnt. In jedes Well wurden anschließend $50 \mu \mathrm{l}$ pipettiert und über Nacht bei Raumtemperatur (RT) auf dem Schüttler inkubiert. Anschließend wurde dreimal pro Well gewaschen (Wasch-Puffer: 0,5 g Tween 20 auf 1 I PBS). Danach wurden $300 \mu \mathrm{l}$ Block-Puffer pro Well pipettiert, wobei je nach Ak unterschiedliche benutzt wurden: 
Für IL-6, IL-10, KC und MIP-2 wurde Reagent Diluent 1 (1 g BSA, bovine serum albumin, auf $100 \mathrm{ml}$ ) verwendet. Für IFN-y wurde dagegen Reagent Diluent 2 (0,1\% BSA, $0,05 \%$ Tween-20 in TBS) benötigt. Die Inkubation erfolgte $1 \mathrm{~h}$ auf dem Schüttler bei Raumtemperatur. Die Proben und Standards wurden nach Vorschrift jeweils mit Reagent Diluent 1 verdünnt und $50 \mu$ pro Well pipettiert. Hiernach wurde $2 \mathrm{~h}$ bei RT auf dem Schüttler inkubiert, dreimal gewaschen und $50 \mu$ detection-Ak pro Well pipettiert. Erneut folgte für $2 \mathrm{~h}$ eine Inkubation und anschließende dreimalige Waschung. Pro Well wurden hiernach $50 \mu \mathrm{l}$ HRP (horseradish peroxidase)-Diluent (40 ml Wasch-Puffer + $40 \mathrm{mg} \mathrm{BSA}+1 \mu \mathrm{l}$ Streptavidin) pipettiert, 20 min bei RT auf dem Schüttler inkubiert und dreimal gewaschen. Danach wurden $100 \mu \mathrm{TMB}$ (3,3',5,5'-Tetramethylbenzidin)-Substratlösung pro Well hinzugefügt. Wenn sich erste blaue Präzipitate im höchsten Standard bildeten, wurde die Reaktion mit Hilfe von $50 \mu$ Stopplösung (1 N Schwefelsäure) beendet. Nach der Entwicklung der Farbreaktion bis zu einer Gelbfärbung wurde die Mikrotiterplatte im ELISA-Reader bei $450 \mathrm{~nm}$ vermessen.

\subsubsection{Auswertung der Ergebnisse des ELISA}

Für jedes Zytokin/Chemokin wurde eine Tabelle mit den gemessenen Extinktionen sowohl der Standards als auch der zu analysierenden Proben angefertigt. Nach Vorgabe wurde mit Hilfe der Verdünnungsschritte eine Standardreihe erstellt, welche für TNF- $\alpha$ und IL-10 andere Werte bereithielt $(0$ pg, 7,5 pg, 15 pg, 31 pg, 62 pg, 125 pg, 250 pg, 500 pg, 750 pg, 1000 pg) als für IL-6, MIP-2 und KC (0 pg, 7,5 pg, 15 pg, 31 pg, 62 pg, 125 pg, 250 pg, 500 pg, 1000 pg, 2000 pg).

Von diesen zehn Standardwerten wurden jedoch nur acht in das Koordinatensystem der Standardkurve (Programm Template, AG Hanisch, Göttingen, DE) übernommen. Somit wurden Proben-und Standardwerte für jedes Zytokin/Chemokin verglichen und die zwei Werte herausgenommen, die am Weitesten von den Proben entfernt waren. Nach Einfügen der Extinktionen der Proben wurden die Konzentrationen der jeweiligen Zytokine/Chemokine gemessen und konnten anschließend grafisch mit Graph Pad Prism 5 dargestellt werden. Die Nachweisgrenze der Zytokine und Chemokine lag jeweils bei $\leq 7,5 \mathrm{pg} / \mathrm{ml}$. 


\subsection{Statistik}

Für alle Auswertungen und grafischen Darstellungen wurde die Software „Graph Pad Prism 5“ (GraphPad Software, San Diega, CA, USA) verwendet. Parametrische Daten wie die Vitamin-D-Konzentrationen im Blutserum, das Gewicht der Mäuse und die bakteriellen Titer von Milz und Kleinhirn wurden als Mittelwerte \pm Standardabweichung (SD) dargestellt. Anschließend erfolgte eine Varianzanalyse (One-Way-ANOVA, analysis of variance) mit Korrektur nach Bonferroni. Nichtparametrische Daten wie die Zytokin/Chemokin-Freisetzung, die meningeale Leukozyteninfiltration und die klinischen Scores wurden als Mediane mit entsprechendem Interquartilsabstand (Q25 und Q75) dargestellt und mit dem anschließenden Kruskal-Wallis-Test mit Korrektur nach Bonferroni verglichen. Für das Überlebensexperiment wurden Kaplan-Meier-Kurven mit Hilfe des Log-rankTests gegenübergestellt. Eine Wahrscheinlichkeit $p$ von $\leq 0,05$ galt als statistisch signifikant. 


\section{Ergebnisse}

\subsection{Die Konzentration von Vitamin $D$ im Blutserum war abhängig von der jeweiligen Vitamin-D-Ernährung}

Die Mäuse wurden sechs Wochen lang unterschiedlich ernährt (s. Tabelle 2-1). Nach dieser Zeit wurden fünf Mäusen pro Gruppe aus dem retroorbitalen Venengeflecht $50 \mu \mathrm{l}$ Blutserum entnommen und mit dem Liquid-Chromatografie-TandemMassenspektrometrie-Test der Gehalt des Metaboliten 25VitD gemessen.

Abbildung 3-1 zeigt die Konzentration des Metaboliten im Blutserum in $\mathrm{ng} / \mathrm{ml}$. Die Daten ( $n=5$ pro Gruppe) sind als Mittelwerte \pm Standardabweichung mit one-wayANOVA und Korrektur nach Bonferroni dargestellt.

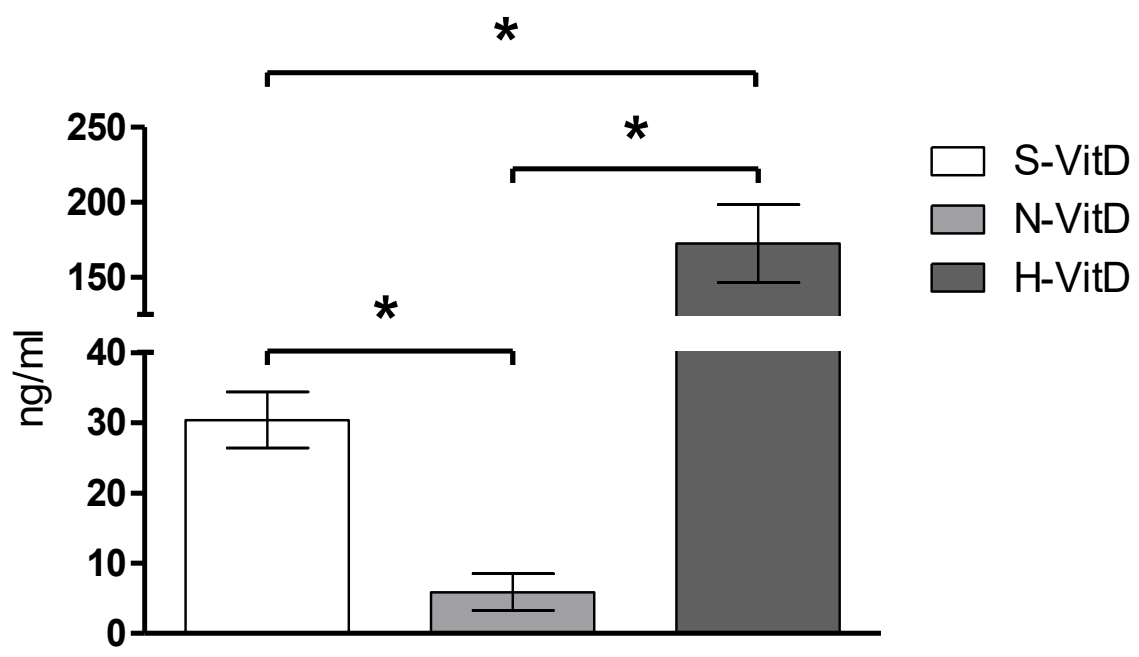

Abbildung 3-1 25-OH Vitamin-D-Konzentration im Blutserum in $\mathrm{ng} / \mathrm{ml}$. Dargestellt sind die Mittelwerte \pm Standardabweichung, $\mathrm{n}=5$.

Es konnte nachgewiesen werden, dass eine Ernährung mit einem niedrigen VitaminD-Gehalt ( $N$-VitD) auch zu einer signifikant geringeren 25VitD-Konzentration im Vergleich zu einer S-VitD- oder H-VitD-Ernährung führte (Mittelwerte \pm Standardabweichung: $5,9 \pm 2,6$ vs. $30,4 \pm 4,0$ und $172,4 \pm 21,1 \mathrm{ng} / \mathrm{ml},{ }^{*} \mathrm{p}<0,05$ ). 


\subsection{Ein Vitamin-D-Mangel verursachte eine erhöhte Sterblichkeit der Mäuse bei einer E.-coli-Meningitis}

Um den Effekt von verschiedenen VitD-Konzentrationen auf den Krankheitsverlauf nach einer E.-coli-K1-Infektion zu zeigen, wurde den Mäusen ( $\pm 20 \mathrm{~g}$ schwer) intrazerebral $4000 \mathrm{CFU}$ von E. coli injiziert. Die Tiere wurden anschließend über einen Beobachtungszeitraum von 14 Tagen regelmäßig gewogen, und es wurde der klinische Score bestimmt. Verstorbene Mäuse wurden bei den folgenden Messungen nicht mehr berücksichtigt. Zur Bestimmung der bakteriellen Titer wurden nach dem Tod Kleinhirn und Milz homogenisiert, Verdünnungsreihen hergestellt und auf Blutagarplatten ausplattiert. Diese wurden anschließend $24 \mathrm{~h}$ lang im Brutschrank bei $37^{\circ} \mathrm{C}$ inkubiert (s. 2.6.4 Ausplattierung und bakterielle Titer).

Die Abbildung 3-2 zeigt die Überlebensrate der Mäuse in Abhängigkeit von der gemessenen Zeit. Nach der Infektion verstarben in der Standardgruppe (S-VitD) 10 von 21 Mäusen (47,62 \%), in der N-VitD-Gruppe 15 von 17 (88,24 \%) und bei H-VitD 8 von 15 Tieren (53,33\%). Diese Ergebnisse waren signifikant. Eine Ernährung mit $\mathrm{N}$-VitD führte demnach signifikant zu einer erhöhten Sterblichkeit im experimentellen Modell der E.-coli-Meningitis.

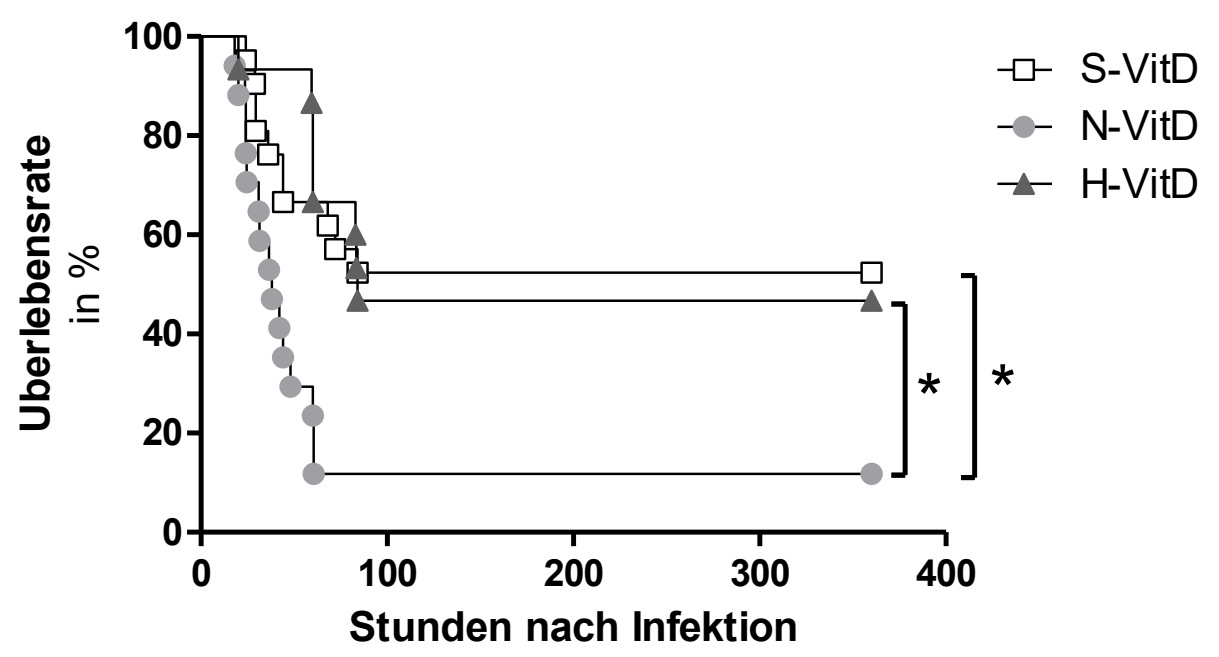

Abbildung 3-2 Überlebensrate (\%) in Abhängigkeit von der Zeit (Stunden nach Infektion). Die KaplanMeier-Kurven der 3 VitD-Ernährungsgruppen wurden mit dem Log-rank Test verglichen $(p=0,03$; SVitD: $n=21$; N-VitD: $n=17 ;$ H-VitD: $n=15$ Mäuse). 
Dagegen gab es bezüglich der Sterblichkeit der Mäuse zwischen der S-VitD- und HVitD-Gruppe nur geringe, nicht statistisch signifikante, Unterschiede. Die KaplanMeier-Kurve von $\mathrm{H}$-VitD ist in Richtung der $\mathrm{x}$-Achse verschoben, was bedeutet, dass die Mäuse erst etwas später verstarben als in den anderen beiden Gruppen. Eine HVitD-Ernährung übte jedoch keinen zusätzlichen protektiven Effekt auf das Überleben der Mäuse aus, sondern zeigte den gleichen Effekt wie die S-VitD-Gruppe.

Bereits $20 \mathrm{~h}$ nach der Infektion wurde beobachtet, dass alle Mäuse leicht lethargisch waren, sich jedoch noch fortbewegten und Nahrung zu sich nehmen konnten. Zusammen mit der objektiven Beurteilung durch den klinischen Score und der Protokollierung des Gewichts wurde der Gesundheitszustand der Mäuse beurteilbar. Das Gewicht wurde vor der Infektion $(0 \mathrm{~h})$ und nach der Infektion alle 12 Stunden protokolliert (12-96 h). Nach dieser akuten Phase wurde an Tag 7 (170 h) gewogen und bis zum Versuchsende (14. Tag) noch viermal. Somit konnte auch kontrolliert werden, ob die Mäuse aus ethischen Gründen getötet werden müssen, wenn sie mehr als $20 \%$ ihres Gewichts im Vergleich zu ihrem Anfangsgewicht $(0 \mathrm{~h})$ verloren.

Die folgende Abbildung 3-3 veranschaulicht den Gewichtsverlust (in g) bei den drei verschiedenen VitD-Konzentrationen $24 \mathrm{~h}$ nach der Infektion. Hierbei zeigte sich, dass die N-VitD- und die S-VitD-Gruppe zu einem höheren Gewichtsverlust neigten als H-VitD. Aufgrund der großen Streuung innerhalb der Gruppen führte dies jedoch zu keinem signifikanten Ergebnis.

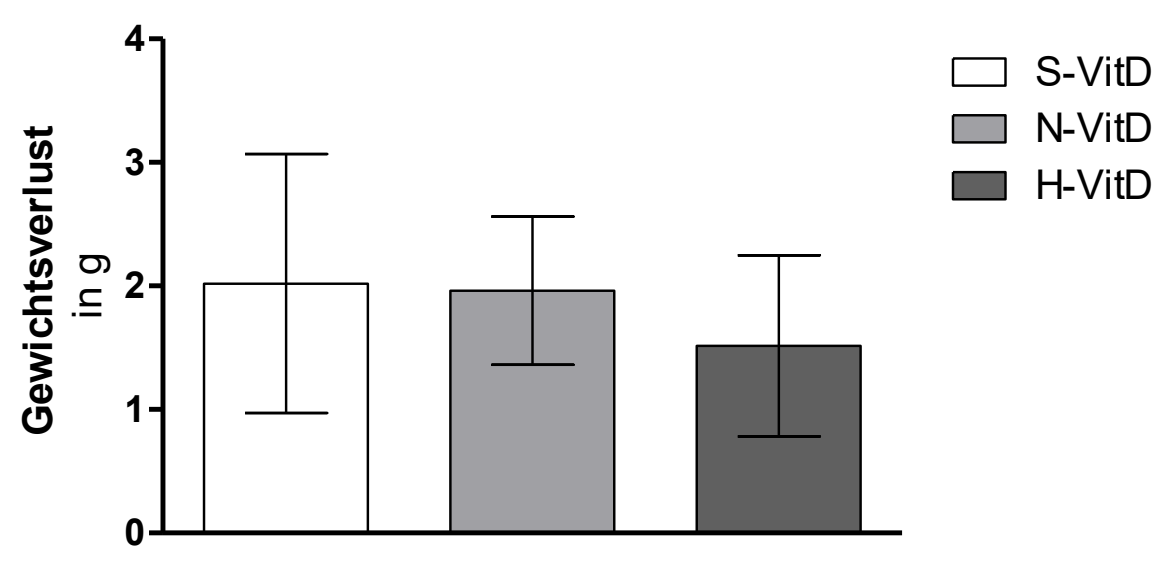

Abbildung 3-3 Gewichtsverlust in g $24 \mathrm{~h}$ nach der Infektion bei S-VitD, N-VitD und H-VitD. Dargestellt sind die Mittelwerte \pm Standardabweichung mit one-way-ANOVA und Korrektur nach Bonferroni. 
Die Abbildung 3-4 zeigt den klinischen Score zum Zeitpunkt $24 \mathrm{~h}$ nach der E.-coliInfektion. Der Score wurde nach der Infektion im 12-Stunden-Rhythmus erhoben (s. 2.5 Induktion der E.-coli-Meningitis) und verdeutlichte somit den Krankheitszustand anhand eines objektiven Scores. Mäuse aus der N-VitD-Gruppe hatten einen signifikant höheren klinischen Score als S-VitD und H-VitD $24 \mathrm{~h}$ nach Infektion $\left({ }^{*} p<0,05\right.$; Kruskal-Wallis-Test mit Korrektur nach Bonferroni).

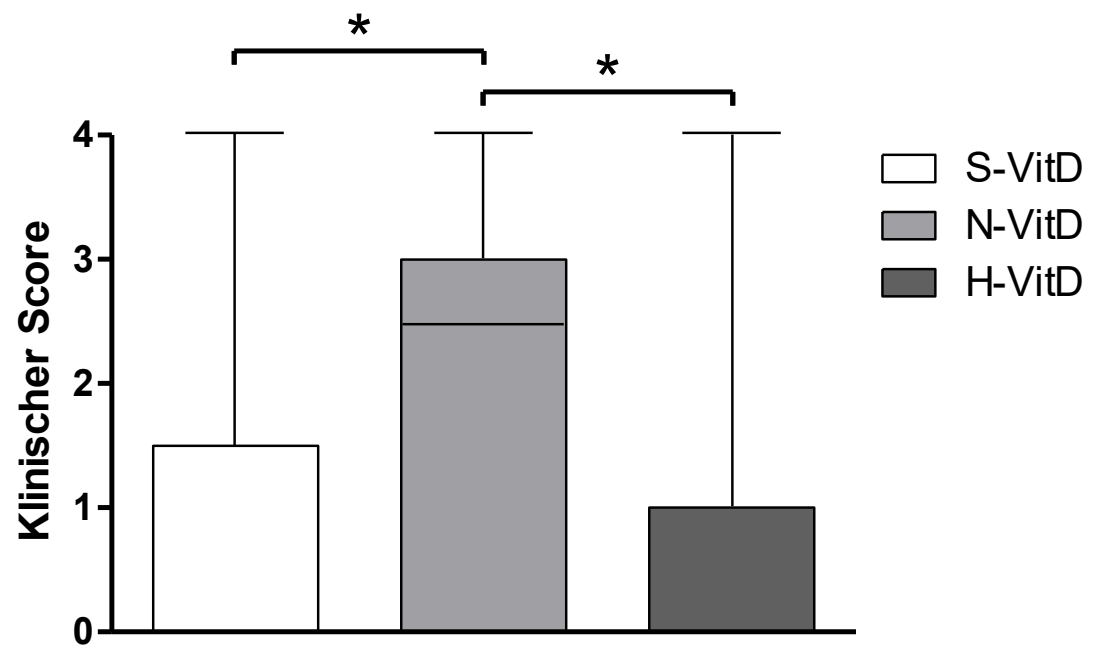

Abbildung 3-4 Klinischer Score $24 \mathrm{~h}$ nach der Infektion. Die Daten sind als Boxplot mit Minimum, Median und Maximum dargestellt und wurden durch den Kruskal-Wallis-Test mit Korrektur nach Bonferroni miteinander verglichen $\left({ }^{*} p<0,05\right)$. 


\subsection{Vitamin D hatte keinen Einfluss auf die bakteriellen Titer in Kleinhirn, Milz und Blut}

Bereits 1986 entdeckten Rook und Kollegen, dass die aktive Form 1,25VitD in vitro das Wachstum von Mycobacterium tuberculosis begrenzte (Rook et al. 1986). Aufgrund der hohen Sterblichkeit der N-VitD-Mäusen im Überlebensversuch galt es somit herauszufinden, ob VitD gegebenenfalls eine antibakterielle Funktion in dem Versuchsmodell zu dieser Dissertation besitzt und eine mögliche Erklärung für das bessere Überleben der mit adäquaten VitD-Dosen ernährten Mäuse liefern würde.

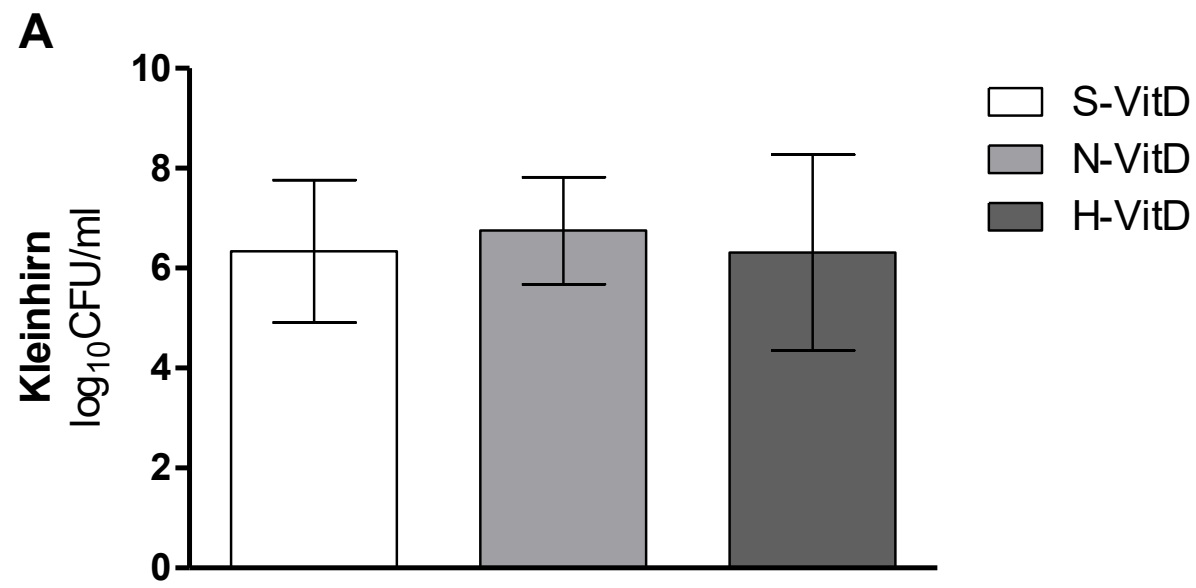

B

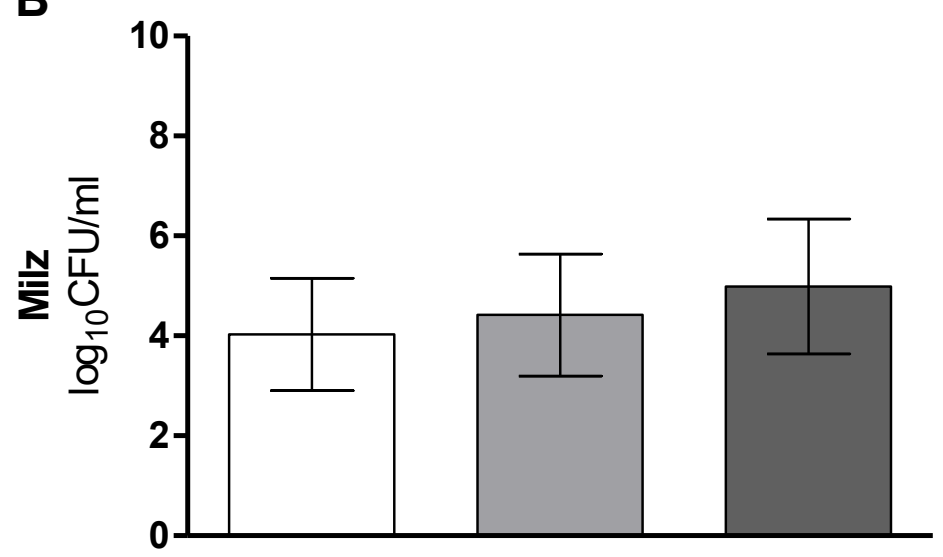

Abbildung 3-5 Bakterientiter von Kleinhirn $(A)$ und Milz $(B)$ im Überlebensversuch mit Mittelwerten \pm Standardabweichung $(p=0,8(A)$ und $p=0,2(B)$; one-way ANOVA, Korrektur nach Bonferroni) 
Die Grafik A der Abbildung 3-5 zeigt die Bakterienkonzentration im Kleinhirn der Mäuse, die im Überlebensversuch nach einer E.-coli-Infektion (4000 CFU intrazerebral) verstarben. Es sind die Mittelwerte \pm SD dargestellt. Die Werte der SVitD-Mäuse waren bei $6,3 \pm 1,4 \log _{10} \mathrm{CFU} / \mathrm{ml}, \quad \mathrm{N}$-VitD-Mäuse hatten eine durchschnittliche Konzentration von 6,8 $\pm 1,1 \log _{10} \mathrm{CFU} / \mathrm{ml}$ und die H-VitD-Gruppe lag bei 6,3 $\pm 2,0 \log _{10} \mathrm{CFU} / \mathrm{ml}$. Es waren keine signifikanten Unterschiede zwischen den Gruppen messbar ( $p=0,8$, one-way ANOVA mit Korrektur nach Bonferroni).

Die Grafik B der Abbildung 3-5 zeigt die Keimkonzentration in der Milz. Die Mittelwerte und Standardabweichungen lagen in der S-VitD-Gruppe bei $4,0 \pm 1,1 \log _{10} \mathrm{CFU} / \mathrm{ml}$, in der N-VitD-Gruppe bei $4,4 \pm 1,2 \log _{10} \mathrm{CFU} / \mathrm{ml}$ und bei H-Vit$D$ waren es $5,0 \pm 1,4 \log _{10} \mathrm{CFU} / \mathrm{ml}$. Es gab keine signifikanten Unterschiede $(p=0,2)$.

In dem Überlebensversuch stellte sich heraus, dass die ersten Mäuse $24 \mathrm{~h}$ nach der Infektion krank wurden und einige auch verstarben. Um die bakterielle Konzentration zu Beginn der Krankheit, also in dieser ersten akuten Phase, bei allen Tieren parallel beurteilen zu können, wurden alle Mäuse $20 \mathrm{~h}$ p. i. getötet ( $\mathrm{n} \geq 15$ pro Gruppe). Die Infektion wurde durch intrazerebrale Injektion von 9000 CFU von E. coli ausgelöst. In der folgenden Abbildung 3-6 sind die bakteriellen Titer von Kleinhirn, Milz und Blut dargestellt. Im Kleinhirn von H-VitD-Mäusen war tendenziell, aber nicht signifikant, eine geringere Anzahl an Bakterien vorhanden $\left(4,9 \pm 2,1 \log _{10} \mathrm{CFU} / \mathrm{ml}\right)$, im Vergleich zu S-VitD $\left(6,1 \pm 1,6 \log _{10} \mathrm{CFU} / \mathrm{ml}\right)$ und $\mathrm{N}$-VitD $\left(5,8 \pm 1,9 \log _{10} \mathrm{CFU} / \mathrm{ml}\right.$, Mittelwerte $\pm S D, p=0,6$, one-way ANOVA mit Korrektur nach Bonferroni). Die Unterschiede zwischen den Gruppen bei Milz und Blut waren nur sehr gering und nicht signifikant.

In den Kontrollgruppen $(\mathrm{n}=5)$, in denen $\mathrm{NaCl}$ injiziert wurde, waren alle Homogenate steril. Diese Mäuse wurden in der Abbildung 3-6 nicht miteinbezogen. 


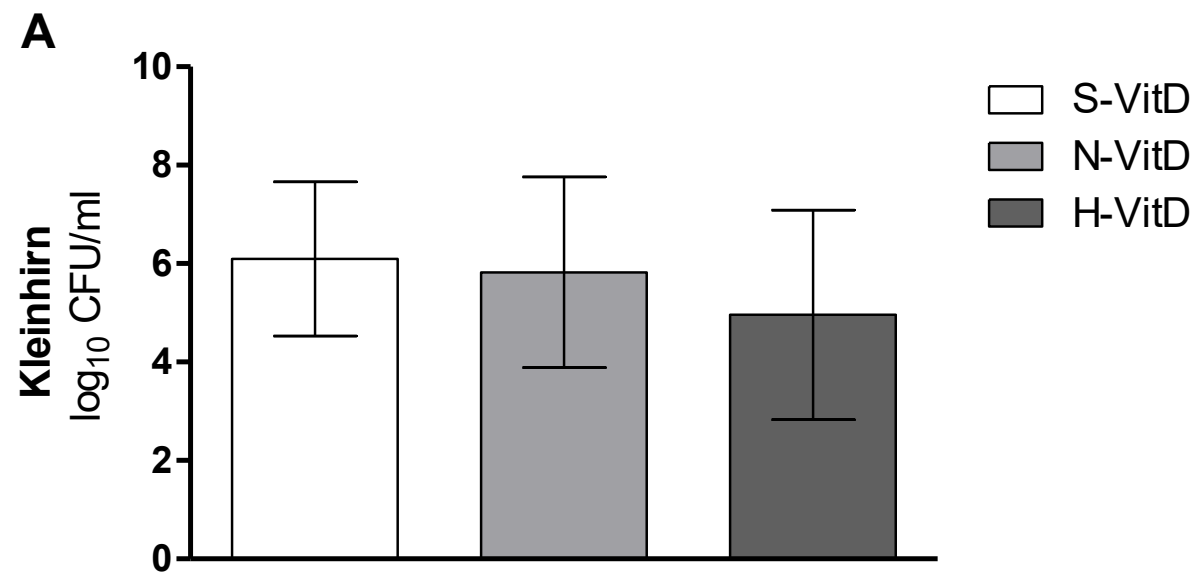

B

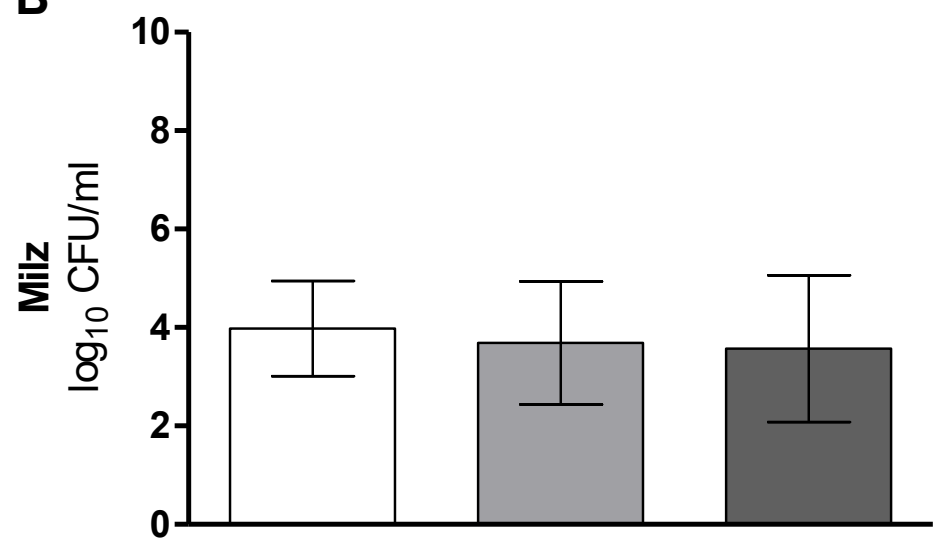

C

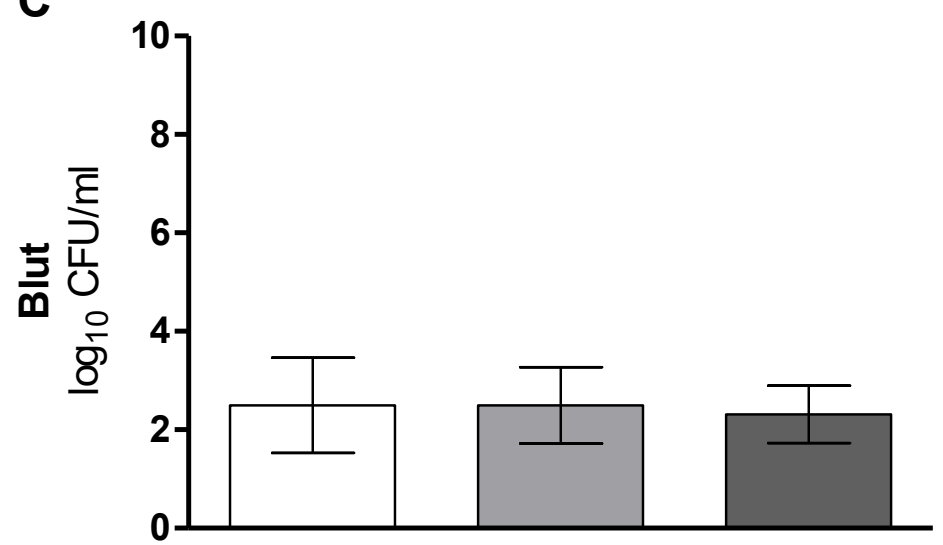

Abbildung 3-6 Bakterielle Titer von Kleinhirn, Milz und Blut im $20 \mathrm{~h}$-Versuch. Dargestellt sind die Mittelwerte \pm SD. 


\subsection{Eine hohe Vitamin-D-Konzentration führte zu einer besseren Eliminierung von Bakterien in Mäusen, die die Infektion überlebten}

Mäuse, die die Infektion überlebten, wurden nach 14 Tagen Beobachtung und Protokollierung des Gesundheitszustandes getötet. Die Homogenate von Kleinhirn, Milz und Blut wurden auf Bakterienlast untersucht und ausgewertet. Die folgende Tabelle zeigt die Anzahl der überlebenden Mäuse 14 Tage p. i. und den Anteil derer, die in den Homogenaten des Kleinhirns noch Bakterien aufwiesen.

\begin{tabular}{llll}
\hline Gruppe & Überlebende & $\begin{array}{l}\text { Homogenate (mit } \\
\text { Bakteriennachweis) }\end{array}$ & $\begin{array}{l}\text { Bakterienlast } \\
(\%)\end{array}$ \\
\hline S-VitD & 10 von 21 & 2 & 20 \\
N-VitD & 2 von 17 & 2 & 100 \\
H-VitD & 7 von 15 & 0 & 0 \\
\hline
\end{tabular}

Tabelle 3-1 Bakterienlast der Kleinhirnhomogenate von Mäusen, die 14 Tage nach der Infektion getötet wurden. S-VitD: Standard-Vitamin-D-Konzentration, N-VitD: Niedrige Vitamin-D-Konzentration, H-VitD: Hohe Vitamin-D-Konzentration.

Bei der N-VitD-Gruppe fanden sich in beiden Kleinhirn-Homogenaten der überlebenden Mäuse $(n=2)$, verglichen mit $20 \%(n=2 / 10)$ der aus der S-VitDGruppe, Bakterien ( $p=0,09$, exakter Fisher-Test). In der H-VitD-ernährten Gruppe waren alle überlebenden Mäuse $(n=7)$ im Kleinhirn steril $(p=0,03$ verglichen mit $N$ VitD und $p=0,5$ verglichen mit S-VitD, exakter Fisher-Test). Somit zeigt sich, dass hohe VitD-Konzentrationen einen positiven Einfluss auf die Eliminierung von Bakterien aus dem ZNS hatten.

In der Milz und im Blut waren alle bakteriellen Titer unterhalb der Nachweisgrenze. 


\subsection{Die verschiedenen Vitamin-D-Ernährungen beeinflussten nicht die} Leukozyteninfiltration in die Meningen $20 \mathrm{~h}$ nach einer E.-coli-Infektion

In den Versuchen zu dieser Dissertation gab es keine signifikanten Unterschiede bezüglich der bakteriellen Titer. Aufgrund dessen wurde als Nächstes untersucht, ob VitD die meningeale Infiltration von Leukozyten bei einer E.-coli-Meningitis beeinflusst. In anderen Studien zur bakteriellen Meningitis mit dem Erreger $S$. pneumoniae wurde festgestellt, dass bereits $12 \mathrm{~h}$ post infectionem eine vermehrte Einwanderung von Granulozyten und Monozyten in die Meningen stattfand (Mildner et al. 2008). Somit wurden in Paraffin fixierte $2 \mu \mathrm{m}$ dicke Frontalschnitte des Großhirns von den Mäusen, die $20 \mathrm{~h} \mathrm{p.i.} \mathrm{getötet} \mathrm{wurden,} \mathrm{angefertigt} \mathrm{und} \mathrm{mit} \mathrm{der}$ CAE-Färbung gefärbt. Anschließend wurden die Schnitte unter dem Mikroskop betrachtet, die Leukozyten pro Bereich gezählt, Mittelwerte aus den fünf Bereichen gebildet und in die zuvor genannten Leukozytenscores umgerechnet (s. 2.7 .2 Mikroskopische Auswertung der Präparate). Histologisch wurde bei jedem Präparat eine Einwanderung von Leukozyten in den Subarachnoidalraum beobachtet.

Die Abbildung 3-7 zeigt die Leukozytenanzahl der drei VitD-Gruppen als Mittelwerte mit den jeweiligen Standardabweichungen $(n=17)$. Mäuse aus der N-VitD-Gruppe hatten im Vergleich zu H-VitD-Mäusen tendenziell eine höhere Anzahl an Leukozyten pro Bereich $(41,6 \pm 16$ vs. $33,1 \pm 21,4$; Mittelwerte $\pm S D, p=0,4$; one-way ANOVA mit Korrektur nach Bonferroni). Jedoch ergab dies kein signifikantes Ergebnis. Somit hatte VitD keinen direkten Einfluss auf die Leukozytenrekrutierung im Modell der bakteriellen Meningitis.

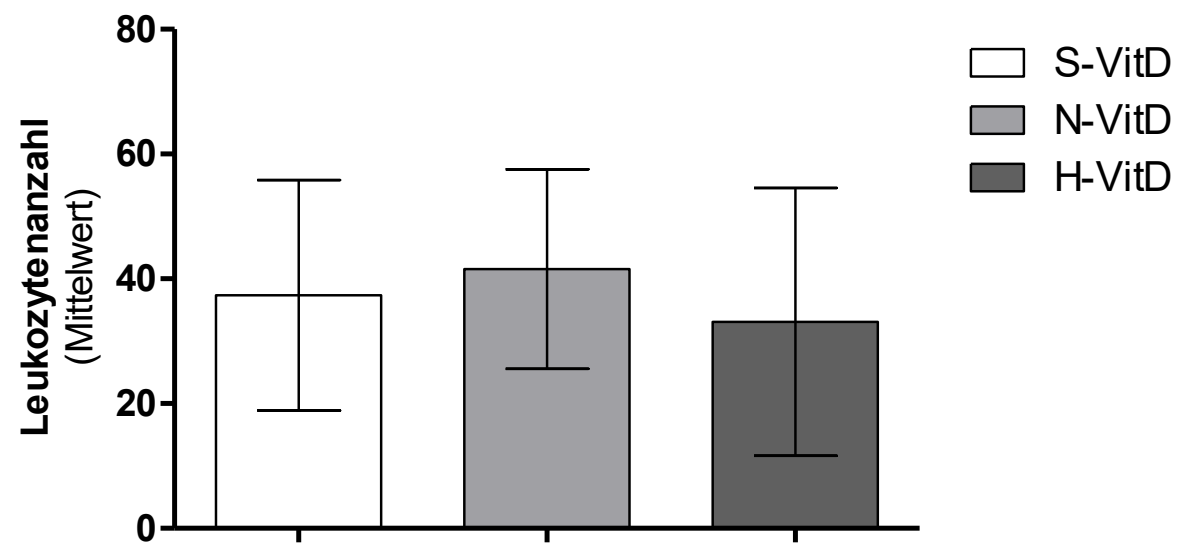

Abbildung 3-7 Leukozytenanzahl der 3 VitD-Gruppen als Mittelwerte (one-way ANOVA mit Korrektur nach Bonferroni, $\mathrm{n}=17$ ) 
In der folgenden Abbildung 3-8 sind drei histologische Präparate (CAE-Färbung) exemplarisch dargestellt, in denen die Einwanderung der Leukozyten sichtbar ist.
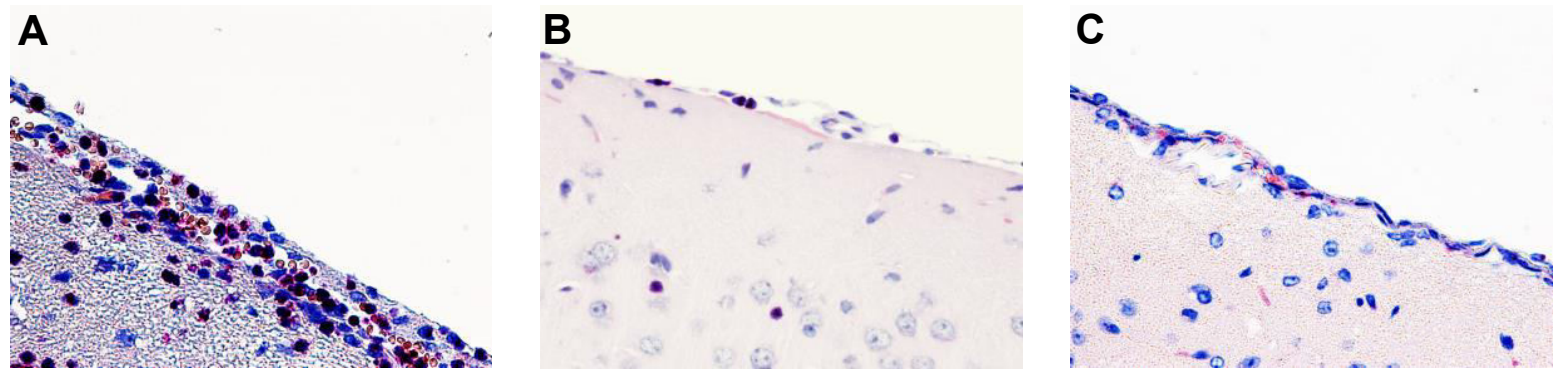

Abbildung 3-8 Meningeale Leukozyteninfiltration mit CAE-Färbung. Leukozyten sind lila gefärbt. (A) S-VitD: Score 2; (B) H-VitD: Score 1; (C) N-VitD: Score 0

Das Präparat (A) stammt von einer S-VitD-Maus und hat den Score 2, (B) von H-VitD mit Score 1 und $(C)$ von $\mathrm{N}-\mathrm{VitD}$ mit Score 0 . Mäuse, denen $\mathrm{NaCl}$ anstatt $E$. coli injiziert wurde, zeigten in ihren Präparaten, wie zu erwarten war, keine Leukozyteninfiltration (Score 0). 
Hinzufügend zur histologischen Analyse wurden die verschiedenen Leukozytenarten prozentual im gesamten Gehirn der Mäuse mit Hilfe der Durchflusszytometrie und der FlowJo Software erfasst. Hierfür wurden Mäuse verwendet, die $20 \mathrm{~h}$ nach einer E.-coli-Infektion getötet wurden.

Die Tabelle 3-2 zeigt die relativen Anteile der Untergruppen an den gesamten CD45 ${ }^{+}$-Zellen. Es sind die Mediane mit 25./75.-Perzentilen angegeben. Auch wenn leichte Tendenzen erkennbar waren, waren die Unterschiede zu gering und somit nicht signifikant ( $p>0,05$; one-way ANOVA mit Korrektur nach Bonferroni).

Anteil an $\mathrm{CD}^{+} 5^{+}$-Zellen (in \%)

\begin{tabular}{|c|c|c|c|}
\hline & S-VitD & N-VitD & H-VitD \\
\hline 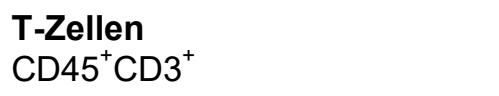 & $11,25(4 / 23,53)$ & $7,5(1,1 / 18,50)$ & $10,70(2,75 / 23,35)$ \\
\hline $\begin{array}{l}\text { Regulatorische T-Zellen } \\
\mathrm{CD} 45^{+} \mathrm{CD} 4^{+} \mathrm{CD} 3^{+} \mathrm{CD} 25^{+} \text {FoxP3 }\end{array}$ & $0,25(0,04 / 0,93)$ & $0,05(0,005 / 0,17)$ & $0,09(0,015 / 0,5)$ \\
\hline $\begin{array}{l}\text { NK-Zellen } \\
\text { CD45 NK1.1CD3- }\end{array}$ & $2,25(1,525 / 3,43)$ & $3(0,95 / 4,4)$ & $1,3(1,15 / 1,65)$ \\
\hline 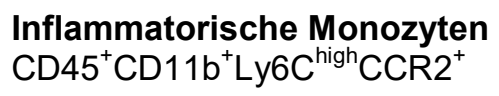 & $28,90(26,95 / 34,75)$ & $36,20(25,9 / 40,85)$ & $27(18,10 / 31,20)$ \\
\hline 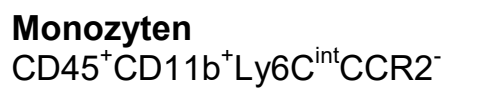 & $35,35(33,3 / 43,33)$ & $42,20(31,4 / 47,3)$ & $34,40(25,75 / 37,85)$ \\
\hline 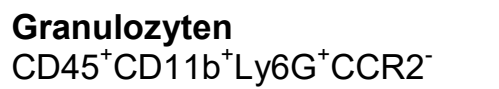 & $43,25(28,85 / 51,58)$ & $26,20(23 / 49,95)$ & $34,20(28,60 / 54,40)$ \\
\hline
\end{tabular}

Tabelle 3-2 Die Daten der FACS (fluorescence-activated cell sorting)-Analyse sind als Mediane (25./75.-Perzentilen) dargestellt. Das gesamte Gehirn von vier bis fünf Tieren pro Gruppe wurde in drei getrennten Versuchen verwendet. Es wurden keine signifikanten Unterschiede gefunden ( $p$ > 0,05; one-way ANOVA mit Korrektur nach Bonferroni). S-VitD: Standard-Vitamin-D-Konzentration, N-VitD: Niedrige Vitamin-D-Konzentration, H-VitD: Hohe Vitamin-D-Konzentration, T-Zellen: ThymusZellen/Lymphozyten, NK-Zellen: natürliche Killerzellen, CD: cluster of differentiation (eBioscience und Biolegend), FoxP3: forkhead box protein 3 (eBioscience), Ly6C: lymphocyte antigen 6C (Biolegend), CCR2: c-c chemokine receptor type 2 ( $R$ \& D Systems). 


\subsection{VitD-Supplementierung inhibierte die Produktion des pro- inflammatorischen IL-6 und förderte die Produktion des anti- inflammatorischen IL-10}

In früheren Publikationen wurde bereits die bedeutende antibakterielle und antivirale Funktion des VitD bei der angeborenen und erworbenen Immunantwort herausgestellt (Mora et al. 2008; Bikle 2008; Beard et al. 2011). VitD beeinflusst die Produktion von Zytokinen, indem es z. B. die IL-10-Sezernierung dendritischer Zellen stimuliert, proinflammatorische Zytokine reguliert oder immunregulatorische T-Zellen erhöht (Bergman et al. 2015; De Castro Kroner et al. 2015). Die Chemokine KC und MIP-2 werden u. a. von Abwehrzellen, Endothelzellen und Fibroblasten sezerniert und ziehen bei der akuten bakteriellen Meningitis Monozyten und Neutrophile aus dem Blutstrom in das ZNS (Lüllmann-Rauch 2009; Prinz et al. 1999).

In dieser Arbeit führte eine E.-coli-Infektion zur Produktion verschiedener Zytokine und Chemokine wie IL-6, IL-10, KC und MIP-2.

Die Abbildung 3-9 zeigt sowohl die Ausschüttung der Zytokine IL-6 und IL-10 als auch der Chemokine KC und MIP-2 im Kleinhirn der Mäuse, die im Überlebensversuch nach einer E.-coli-Infektion (4000 CFU) verstarben oder aus ethischen Gründen getötet wurden ( $n \geq 7$ pro Gruppe). Dargestellt sind jeweils die Mediane. Die statische Auswertung wurde durch den Kruskal-Wallis-Test mit Korrektur nach Bonferroni vorgenommen. Die Grafik A der Abbildung zeigt die Ausschüttung von IL-6. Der Median der S-VitD-Mäuse $(n=7)$ lag bei $1573 \mathrm{pg} / \mathrm{ml}, \mathrm{N}$ VitD $(n=12)$ bei $1999 \mathrm{pg} / \mathrm{ml}$ und H-VitD $(n=8)$ bei $374,5 \mathrm{pg} / \mathrm{ml}$. Somit konnte nachgewiesen werden, dass eine H-VitD-Ernährung zu einer signifikant verringerten Ausschüttung des proinflammatorischen Zytokins IL-6 im Vergleich zu einer N-VitDErnährung führte $(p<0,05$; kein signifikanter Unterschied zwischen $S-V i t D$ und $N$ VitD feststellbar). Die S-VitD-Gruppe zeigte tendenziell eine höhere Ausschüttung von IL-6 als die H-VitD-Mäuse, jedoch war dieses Ergebnis nicht signifikant $(p=0,2)$. Die Grafik B der Abbildung 3-9 veranschaulicht die Konzentration des antiinflammatorischen Zytokins IL-10. H-VitD-Mäuse hatten einen höheren Median $(270 \mathrm{pg} / \mathrm{ml})$ als N-VitD $(83,4 \mathrm{pg} / \mathrm{ml})$ und S-VitD $(58,2 \mathrm{pg} / \mathrm{ml})$. Die Unterschiede waren signifikant $\left({ }^{*} \mathrm{p}<0,05\right)$. 
Bei der Produktion des Chemokins KC (Grafik C) gab es auch signifikante Unterschiede zwischen der N-VitD- und H-VitD-Gruppe: Die H-VitD-Gruppe hatte tendenziell einen niedrigeren Wert als $\mathrm{N}$-VitD $\left({ }^{*} \mathrm{p}<0,05\right)$. Des Weiteren ist auffällig, dass die Konzentration des MIP-2 (D) in der N-VitD-Gruppe sehr hoch war: N-VitD hatte einen Median von $5237 \mathrm{pg} / \mathrm{ml}$ (25./75. Perzentile in pg/ml: 1801/6287) im Gegensatz zu S-VitD mit $2937 \mathrm{pg} / \mathrm{ml}(215,9 / 5912)$ und H-VitD mit $2859 \mathrm{pg} / \mathrm{ml}$ (402,9/4294). Jedoch gab es keine signifikanten Unterschiede.

Somit führte eine Ernährung mit H-VitD zu einer signifikant vermehrten Ausschüttung des antiinflammatorischen Zytokins IL-10 und zu einer verringerten Produktion des proinflammatorischen Zytokins IL-6 im Kleinhirn.

Die Abbildung 3-10 zeigt die Produktion der Zytokine/Chemokine in der Milz. Bei IL-6 (A) und IL-10 (B) gab es zwischen den drei Gruppen keine statistisch signifikanten Unterschiede $(p>0,05)$. Jedoch wurden KC (C) und MIP-2 (D) von der H-VitDGruppe signifikant weniger sezerniert als von N-VitD $\left({ }^{*} p<0,05\right)$. Zwischen N-VitD und S-VitD gab es keine signifikanten Unterschiede. 


\section{Überlebensversuch: Kleinhirn}
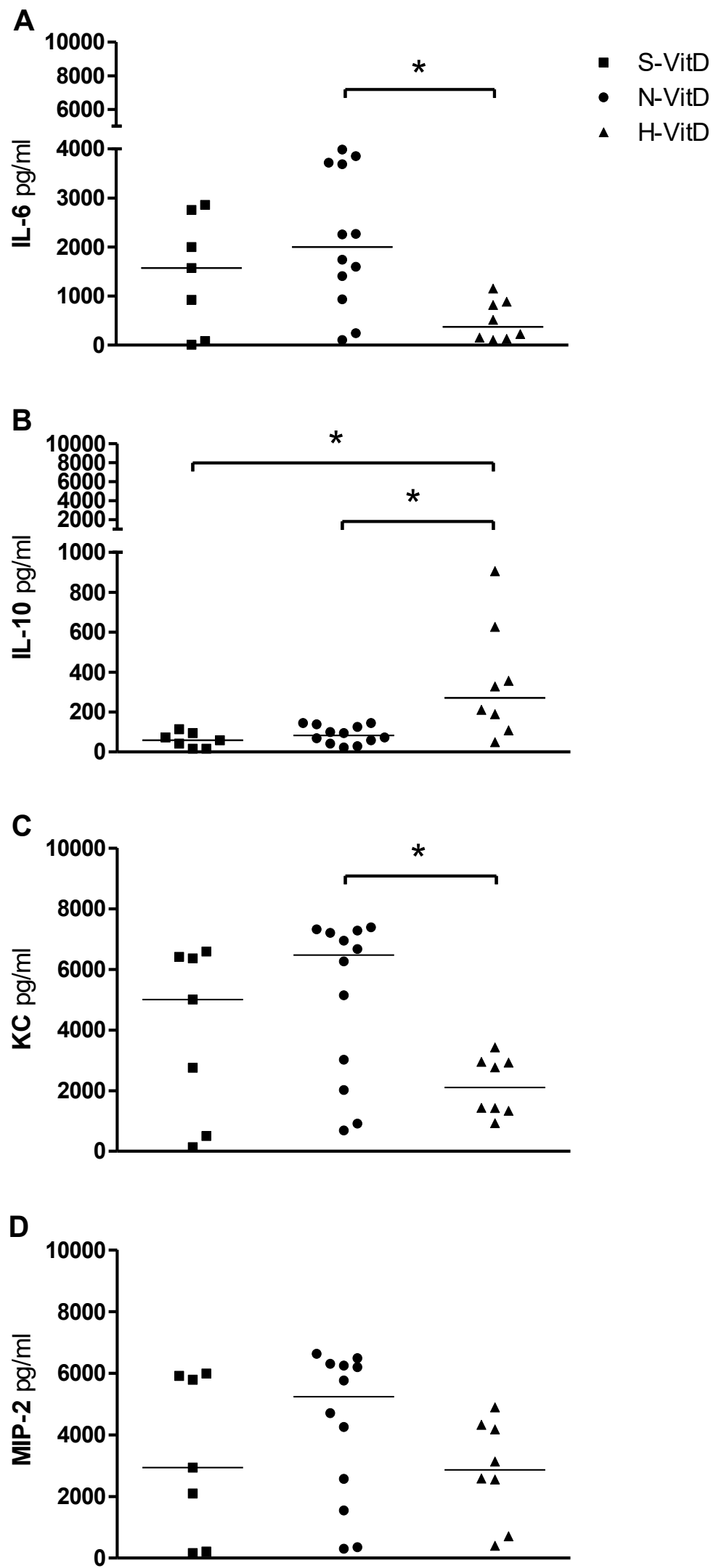

Abbildung 3-9 Zytokine IL-6 (A), IL-10 (B) und Chemokine KC (C), MIP-2 (D) des Kleinhirns der verstorbenen und getöteten Mäuse im Überlebensversuch ( $n \geq 7$ pro Gruppe). Dargestellt sind die Mediane. Für die Auswertung wurde der Kruskal-Wallis-Test mit Korrektur nach Bonferroni verwendet $\left({ }^{*} p<0,05\right)$. 


\section{Überlebensversuch: Milz}

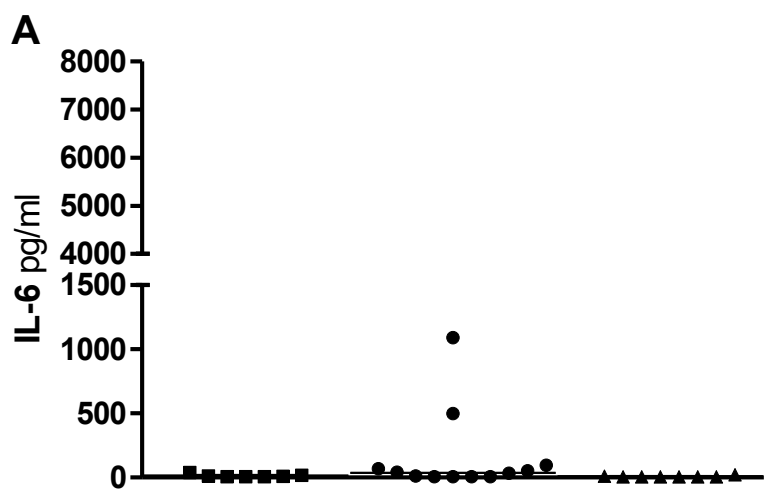

- S-VitD

- N-VitD

- H-VitD
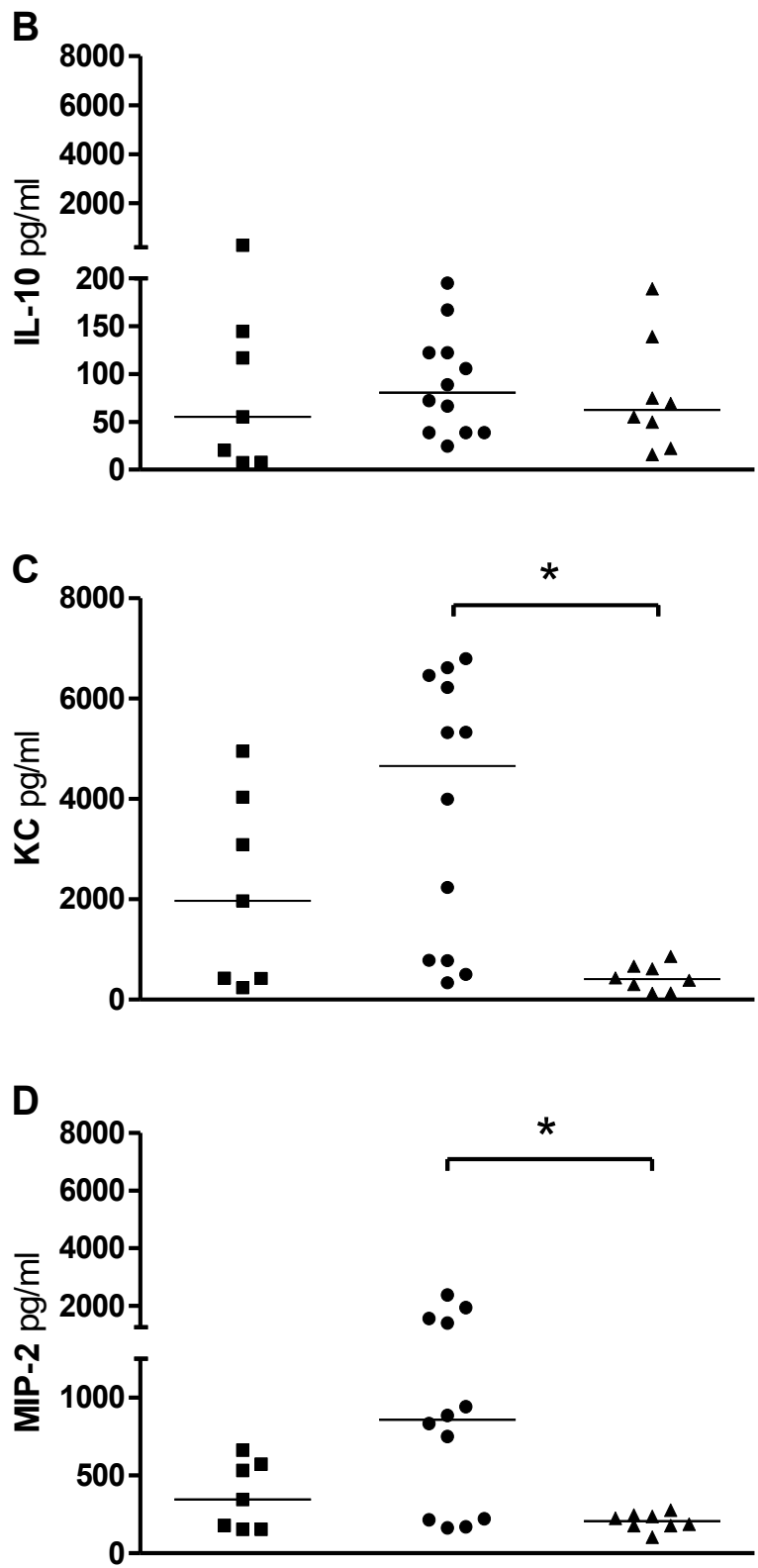

Abbildung 3-10 Zytokine IL-6 (A), IL-10 (B) und Chemokine KC (C), MIP-2 (D) der Milz der verstorbenen und getöteten Mäuse im Überlebensversuch ( $n \geq 7$ pro Gruppe). Dargestellt sind die Mediane. Für die Auswertung wurde der Kruskal-Wallis-Test mit Korrektur nach Bonferroni verwendet $\left({ }^{*} p<0,05\right)$. 
In der nachfolgenden Abbildung 3-11 ist die Produktion der Zytokine (IL-6 und IL-10) und die der Chemokine (KC, MIP-2) im Kleinhirn der Mäuse, die $20 \mathrm{~h}$ nach einer E.coli-Infektion (9000 CFU) getötet wurden, verbildlicht. Die statistische Auswertung wurde durch Verwendung des Kruskal-Wallis-Tests mit Korrektur nach Bonferroni vorgenommen. Die Mediane sind als horizontale Linien gekennzeichnet.

Es ist erkennbar, dass das proinflammatorische Zytokin IL-6 (A) und das Chemokin $\mathrm{KC}(C)$ von $\mathrm{H}$-VitD-Mäusen signifikant weniger sezerniert wurden als von $\mathrm{N}$-VitD $\left({ }^{*} p<0,05\right)$. Bei dem antiinflammatorischen Zytokin IL-10 (B) war tendenziell in der HVitD-Gruppe eine vermehrte Ausschüttung erkennbar, jedoch war es statistisch nicht signifikant $(p>0,05)$. Bei dem Chemokin MIP-2 (D) gab es auch keine signifikanten Unterschiede $(p>0,05)$. Diese Ergebnisse stimmen mit jenen aus dem Überlebensversuch überein.

Die Abbildung 3-12 stellt dagegen die Produktion der Zytokine und Chemokine in der Milz dar $(20$ h p. i.). Es gab keine signifikanten Unterschiede zwischen den Gruppen S-VitD, N-VitD und H-VitD $(p>0,05)$. 


\section{0 h-Versuch: Kleinhirn}
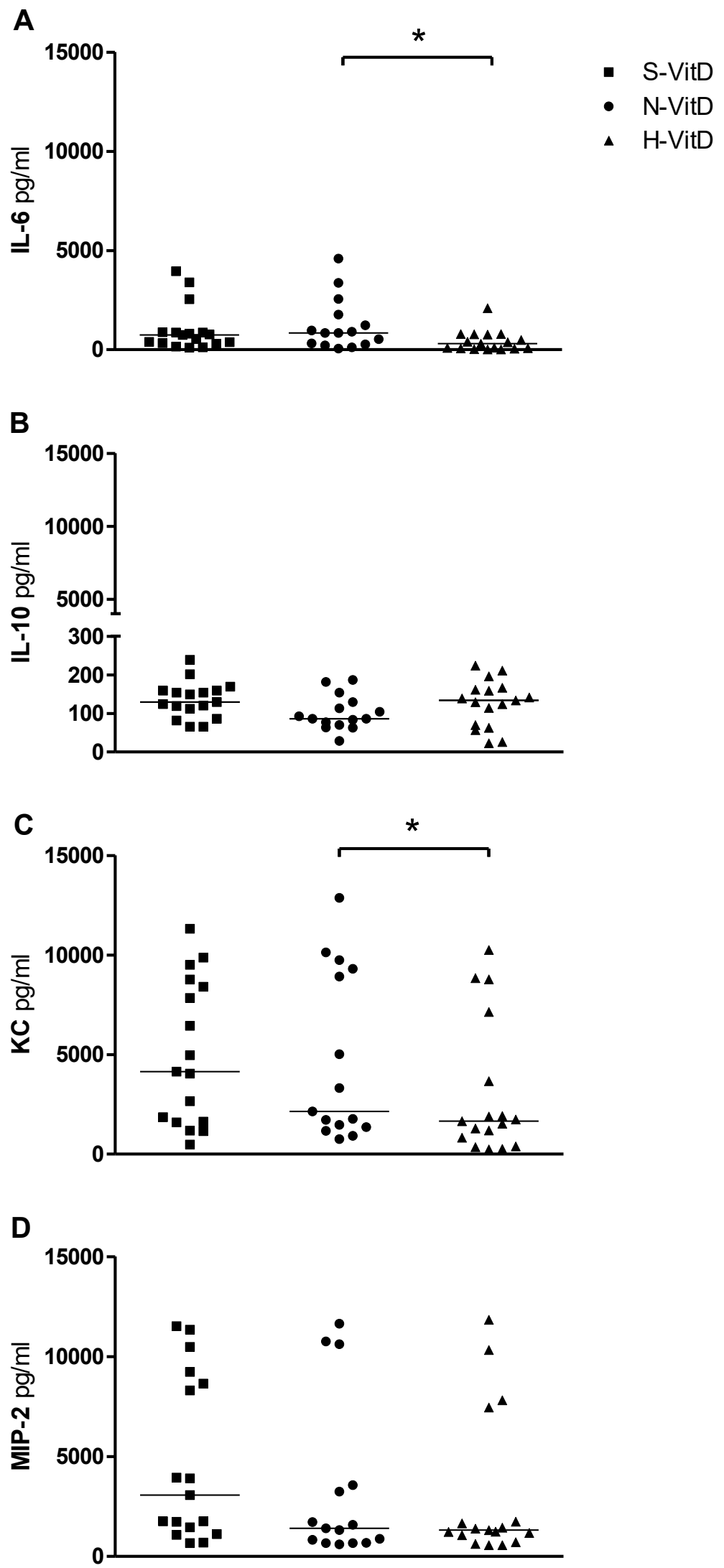

Abbildung 3-11 Zytokine IL-6 (A), IL-10 (B) und Chemokine KC (C), MIP-2 (D) des Kleinhirns $20 \mathrm{~h}$ post infectionem. Die Mediane sind als horizontale Linien gekennzeichnet. Für die Auswertung wurde der Kruskal-Wallis-Test mit Korrektur nach Bonferroni verwendet $\left({ }^{*} p<0,05\right)$. 


\section{0 h-Versuch: Milz}
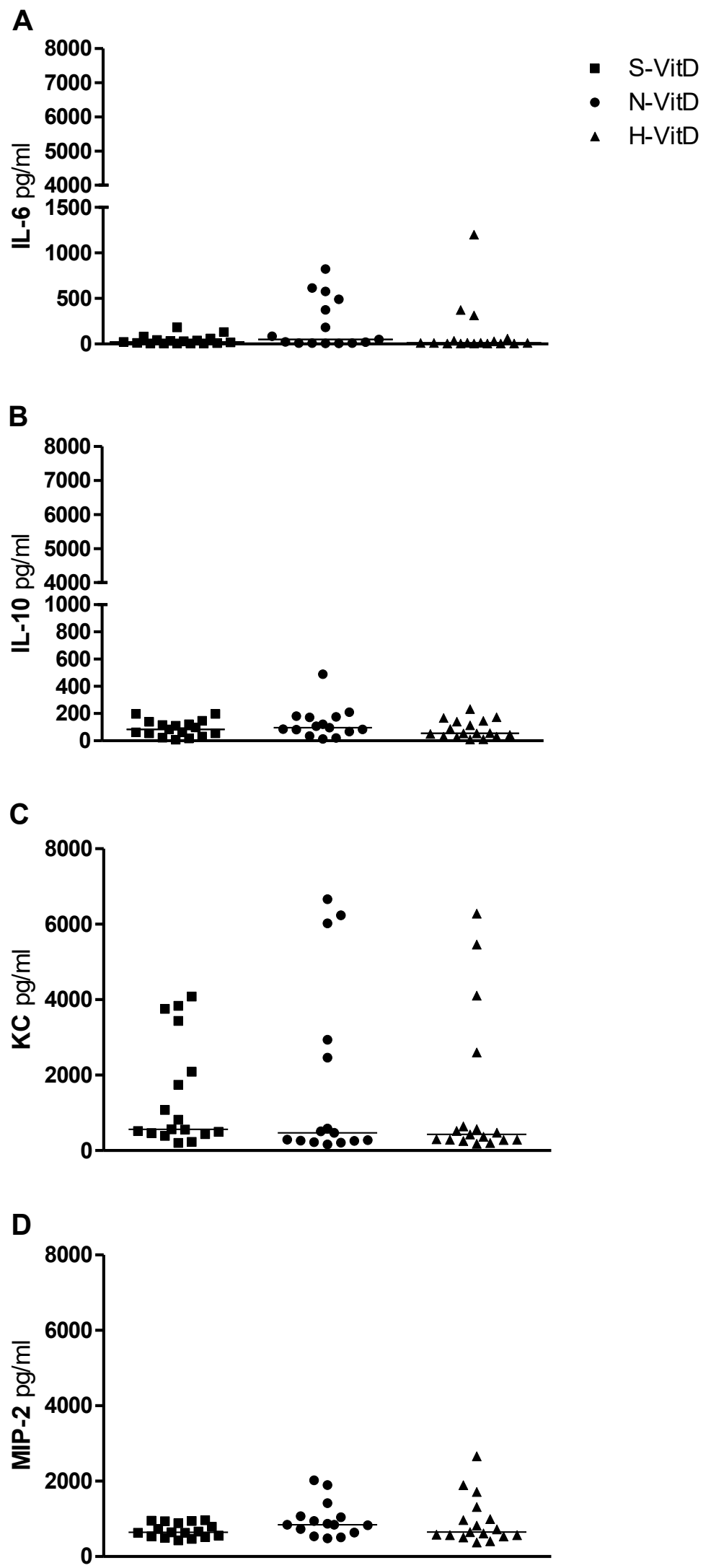

Abbildung 3-12 Zytokine IL-6 (A), IL-10 (B) und Chemokine KC (C), MIP-2 (D) der Milz $20 \mathrm{~h}$ post infectionem. Die Mediane sind als horizontale Linien gekennzeichnet. Für die Auswertung wurde der Kruskal-Wallis-Test mit Korrektur nach Bonferroni verwendet $(p>0,05)$. 
Das Zytokin IFN-y intensiviert laut Literatur durch Aktivierung von neutrophilen Granulozyten, Monozyten und Makrophagen die Inflammation und nachfolgende Krankheiten (Mitchell et al. 2012). Dagegen beeinflusst 1,25VitD T-Zellen, indem IFN-y gehemmt wird. (Mora et al. 2008; De Castro Kroner et al. 2015). Somit führt VitD durch Hemmung von IFN-ץ zu einer Abschwächung der Inflammation. In dieser Dissertation wurde die Konzentration an IFN- $\gamma$ in $\mathrm{pg} / \mathrm{ml}$ in den Kleinhirn- und Milzhomogenaten von Mäusen gemessen, die $20 \mathrm{~h}$ nach einer Infektion getötet wurden.

Anhand der Abbildung 3-13 ist sichtbar, dass es keine signifikanten Unterschiede zwischen den Gruppen gab ( $p>0,05$; Kruskal-Wallis-Test mit Korrektur nach Bonferroni). Viele Werte waren unterhalb der Nachweisgrenze $(<7,5 \mathrm{pg} / \mathrm{ml})$. Diese wurden in der Grafik somit einheitlich als $7,4 \mathrm{pg} / \mathrm{ml}$ bezeichnet. Anhand der Untersuchungsergebnisse dieser Arbeit kann keine Aussage zum Zusammenhang zwischen VitD und IFN-y getroffen werden.
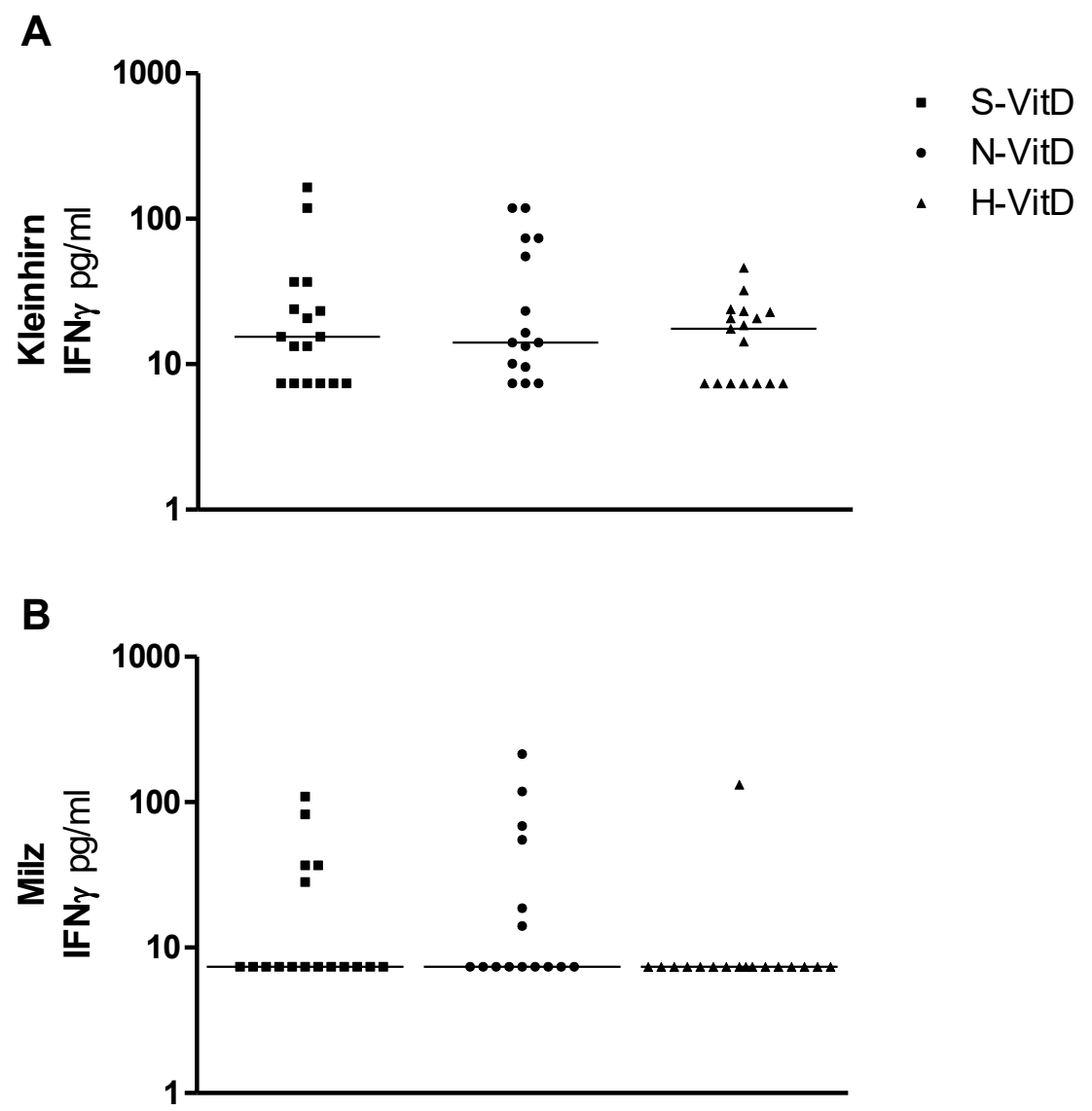

Abbildung 3-13 Konzentration des Zytokins IFN-y in Kleinhirn und Milz im 20 h-Versuch. Die Mediane sind als horizontale Linien gekennzeichnet $(p>0,05$; Kruskal-Wallis-Test mit Korrektur nach Bonferroni). Die Nachweisgrenze lag bei $\leq 7,5 \mathrm{pg} / \mathrm{ml}$. 


\section{Diskussion}

Die bakterielle Meningitis gilt noch immer als eine lebensbedrohliche Erkrankung (Adriani et al. 2015). Der signifikante Anstieg multiresistenter Erregerstämme, wie z. B. des E. coli, erschwert die Antibiotikatherapie erheblich. Aktuell stehen noch keine Impfstoffe gegen die E.-coli-Meningitis zur Verfügung (Pouillot et al. 2012; Allocati et al. 2013, Robert Koch-Institut 2016). Aufgrund dessen sind neue Erkenntnisse in der Therapie nötig, um sowohl Morbidität als auch Mortalität zu verringern. In den letzten Jahren wurde bekannt, dass VitD nicht nur den Kalziumund Knochenstoffwechsel beeinflusst, sondern außerdem extraskelettale Funktionen besitzt. So exprimieren z. B. Zellen des Immunsystems, wie Monozyten und APCs (antigen presenting cells), den Vitamin-D-Rezeptor, wodurch dem VitD auch eine immunmodulatorische Funktion zugeschrieben wird (Berge et al. 2016).

Die große Bedeutung, die das VitD bei der Infektionsresistenz ausübt, ist lange erforscht, aber bisher kaum verstanden. Untersucht wurde bisher u. a. das Zusammenspiel von VitD und Infektionen des respiratorischen Systems. Bergman und Kollegen zeigten in zwei Studien, dass die VitD-Gabe per os möglicherweise die Krankheitserscheinungen bei chronischen Infektionen des respiratorischen Systems milderte, das erstmalige Vorkommen dieser hinauszuzögern vermag sowie die Menge an Antibiotika verringerte (Bergman et al. 2015; Bergman et al. 2012). In einer der Studien (Bergman et al. 2012) wurden zwei Patientengruppen mit Immunschwäche miteinander verglichen: Eine Gruppe erhielt ein Jahr lang per os $4000 \mathrm{IE} / \mathrm{Tag}$ VitD und die andere bekam ein Placebo. Es wurde festgestellt, dass eine VitD-Gabe im Vergleich zur Placebo-Gabe zu einer geringeren Infektionslast an Erregern wie Haemophilus influenzae führte. Als möglicher protektiver Mechanismus wurde hierbei die Beeinflussung antimikrobieller Peptide (AMP) vermutet.

Eine besonders lang erforschte Erkrankung des respiratorischen Systems ist die Tuberkulose. Diese aerogene Infektion, die die Lunge betrifft, verursacht Husten, Fieber und Thoraxschmerzen. Im 18. Jahrhundert galten Schlaf und ein nahrhaftes Essen als alleinige Empfehlung. Seitdem in der Mitte des 20. Jahrhunderts Medikamente gegen das Mycobacterium tuberculosis entwickelt wurden, ist die Sterblichkeit erheblich zurückgegangen. Jedoch führten die Kosten der medikamentösen Behandlung und die Ausbildung von Resistenzen gegenüber Antibiotika zur Suche nach neuen Behandlungsmethoden, zu denen auch VitD gehörte (Chun et al. 2011). 
Hierbei wurde schon 1986 in vitro entdeckt, dass die aktive Form des Vitamin D $(1,25 \mathrm{VitD})$ das Wachstum von Mycobacterium tuberculosis begrenzte (Rook et al. 1986). Ein protektiver Effekt des VitD konnte auch im Rahmen einer Sepsis gezeigt werden. Ein VitD-Mangel $(<15-20 \mathrm{ng} / \mathrm{ml})$ führte in einer der Studien zu einem höheren Risiko, an dieser zu erkranken (Upala et al. 2015). Dagegen war in einer anderen Studie bei Patienten, die schon an einer Sepsis litten, bei VitD-Gabe (per os oder Magensonde) im Gegensatz zur Placebo-Gruppe eine erhöhte Konzentration des antimikrobiellen Peptids LL-37 feststellbar. Hierdurch konnte in diesem Modell der antibakterielle Effekt des VitD gezeigt werden konnte (Quraishi et al. 2015). Bei neugeborenen Ratten sicherte eine pränatale VitD-Therapie das Überleben und verbesserte die Lungenstruktur, nachdem sie Endotoxinen ausgesetzt worden waren (Mandell et al. 2014).

Vitamin D wirkt auch auf Autoimmunerkrankungen wie Diabetes mellitus Typ 1. Bei dieser Form des Diabetes kommt es durch Autoimmunprozesse zu einem Untergang der Inselzellen des Pankreas. Es resultiert ein absoluter Insulinmangel (LüllmannRauch 2009). Dagegen verbessert eine Vitamin-D-Gabe die Insulinproduktion und Insulinsensitivität und verhindert die Zerstörung der eigenen Inselzellen (Schwalfenberg 2008; Liu et al. 2015). Außerdem beeinflusst VitD die Glucosehomöostase, indem es u. a. einen direkten Effekt auf diese ausübt (Savastio et al. 2016). Bei einer über 30 Jahre andauernden Gabe von 2000 IE/Tag bei Kindern verminderte sich das Risiko, an Diabetes mellitus Typ 1 zu erkranken, um $78 \%$ (Schwalfenberg 2012).

Außerdem ist ein Zusammenhang zwischen VitD und der autoimmunen chronisch entzündlichen ZNS-Erkrankung multiple Sklerose erforscht. Diese Erkrankung wird durch inflammatorische Prozesse ausgelöst, führt zu einer Demyelinisierung im Nervensystem und klinisch zu physischen und kognitiven Beeinträchtigungen (Berge et al. 2016). In einer zwischen 1980 und 2001 durchgeführten amerikanischen Studie an 187.000 Frauen, die 10-20 Jahre lang begleitet wurden und mehr als $400 \mathrm{IE} / \mathrm{Tag}$ VitD zusätzlich einnahmen, verringerte sich das Risiko, an multipler Sklerose zu erkranken, um $40 \%$ (Munger et al. 2004). Im Tiermodell der multiplen Sklerose wurde nachgewiesen, dass 1,25VitD auf den VDR der CD4 $4^{+}$-T-Lymphozyten wirkte und aufgrund dessen die experimentelle autoimmune Enzephalomyelitis minderte (Berge et al. 2016). 
Wie VitD das ZNS in vivo bei erregerbedingten ZNS-Infektionen beeinflusst, wurde bisher noch nicht analysiert. Deshalb sollte in dieser Arbeit untersucht werden, ob eine orale VitD-Supplementierung im experimentellen Modell der bakteriellen Meningitis zu einer erhöhten Infektionsresistenz des Gehirns gegenüber E.-coliInfektionen und infolgedessen zu einer verringerten Sterblichkeit in vivo führte. Es wurde die Fähigkeit des Immunsystems der Maus, Erreger im Gehirn und im ZNS zu eliminieren, getestet und somit hinterfragt, ob VitD als ein mögliches Therapeutikum fungieren könnte. Die Mäuse erhielten währenddessen kein Antibiotikum.

Die Experimente unterstützen die Hypothese, dass VitD antiinflammatorische Eigenschaften besitzt und die Immunantwort während einer bakteriellen Meningitis beeinflusst. Mäuse, die einen niedrigen VitD-Gehalt im Futter hatten, starben eher als Mäuse, die eine normale oder eine VitD-reiche-Ernährung erhielten. Außerdem überlebten am Ende des Versuches weniger Mäuse als in den beiden letztgenannten Gruppen. Es wurde nachgewiesen, dass eine VitD-Supplementierung zu einer signifikant erhöhten Produktion des antiinflammatorischen Zytokins IL-10 und zu einer signifikant verringerten Produktion des proinflammatorischen Zytokins IL-6 im ZNS führte.

\subsection{Der Zusammenhang zwischen einem Vitamin-D-Mangel und der erhöhten Sterblichkeit der Mäuse bei einer E.-coli-Meningitis}

Im ersten Versuch zur Sterblichkeit der Mäuse wurden diese nach der intrazerebralen Infektion mit E. coli 14 Tage lang in regelmäßigen Abständen beobachtet und deren Verhalten protokolliert. Das Ergebnis war, dass signifikant mehr N-VitD-Mäuse (15 von 17$)$ als S-VitD (10 von 21$)$ oder H-VitD (8 von 15) verstarben. Dies bedeutet, dass ein Vitamin-D-Mangel zu einer signifikant erhöhten Sterblichkeit der Mäuse bei der experimentellen bakteriellen Meningitis führte.

De Haan und Kollegen (2014) untersuchten in einer Metaanalyse anhand von zwei Patientengruppen (VitD $\leq 50 \mathrm{nmol} / \mathrm{l} v \mathrm{vs} \geq 50 \mathrm{nmol} / \mathrm{l}$ ) den Zusammenhang zwischen einem Vitamin-D-Mangel und einer erhöhten Mortalität bei schwerkranken Patienten. Schwerkranke Patienten wurden definiert als Patienten mit einer hohen Infektanfälligkeit, wodurch sie ein hohes Risiko für lebensbedrohliche Krankheiten hatten. 
Es wurden 9715 schwerkranke Patienten (im Durchschnitt 62 Jahre alt, $53 \%$ Männer) mit einer durchschnittlichen 25VitD-Serumkonzentration von $45 \mathrm{nmol} / \mathrm{l}$ analysiert. Das Ergebnis dieser Untersuchung war, dass ein VitD-Mangel ( $\leq 50 \mathrm{nmol} / \mathrm{l}$ ) das Auftreten von Sepsis (RR: relatives Risiko: 1,46) und Infektionen $(1,49)$ sowie die 30 -Tage-Mortalität $(1,42)$ und die intrahospitale Mortalität $(1,79)$ erhöhte. Passend zu den Ergebnissen dieser Dissertation war somit die Mortalität in der Vitamin-D-Mangel-Gruppe höher als in der suffizienten VitD-Gruppe. Außerdem erhöht ein VitD-Mangel die systemische Entzündungsreaktion, was zu einem Multiorganversagen und somit zu einer erhöhten Mortalität führen kann (De Haan et al. 2014). Der neuronale Schaden bei einer bakteriellen Meningitis entsteht gleichzeitig durch Nekrosen im Neokortex und anderen Hirnregionen sowie durch Apoptosen im Gyrus dentatus hippocampi (Nau et al. 1999; Zysk et al. 1996). Bei einer Pneumokokken-Meningitis führt $u$. a. die vom Erreger freigesetzte Lipoteichonoder Teichonsäure direkt zu einer Apoptose (Bermpohl et al. 2005). Das 1,25VitD kann hier eingreifen, da es direkt oder indirekt mehr als 200 Gene kontrolliert und somit z. B. die Regulation der Zellproliferation und deren Differenzierung und u. a. auch die Apoptose beeinflusst (Holick 2007). Es scheint somit einen Zusammenhang zwischen VitD und der Beeinflussung der Apotose zu geben, was in dieser Arbeit jedoch nicht näher untersucht wurde.

Bei der Behandlung einer bakteriellen Meningitis gilt es nicht nur, die Mortalität und Morbidität mit einer geeigneten Therapie (s. 1.1) zu verringern, sondern schon im Vorfeld schädigende Erkrankungsfaktoren einzudämmen bzw. geeignete Prophylaxemaßnahmen zu entwickeln. Deshalb wird nun auf die antibakterielle Rolle des VitD sowie auf die meningeale Leukozyteninfiltration eingegangen. Anschließend wird die bei VitD-Gabe erhöhte Produktion des antiinflammatorischen IL-10 und die verringerte Produktion des proinflammatorischen IL-6 im ZNS diskutiert.

\subsection{Die geringe antibakterielle Funktion des Vitamin D}

In den Versuchen waren zwischen den drei Gruppen keine signifikanten Unterschiede bezüglich der bakteriellen Titer feststellbar, weder in Kleinhirn und Milz im Überlebensversuch noch in Kleinhirn, Milz und Blut bei Mäusen, die 20 Stunden nach der Infektion getötet wurden. 
Es zeigte sich jedoch, dass es bei den überlebenden Mäusen aufgrund einer hohen VitD-Konzentration 14 Tage nach der Infektion zu einer besseren Eliminierung von Bakterien im Kleinhirn kam. Dies bedeutet, dass normale sowie höhere Vitamin-DKonzentrationen zu einer höheren Infektionsresistenz führen, da Mäuse dieser beiden Gruppen Pathogene offensichtlich besser eliminieren konnten. Ein antibakterieller Effekt des VitD konnte in dieser Arbeit jedoch nicht dargestellt werden. Die im Vorfeld aufgestellte Hypothese, dass VitD eventuell antibakteriell bei der bakteriellen Meningitis wirken könnte, beruht auf Vorarbeiten von Rook und Kollegen (1986), die Untersuchungen zur Rolle des VitD bei der Tuberkulose durchführten. Menschliche Monozyten wurden drei Tage lang mit oder ohne Metabolite von VitD kultiviert und anschließend mit dem Erreger Mycobacterium tuberculosis infiziert. Es stellte sich hierbei heraus, dass die aktive Form 1,25VitD in vitro das Wachstum von M. tuberculosis begrenzen konnte. Wie genau dieser antibakterielle Effekt des VitD zustande kam, war 1986 jedoch noch nicht bekannt. In aktuelleren Studien zum Mycobacterium tuberculosis (Yuk et al. 2009) wurde nun gezeigt, dass 1,25VitD zu einer Autophagozytose in menschlichen Monozyten über Expression des antimikrobiellen Peptids Cathelicidin führte.

Vitamin D scheint somit in der Lage zu sein, die Expression von antibakteriellen Proteinen wie Cathelicidin und ß-Defensin in einer Vielzahl von Zelltypen mit hieraus resultierender erhöhter Erreger-Phagozytose zu induzieren (Hewison 2011). Dass das VitD für die antimikrobielle Aktivität des Cathelicidins unverzichtbar ist, spiegelt sich auch in der Tatsache wider, dass die Promotorregion des Cathelicidin-Gens ein VDRE (vitamin D response element) besitzt (Liu et al. 2007). Cathelicidine gehören zur Familie der antimikrobiellen Peptide und somit zum angeborenen Immunsystem. Sie werden u. a. in Neutrophilen und Epithelzellen als inaktive Propeptide gespeichert, nach Aktivierung sezerniert und können anschließend ihre antimikrobielle Wirkung entfalten (Cowland et al. 1995). Sie sind in der Lage u. a. gramnegative Bakterien abzutöten, indem sie die Bakterienmembranen penetrieren können (Niyonsaba et al. 2003).

Eine Tuberkulose wird ausgelöst, indem zunächst das $M$. tuberculosis auf Makrophagen des angeborenen Immunsystems trifft: Die Makrophagen exprimieren an ihrer Oberfläche den TLR, der die PAMPs auf den M.-tuberculosis-Erregern erkennt. Die Erreger werden phagozytiert und können über Jahre hinweg in den Makrophagen weiterleben (Xu et al. 2014). 
Die Aktivierung des TLR durch die PAMPS führt außerdem zu einer vermehrten Expression des VDR und des Enzyms CYP27B1, welches 25VitD zu 1,25VitD hydroxyliert. Somit nimmt VitD an der Immunantwort der Tuberkulose teil. Zusammen mit der durch TLR-Aktivierung ausgelösten Produktion u. a. des proinflammatorischen TNF wird die Apoptose und Autophagie von infizierten Makrophagen reguliert. Die Autophagie dient dazu, die in Makrophagen residenten Pathogene zu eliminieren, um eine unkontrollierte Inflammation des Wirts und somit seiner Schädigung zu minimieren (Xu et al. 2014). Nicht nur in vitro wurde ein positiver Effekt des VitD bei der Tuberkulose nachgewiesen, sondern auch in klinischen Studien. Bei Patienten mit einer pulmonalen Tuberkulose führte die Substitution hoher Vitamin-D-Dosen nach 12 Wochen zu einer Verbesserung der klinischen und bildgebenden Befunde. Ebenfalls konnte bei betroffenen Patienten unter dieser Therapie eine verbesserte Immunaktivierung, gemessen an einer IFN- $\gamma$ Freisetzung, gezeigt werden (Salahuddin et al. 2013). Somit ist bei der Tuberkulose ein antibakterieller Effekt des VitD nachgewiesen.

Aufgrund dessen wurden vergleichende Studien zur Rolle des VitD bei der bakteriellen Meningitis durchgeführt. In der in-vitro-Studie von Djukic und Kollegen (2014) im experimentellen Modell der E.-coli-Meningitis wurde gezeigt, dass ein VitDMangel in kultivierten Mikrogliazellen zu einer verringerten Phagozytoserate und einer reduzierten intrazellulären Tötung von E. coli führte. Somit kann hieraus geschlussfolgert werden, dass ein VitD-Mangel die Resistenz des Gehirns gegenüber bakteriellen Infektionen schwächt (Djukic et al. 2014).

Der Grund für die nur geringen antibakteriellen Eigenschaften des VitD in dem Mausmodell dieser Dissertation könnte sein, dass es bei der Maus im Gegensatz zum Menschen und Schimpansen kein vitamin $D$ response element und kein Cathelicidin-Gen, welches durch VitD induziert wird, gibt (Gombart et al. 2005). Vermutlich gibt es noch andere Mediatoren, die an der VitD-abhängigenImmunantwort beteiligt sind, in dieser Arbeit jedoch nicht untersucht wurden.

\subsection{Vitamin D und die meningeale Leukozyteninfiltration}

Aufgrund der Tatsache, dass es im Gehirn eine Blut-Hirn-Schranke und eine BlutLiquor-Schranke gibt, sieht es zunächst so aus, als ob es einen zuverlässigen Schutz vor dem unkontrollierten Eintritt schädlicher Pathogene gäbe (Lüllmann-Rauch 2009). 
Auf der anderen Seite verhindert die BHS aber auch, dass Blutbestandteile, die für eine Immunantwort benötigt werden, in den Liquor gelangen (Arda et al. 2008; Pachter et al. 2003). Ein weiteres Problem ist, dass Pathogene die Möglichkeit haben die BHS und BLS transzellulär, parazellulär oder durch infizierte Phagozyten zu passieren (Pulzova et al. 2009). Bei einer Infektion der bakteriellen Meningitis werden sowohl beim Menschen als auch im Tiermodell vermehrt Leukozyten, besonders Granulozyten und in geringem Maße Monozyten und Makrophagen gebildet, da es nur wenige immunkompetente Zellen wie ortsständige Makrophagen und dendritische Zellen im ZNS gibt (Nau und Brück 2002; Doran et al. 2016; Johnston et al. 2004). Die Leukozytenrekrutierung aus dem Blut in den Liquor wird hierbei durch die Interaktion zwischen PAMPs auf den S.-pneumoniae-Erregern der bakteriellen Meningitis und den PRRs von den APCs durch eine Inflammation mit Bildung von Zytokinen, Chemokinen und anderen inflammatorischen Produkten und infolge einer Schwächung der BHS begünstigt (Doran et al. 2016).

In einer Studie von Mildner und Kollegen (2008) zur experimentellen bakteriellen Meningitis mit dem Erreger $S$. pneumoniae wurde festgestellt, dass bereits 12 Stunden nach der bakteriellen Infektion einer Maus sowohl

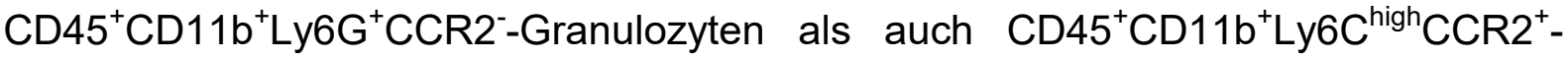
inflammatorische-Monozyten vermehrt in die Meningen einwanderten. Durch die Freigabe inflammatorischer Mediatoren können Granulozyten dem ZNS Schaden zufügen. Aufgrund dessen haben die Makrophagen in den Meningen die Funktion, das Gewebe des Gehirns vor der Invasion von Granulozyten und Bakterien zu schützen. Hierdurch wurden neuronale Verletzungen bei der S.-pneumoniaeMeningitis verhindert. Andererseits üben Granulozyten auch positive Effekte aus, da Mäuse mit fehlender Expression der CD45 ${ }^{+} \mathrm{CD} 11 \mathrm{~b}^{+} \mathrm{Ly} 6 \mathrm{G}^{+} \mathrm{CCR} 2^{-}-\mathrm{Granulozyten}$ eine höhere Letalität sowie höhere bakterielle Titer im Gehirn zeigten. Dagegen waren CD $45^{+}$CD $11 b^{+}{\text {Ly } 6 C{ }^{\text {high }} \text { CCR2 }}^{+}$-Monozyten offenbar nicht an der Kontrolle einer bakteriellen S.-pneumoniae-Infektion beteiligt. Mäuse mit fehlender Expression dieser Monozyten hatten keinen schweren Krankheitsverlauf bei der experimentellen S.-pneumoniae-Meningitis (Mildner et al. 2008). 
Im Rahmen der E.-coli-Meningitis schien das Fehlen der Monozyten einen gewissen immunsupressiven Effekt auszuüben. Mäuse mit gleichzeitiger fehlender Expression der Monozyten und Granulozyten zeigten eine höhere Infektionsanfälligkeit und wiesen höhere Bakterientiter in der Milz und im Kleinhirn auf als Mäuse, denen nur Granulozyten fehlten (Ribes et al. 2013).

In den Ergebnissen dieser Dissertation wurde die meningeale Leukozyteninfiltration nicht signifikant durch unterschiedliche VitD-Ernährungen beeinflusst. Auf den Frontalschnitten des Großhirns der Mäuse, die $20 \mathrm{~h} \mathrm{p}$. i. getötet wurden, zeigten sich keine Unterschiede bezüglich der Leukozytenanzahl. Im Einklang dazu steht die Tatsache, dass auch mit der FACS-Analyse keine signifikanten Ergebnisse bezüglich der unterschiedlichen Zellreihen erzielt werden konnten.

\subsection{Vitamin D und dessen Wirkung auf die Ausschüttung von Zytokinen und Chemokinen}

Als Nächstes wurde die Produktion von Zytokinen und Chemokinen nach einer E.coli-Infektion in diesem Mausmodell untersucht. Es ist allgemein bekannt, dass Pathogene der bakteriellen Meningitis wie S. pneumoniae das ZNS z. B. über den hämatogenen Weg oder per continuitatem nach einer Mastoiditis, Otitis oder Sinusitis erreichen. Der Kontakt mit dem Erreger oder seinen Zellwandbestandteilen löst infolgedessen eine Immunantwort aus (Doran et al. 2016; Mildner et al. 2008). Es resultiert eine Entzündungsreaktion, indem vermehrt Zytokine, Chemokine, Stickstoffmonoxid (NO) oder Matrix-Metalloproteasen (MMP) freigesetzt werden (Leib und Täuber 2000; lliev et al. 2004). Mikrogliazellen reagieren auf bakterielle und endogene Stimulantien z. B. mit der Freisetzung proinflammatorischer Zytokine und Stickoxid-Radikale (NO) (Iliev et al. 2004, Ebert et al. 2005, Lotz et al. 2005).

In einem Rattenmodell wurde gezeigt, dass Lipoteichonsäuren (Zellwandbestandteile von grampositiven Erregern) sowohl ortsständige als auch eingewanderte Leukozyten dazu veranlassten, verstärkt MMP-9 zu produzieren. MMP-9 führte infolgedessen zu einer Schädigung der BHS (Hsieh et al. 2010; Sellner und Leib 2006). 
Diese Entzündungsreaktion dient auf der einen Seite dazu, die Immunabwehr des Körpers zu aktivieren, um nachfolgende Reaktionen zu kontrollieren. Auf der anderen Seite können durch eine unkontrollierte Inflammation diese Bestandteile der Abwehr jedoch auch einen Neuronenschaden hervorrufen (Leib und Täuber 2000; Ramesh et al. 2013). Das NO kann z. B. toxisch für die Wirtszelle sein und eine hohe Konzentration des MMP-9 ist z. B. bekannt für neurologische Spätfolgen nach einer bakteriellen Meningitis (lliev et al. 2004; Nau et al. 2015). Hierzu gehören u. a. Gehörverlust und kognitive Beeinträchtigungen (Leppert et al. 2000). Es ist bekannt, dass das Vitamin $D$ in all diese Immunreaktionen eingreift: Es scheint z. B. eine wichtige Rolle als Antioxidans bei zerebralen oxidativen Prozessen durch seine Interaktion mit reaktivem Sauerstoff und Stickoxid zu spielen (Garcion et al. 2002; Garcion et al. 2003). Djukic und Kollegen (2014) zeigten bei experimentellen Arbeiten zur E.-coli-Meningitis anhand von murinen Mikrogliazellkulturen, die aus den Gehirnen neugeborener Mäuse präpariert wurden, dass eine Ernährung der Mäuse mit hoher VitD-Konzentration zu einem Anstieg der E.-coli-Phagozytoserate in den aus Neugeborenen gewonnenen Mikrogliazellen zur Folge hatte, wodurch die Infektionsresistenz gestärkt wurde. Außerdem besteht die Vermutung, dass 1,25VitD die Genexpression antimikrobieller Proteine unterstützt und bei der Regulation antiund proinflammatorischer Zytokine mitwirkt (Bergman et al. 2015).

In den Untersuchungen zu dieser Dissertation führte eine E.-coli-Infektion zu der Produktion verschiedener Zytokine und Chemokine wie IL-6, IL-10, KC und MIP-2. Dabei waren bei den H-VitD-Mäusen die Menge an proinflammatorischen IL-6 im Kleinhirn (Überlebensversuch, 20 h-Versuch), KC im Kleinhirn (Überlebensversuch, 20 h-Versuch) sowie in der Milz (Überlebensversuch) und MIP-2 in der Milz (Überlebensversuch) reduziert, währenddessen die Bakterientiter unverändert blieben. Die Vermutung ist, dass die protektive Rolle des VitD mit der verringerten Produktion proinflammatorischer Zytokine wie IL-6 und anderer Chemokine wie KC und MIP-2 und der erhöhten Produktion des antiinflammatorischen Zytokins IL-10 zusammenhing. Diese Ergebnisse werden nun im Folgenden mit anderen Studien zur bakteriellen Meningitis verglichen. Hierbei wird zunächst die Rolle diverser Zytokine (IL-6, IL-10 und IFN-y) und die der Chemokine (KC und MIP-2) bei der Inflammationsreaktion diskutiert. Im Fokus steht dabei immer der Einfluss des Vitamin D auf diese Entzündungsmediatoren. 
Studien von Mook-Kanamori et al. (2011) und Doran et al. (2016) zeigen, dass zu Beginn einer S.-pneumoniae-Meningitis u. a. die proinflammatorischen Zytokine IL-1, TNF- $\alpha$ und IL-6 produziert werden. Diese sorgen für eine Erhöhung der Ädhäsionsfaktoren am Kapillarendothel und locken somit weitere Leukozyten aus dem Blut in den Liquorraum. Das proinflammatorische IL-6 ist überaus wichtig, da es die Akute-Phase-Reaktion induziert und zur Produktion der Akute-Phase-Proteine in der Leber führt (Hansen et al. 2015). In dieser Dissertation führte eine hohe VitDKonzentration zu einer verringerten Produktion des proinflammatorischen IL-6. Hieraus resultierte vermutlich eine geringere Mortalitätsrate. Im Einklang hierzu stehen Studien von Zhang und Kollegen (2012), die untersuchten, wie sich VitD auf die IL-6-Produktion auswirkt: Es wurden menschliche Zellen (PBMC) 24 Stunden lang mit VitD vorbehandelt und anschließend mit LPS stimuliert. VitD verringerte hierbei die Produktion des IL-6.

Ein weiteres proinflammatorisches Zytokin, das IFN- $\mathrm{y}$, ist eines der bedeutendsten Zytokine im T-Helferzellen-Signalweg bei der bakteriellen Meningitis. Bei der Pneumokokken-Meningitis war dessen Konzentration im Liquor erhöht (MookKanamori et al. 2011). Das Zusammenspiel von VitD und IFN- $\gamma$ zeigten Fabri und Kollegen (2011) in einer Studie an menschlichen Monozyten mit dem Erreger Mycobacterium tuberculosis. Die Monozyten wurden mit diesem Erreger infiziert und anschließend mit IFN-ץ behandelt. Hierbei sollte überprüft werden, ob VitD Einfluss auf die antimikrobielle Tätigkeit des IFN-Y ausübte. Das Ergebnis war, dass eine hohe VitD-Konzentration das Wachstum des M. tuberculosis signifikant verringerte. Eine niedrige VitD-Konzentration hatte jedoch keinen bzw. nur einen geringen Effekt. In dieser Dissertation gab es jedoch keine signifikanten Ergebnisse bei der Produktion dieses Zytokins in der akuten Phase der Infektion (Überlebensversuch). Die Konzentrationen des IFN- $\gamma$ waren bei allen Gruppen unterhalb der Nachweisgrenze $(\leq 7,5 \mathrm{pg} / \mathrm{ml})$. Bei dem $20 \mathrm{~h}$-Versuch waren die IFN- $\gamma$ Konzentrationen sehr gering. Es zeigten sich auch hier keine Unterschiede zwischen den Gruppen. Daraus ist abzuleiten, dass IFN- $y$ in diesem Modell der bakteriellen Meningitis nicht durch eine VitD-Supplementation beeinflussbar ist und auch keinen protektiven Effekt in diesem Modell ausübte. 
Signifikant war dagegen die Produktion des antiinflammatorischen IL-10 im Kleinhirn der H-VitD-Mäuse im Überlebensversuch dieser Dissertation. Antiinflammatorische Zytokine sind äußerst wichtig für den Organismus des Wirts, da eine unregulierte Produktion von Zytokinen und Chemokinen zu überschießenden Immunreaktionen führen kann, wodurch Zellschäden und Krankheiten entstehen können (Kishimoto 2006). Mittal et al. (2010) führten in-vivo-Versuche an Mäusen zur Funktion des IL-10

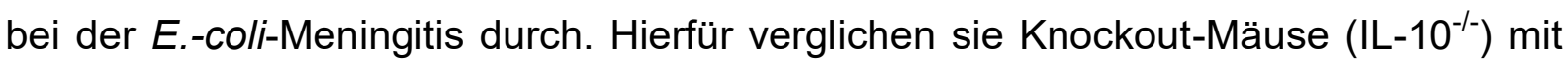
Wildtyp-Mäusen: Beide Gruppen wurden intranasal mit $10^{3} \mathrm{CFU}$ E. coli infiziert. Hierbei zeigte sich histopathologisch, dass die Knockout-Mäuse mehr Neutrophile u. a. in den Leptomeningen vorwiesen als die Wildtyp-Mäuse und auch die Entzündungsreaktion im Gehirn ausgeprägter war. Somit wurde verdeutlicht, dass die Produktion des IL-10 das Überleben des Wirts und die Kontrolle über die Pathogene sicherte. Orihuela et al. (2006) führten eine in-vivo-Studie an Mäusen durch, die an einer S.-pneumoniae-Meningitis litten. Eine Überexpression des IL-10 führte hierbei zu einer Verringerung des neuronalen Schadens, der durch die Pathogene ausgelöst wurde. VitD wirkt hierbei verstärkend antiinflammatorisch auf das Immunsystem u. a. durch Stimulierung der IL-10-Sezernierung dendritischer Zellen und durch Regulation der proinflammatorischen Zytokine (Bergman et al. 2015; De Castro Kroner et al. 2015).

Des Weiteren gab es Unterschiede bei der Produktion der Chemokine KC und MIP-2 zwischen der $\mathrm{H}$ - und $\mathrm{N}$-VitD-Gruppe: Im Kleinhirn und in der Milz schüttete die $\mathrm{H}$ VitD-Gruppe weniger KC und MIP-2 als die N-VitD-Gruppe aus (Überlebensversuch und $20 \mathrm{~h}$-Versuch). Studien zeigen, dass die Produktion des MIP-2 durch Immunzellen des Gehirns u. a. eine Zerstörung der BHS, ein Hirnödem und eine Liquor-Leukozytose bei der S.-pneumoniae-Meningitis (Kaninchenmodell) verursachte. Auch KC kann hierzu beitragen (Ribes et al. 2013; Ramesh et al. 2013). Somit führte eine hohe VitD-Konzentration in den Versuchen zu dieser Dissertation zu einer verringerten Produktion der Chemokine KC und MIP-2 und verhinderte aufgrund dessen vermutlich die zuvor genannten negativen Effekte, die KC und MIP2 bei einer bakteriellen Meningitis ausüben.

Im Folgenden werden nun Therapiemöglichkeiten der bakteriellen Meningitis und insbesondere die zukünftige Rolle des Vitamin D diskutiert. 


\subsection{Ausblick}

Die bakterielle Meningitis stellt, wie eingangs beschrieben, aufgrund der hohen Letalität und der neuronalen Spätfolgen noch immer eine gravierende Erkrankung dar (Adriani et al. 2015). Der ungünstige klinische Verlauf wird hierbei u. a. durch die massive Inflammation des Immunsystems als Antwort auf Erregerbestandteile hervorgerufen (Doran et al. 2016). Die initiale Antibiotikatherapie bei der ambulant erworbenen bakteriellen Meningitis im Erwachsenenalter beinhaltet eine Kombination aus Ampicillin und einem Cephalosporin der Gruppe 3a (z. B. Ceftriaxon) (DGN 2016; Nau et al. 2015). Ceftriaxon ist ein Cephalosporin der dritten Generation und gehört zur Gruppe der $\beta$-Laktam-Antibiotika. Adjunktiv wird die Gabe von Dexamethason, einem Kortikosteroid, empfohlen (DGN 2016). In einer aktualisierten Metaanalyse (25 Studien, 4121 Patienten) reduzierte Dexamethason die Letalität der Pneumokokken-Meningitis und verringerte die Häufigkeit schwerer Hörstörungen bei der Haemophilus-influenzae-Meningitis. Bei der Meningokokken-Meningitis konnten keine positiven Effekte nachgewiesen werden. Auch in Entwicklungsländern gab es keine Vorteile bei der Gabe von Dexamethason (DGN 2016). Das Kortikosteroid Dexamethason wird jedoch auch ambivalent gesehen, da es z. B. im Rattenmodell der S.-pneumoniae-Meningitis den Neuronenschaden und kognitive Defizite verschlimmerte ( $\mathrm{Nau}$ et al. 2015). Dexamethason und das Antibiotikum wurden 18 Stunden nach der Infektion zusammen injiziert. Im Gegensatz zur Kontrollgruppe war bei der Dexamethasongruppe 34 Stunden nach der Infektion signifikant mehr neuronale Apoptose im Gyrus dentatus des Hippocampus sichtbar (Leib et al. 2003). Somit muss nach weiteren Therapiemöglichkeiten gesucht werden, da z. B. in den letzten Jahren auch ein signifikanter Anstieg multiresistenter Stämme, u. a. von E. coli, beobachtet wurde (Pouillot et al. 2012). Zusätzlich fordert die zuvor genannte Ambivalenz des Kortikosteroids eine Suche nach anderen Adjuvantien. Die Entwicklung neuer entzündungshemmender Therapien ist hierbei die einzige erfolgsversprechende Strategie, um die Prognose der bakteriellen Meningitis zu verbessern. Somit rückt die Gabe von VitD in den Vordergrund, da in dieser Dissertation herausgestellt wurde, dass VitD Entzündungsvorgänge während der E.coli-Meningitis beeinflusste und somit zukünftig ein vielversprechendes Mittel zur Steigerung der Infektionsresistenz darstellt. 
In dieser Dissertation wurde sowohl die Gefahr eines VitD-Mangels bei einer E.-coliMeningitis verdeutlicht als auch die immunmodulatorischen Funktionen des VitD herausgestellt. Jeder Einzelne kann präventiv durch die Beachtung eines gesunden Lebensstils, der sich durch Aufhalten im Freien bei Sonnenlicht und durch eine gesunde ausgewogene Ernährung äußert, einen VitD-Mangel und nachfolgende Erkrankungen von Beginn an verhindern (Spiro und Buttriss 2014). Da das VitD aktuell und auch in Zukunft ein vielversprechendes Adjuvans darstellen wird, ist es erforderlich, Fragen, die durch diese Dissertation nicht beantwortet wurden, mit Hilfe von weiteren klinischen, in-vivo-, und in-vitro-Studien zu klären. Um die Letalität und neurologischen Komplikationen bei Patienten mit bakterieller Meningitis zu mindern, stellt die Beeinflussung der Entzündungsreaktion und der am Neuronenuntergang beteiligten Mediatoren somit derzeit einen der möglichen Ansatzpunkte dar. 


\section{Zusammenfassung}

Die bakterielle Meningitis, welche besonders Früh- und Neugeborene sowie geriatrische und immunsupprimierte Menschen betrifft, stellt eine gravierende Infektion des Zentralnervensystems dar. Trotz einer Antibiotikatherapie führt diese Erkrankung bei $20 \%$ der Patienten zum Tod. Nach dem Überleben der Krankheit können in bis zu 70 \% der Fälle neurologische und neuropsychologische Spätfolgen auftreten. Des Weiteren erschwert der Anstieg mulitiresistenter Erregerstämme, wie z. B. des E. coli, die Therapie erheblich. Hinsichtlich der Suche nach neuen Therapieansätzen zeigen Studien, dass das Vitamin D eine wichtige Rolle bei der Infektionsbekämpfung hat und Entzündungsreaktionen von Immunzellen kontrolliert. Die Pathophysiologie des Wirkmechanismus von Vitamin D im ZNS bei der E.-coliMeningitis wurde bisher noch nicht dargestellt.

Infolgedessen sollte in dieser Arbeit untersucht werden, ob eine orale Vitamin-DGabe zu einer erhöhten Infektionsresistenz des Gehirns gegenüber E.-coliInfektionen und zu einer verringerten Sterblichkeit in vivo führte. Die Hypothese war, dass Mäuse, die mit Vitamin D angereichertes Futter erhielten, eine höhere Infektionsresistenz gegenüber Mäusen mit einer niedrigen Vitamin-D-Aufnahme zeigten. Mit Hilfe der in-vivo-Experimente wurde untersucht, ob Vitamin D nach intrazerebraler Infektion mit E.-coli-Erregern den klinischen Verlauf der Infektion, die Bakterientiter, die meningeale Leukozyteninfiltration sowie die Entzündungsreaktion von Zytokinen und Chemokinen beeinflusste. Hierzu erhielt die erste Gruppe eine Diät mit einer Standard-Vitamin-D-Konzentration, die zweite eine verringerte und die dritte eine erhöhte Vitamin-D-Konzentration. Mit diesen Experimenten konnte zum ersten Mal ein nachteiliger Effekt eines Vitamin-D-Mangels auf das Überleben von Mäusen bei der experimentellen E.-coli-Meningitis nachgewiesen werden. Mäuse mit einem Vitamin-D-Mangel starben eher und häufiger als Mäuse, die eine normale oder eine Vitamin-D-reiche Ernährung erhielten. Außerdem überlebten am Ende des Versuches weniger Vitamin-D-Mangel-ernährte-Mäuse als in den anderen beiden Gruppen. Die Versuche zeigten, dass eine Vitamin-D-Supplementierung zu einer signifikant erhöhten Produktion des antiinflammatorischen Zytokins IL-10 führte und zu einer signifikant verringerten Produktion des proinflammatorischen Zytokins IL-6 im Kleinhirn. 
Hieraus lässt sich ableiten, dass bereits eine Ernährung mit einer Standard-VitaminD-Konzentration (1500 IE/kg Futter) ausreicht, um die Anfälligkeit des Gehirns gegenüber einer E.-coli-Meningitis zu verringern. In dieser Studie konnte jedoch kein Vorteil hoher Vitamin-D-Dosen (75000 IE/kg Futter) im Vergleich zur Standard-Diät bezüglich Überleben und Krankheitsschwere gezeigt werden.

Einen weiteren Ansatz, der bisher noch nicht erforscht wurde, stellt die mögliche unterstützende protektive Funktion des Vitamin D bei der Antibiotikatherapie dar. Zukünftig soll die detaillierte Aufklärung der Pathophysiologie des Vitamin D und der damit verbundenen Aktivierung der Zytokin-/Chemokin-Kaskade ermöglichen, gezielt in die Immunantwort des ZNS einzugreifen und sowohl die Letalität als auch die neurologischen Spätfolgen der Erkrankung unter antibiotischer Therapie zu verringern. 


\section{Literaturverzeichnis}

Adam D, Doerr HW, Link H, Lode H (Hrsg.): Die Infektiologie. 1. Auflage; Springer Verlag Berlin, Heidelberg 2004

Adriani KS, Brouwer MC, van de Beek D (2015): Risk factors for community-acquired bacterial meningitis in adults. Neth $\mathrm{J}$ Med $\underline{73}, 53-60$

Albrecht LJ, Tauber SC, Merres J, Kress E, Stope MB, Jansen S, Pufe T, Brandenburg LO (2016): Lack of proinflammatory cytokine interleukin- 6 or tumor necrosis factor receptor- 1 results in a failure of the innate immune response after bacterial meningitis. Mediat Inflamm 2016, 7678542

Allocati N, Masulli M, Alexeyev MF, Di llio C (2013): Escherichia coli in europe: an overview. Int J Environ Res Public Health 10, 6235-6254

Arda B, Sipahi OR, Atalay S, Ulusoy S (2008): Pooled analysis of 2,408 cases of acute adult purulent meningitis from turkey. Med Princ Pract $17,76-79$

Balvers MGJ, Brouwer-Brolsma EM, Endenburg S, de Groot LCPGM, Kok FJ, Gunnewiek JK (2015): Recommended intakes of vitamin $D$ to optimise health, associated circulating 25 -hydroxyvitamin $D$ concentrations, and dosing regimens to treat deficiency: workshop report and overview of current literature. J Nutr Sci $\underline{4}$, e23

Beard JA, Bearden A, Striker R (2011): Vitamin D and the anti-viral state. J Clin Virol $\underline{50}, 194-200$

Berge T, Leikfoss IS, Brorson IS, Bos SD, Page CM, Gustavsen MW, Bjølgerud A, Holmøy T, Celius EG, Damoiseaux J (2016): The multiple sclerosis susceptibility genes TAGAP and IL2RA are regulated by vitamin $\mathrm{D}$ in $\mathrm{CD} 4^{+} \mathrm{T}$ cells. Genes Immun $\underline{14}, 118-127$

Bergman P, Norlin AC, Hansen S, Rekha RS, Agerberth B, Björkhem-Bergman L, Ekström L, Lindh JD, Andersson $J$ (2012): Vitamin $D_{3}$ supplementation in patients with frequent respiratory tract infections: a randomised and double-blind intervention study. BMJ Open 2, e001663

Bergman P, Norlin AC, Hansen S, Björkhem-Bergman L (2015): Vitamin D supplementation to patients with frequent respiratory tract infections: a post hoc analysis of a randomized and placebocontrolled trial. BMC Res Notes $\underline{8}, 391$

Bermpohl D, Halle A, Freyer D, Dagand E, Braun JS, Bechmann I, Schröder NWJ, Weber JR (2005): Bacterial programmed cell death of cerebral endothelial cells involves dual death pathways. J Clin Invest $\underline{115}, 1607-1615$

Bikle DD (2008): Vitamin D and the immune system: role in protection against bacterial infections. Curr Opin Nephrol Hypertens 17, 348-352

Chowdhury R, Kunutsor S, Vitezova A, Oliver-Williams C, Chowdhury S, Kiefte-de-Jong JC, Khan H, Baena CP, Prabhakaran D, Hoshen MB (2014): Vitamin D and risk of cause specific death: systematic review and meta-analysis of observational cohort and randomised intervention studies. BMJ $\underline{348}, \mathrm{~g} 1903$

Chun RF, Adams JS, Hewison M (2011): Immunomodulation by vitamin D: implications for TB. Expert Rev Clin Pharmacol 4 , 583-591

Cowland JB, Johnsen AH, Borregaard N (1995): hCAP-18, a cathelin/pro-bactenecin-like protein of human neutrophil specific granules. FEBS Lett $\underline{368}, 173-176$ 
De Castro Kroner J, Sommer A, Fabri M (2015): Vitamin D every day to keep the infection away? Nutrients $\underline{7}, 4170-4188$

De Haan K, Groeneveld ABJ, de Geus HRH, Egal M, Struijs A (2014): Vitamin D deficiency as a risk factor for infection, sepsis and mortality in the critically ill: systematic review and meta-analysis. Crit Care $\underline{18}, 660$

Deluca HF (2004): Overview of general physiologic features and functions of vitamin D. Am J Clin Nutr 80, $1689 S-1696 S$

DGE 2015 (Deutsche Gesellschaft für Ernährung), ÖGE (Österreichische Gesellschaft für Ernährung), SGE (Schweizerische Gesellschaft für Ernährungsforschung), SVE (Schweizerische Vereinigung für Ernährung): D-A-CH: Referenzwerte für die Nährstoffzufuhr. 2. Auflage, 1. Ausgabe; DGE, Bonn 2015

DGN-Leitlinie 2016: Leitlinien für Diagnostik und Therapie in der Neurologie. Kapitel: entzündliche und erregerbedingte Krankheiten. Ambulant erworbene bakterielle (eitrige) Meningoenzephalitis. [http://www.dgn.org/leitlinien (abgerufen am 22.10.2016)]

Djukic M, Onken ML, Schütze S, Redlich S, Götz A, Hanisch UK, Bertsch T, Ribes S, Hanenberg A, Schneider $S$ (2014): Vitamin $D$ deficiency reduces the immune response, the phagocytosis rate and intracellular killing rate of microglial cells. Infect Immun 82, 2585-2594

Doran KS, Fulde M, Gratz N, Kim BJ, Nau R, Prasadarao N, Schubert-Unkmeir A, Tuomanen El, Valentin-Weigand $P$ (2016): Host-pathogen interactions in bacterial meningitis. Acta Neuropathol 131, 185-209

Dusso AS, Brown AJ, Slatopolsky E (2005): Vitamin D. Am J Physiol Renal Physiol 2899, F8-F28

Ebert S, Gerber J, Bader S, Mühlhauser F, Brechtel K, Mitchell TJ, Nau R (2005): Dose-dependent activation of microglial cells by toll-like receptor agonists alone and in combination. $J$ Neuroimmunol $2005 \underline{159}, 87-96$

Fabri M, Stenger S, Shin DM, Yuk JM, Liu PT, Realegeno S, Lee HM, Krutzik SR, Schenk M, Sieling PA (2011): Vitamin D is required for IFN- $y$-mediated antimicrobial activity of human macrophages. Sci Transl Med $\underline{3}, 104 r a 102$

Fagan RP, Lambert MA, Smith SGJ (2008): The Hek outer membrane protein of Escherichia coli strain RS218 binds to proteoglycan and utilizes a single extracellular loop for adherence, invasion, and autoaggregation. Infect Immun $\underline{76}, 1135-1142$

Flicker L, Maclnnis RJ, Stein MS, Scherer SC, Mead KE, Nowson CA, Thomas J, Lowndes C, Hopper JL, Wark JD (2005): Should older people in residential care receive vitamin D to prevent falls? Results of a randomized trial. J Am Geriatr Soc $\underline{53}, 1881-1888$

Garcion E, Sindji L, Nataf S, Brachet P, Darcy F, Montero-Menei CN (2003): Treatment of experimental autoimmune encephalomyelitis in rat by 1,25 -dihydroxyvitamin $D_{3}$ leads to early effects within the central nervous system. Acta Neuropathol 105, 438-448

Garcion E, Wion-Barbot N, Montero-Menei CN, Berger F, Wion D (2002): New clues about vitamin D functions in the nervous system. Trends Endocrinol Metab $\underline{13}, 100-105$

Gerber J, Raivich G, Wellmer A, Noeske C, Kunst T, Werner A, Brück W, Nau R (2001): A mouse model of Streptococcus pneumonia meningitis mimicking several features of human disease. Acta Neuropathol 101, 499-508 
Gloth FM III, Gundberg CM, Hollis BW, Haddad JG Jr, Tobin JD (1995): Vitamin D deficiency in homebound elderly persons. JAMA $\underline{274}, 1683-1686$

Gombart AF, Borregaard N, Koeffler HP (2005): Human cathelicidin antimicrobial peptide (CAMP) gene is a direct target of the vitamin $\mathrm{D}$ receptor and is strongly up-regulated in myeloid cells by 1,25-dihydroxyvitamin $\mathrm{D}_{3}$. FASEB J $\underline{19}, 1067-1077$

Hanamsagar R, Hanke ML, Kielian T (2012): Toll-like receptor (TLR) and inflammasome actions in the central nervous system: new and emerging concepts. Trends Immunol $\underline{33}, 333-342$

Hansen JF, Bendtzen K, Boas M, Frederiksen H, Nielsen CH, Rasmussen ÅK, Feldt-Rasmussen U (2015): Influence of phthalates on cytokine production in monocytes and macrophages: a systematic review of experimental trials. PLoS ONE $\underline{10}$, e0120083

Hemachandar R, Shanmugam L, Malepati B, Venugopal S (2014): Hyper vitaminosis D: are we overprescribing vitamin D? J Family Med Prim Care $\underline{3}$, 464-466

Hewison M (2011): Antibacterial effects of vitamin D. Nat Rev Endocrinol $\underline{7}$, 337-345

Holick MF (2006): High prevalence of vitamin D inadequacy and implications for health. Mayo Clin Proc $\underline{81}, 353-373$

Holick MF (2007): Vitamin D deficiency. N Engl J Med $\underline{357}, 266-281$

Holick MF (2008): Vitamin D and sunlight: strategies for cancer prevention and other health benefits. Clin J Am Soc Nephrol $\underline{3}, 1548-1554$

Hsieh HL, Wang HH, Wu CY, Tung WH, Yang CM (2010): Lipoteichoic acid induces matrix metalloproteinase-9 expression via transactivation of PDGF receptors and NF-kappaB activation in rat brain astrocytes. Neurotox Res 17 , 344-359

Ibi M, Sawada H, Nakanishi M, Kume T, Katsuki H, Kaneko S, Shimohama S, Akaike A (2001): Protective effects of $1 \alpha, 25-(\mathrm{OH})_{2} \mathrm{D}_{3}$ against the neurotoxicity of glutamate and reactive oxygen species in mesencephalic culture. Neuropharmacology $\underline{40}, 761-771$

Iliev Al, Stringaris AK, Nau R, Neumann H (2004): Neuronal injury mediated via stimulation of microglial toll-like receptor-9 (TLR9). FASEB J 18 , 412-414

Isenberg H: Meningitis im Kindesalter und Neugeborenensepsis. 3. Auflage; Steinkopff Verlag Heidelberg, Darmstadt 1993

Johal M, Levin A (2009): Vitamin D and parathyroid hormone in general populations: understandings in 2009 and applications to chronic kidney disease. Clin J Am Soc Nephrol 4, 1508-1514

Johnston M, Zakharov A, Papaiconomou C, Salmasi G, Armstrong D (2004): Evidence of connections between cerebrospinal fluid and nasal lymphatic vessels in humans, non-human primates and other mammalian species. Cerebrospinal Fluid Res 1,2

Kim KS (2002): Strategy of Escherichia coli for crossing the blood-brain barrier. J Infect Dis $\underline{186}$, S220-S224

Kishimoto T (2006): Interleukin-6: discovery of a pleiotropic cytokine. Arthritis Res Ther $\underline{8}$, S2

Kob R, Bollheimer LC, Bertsch T, Fellner C, Djukic M, Sieber CC, Fischer BE (2014): Sarcopenic obesity: molecular clues to a better understanding of its pathogenesis? Biogerontology $\underline{16}, 15-29$ 
Koletzko B: Kinder- und Jugendmedizin. 13. Auflage; Springer Verlag Berlin Heidelberg, München 2007

Lagishetty V, Liu NQ, Hewison M (2011): Vitamin D metabolism and innate immunity. Mol Cell Endocrinol 347, 97-105

Lang PO, Aspinall R (2015): Can we translate vitamin D immunomodulating effect on innate and adaptive immunity to vaccine response? Nutrients $\underline{7}, 2044-2060$

Lee YH, Song GG (2015): Vitamin D receptor gene Fokl, Taql, Bsml, and Apal polymorphisms and susceptibility to pulmonary tuberculosis : a meta-analysis. Genet Mol Res $\underline{14}$, 9118-9129

Leib SL, Täuber MG (2000): Suche nach Strategien zur Verhinderung des Hirnschadens als Folge von bakterieller Meningitis. Schweiz Med Wochenschr 130, 928-935

Leib SL, Heimgartner C, Bifrare YD, Loeffler JM, Täuber MG (2003): Dexamethasone aggravates hippocampal apoptosis and learning deficiency in pneumococcal meningitis in infant rats. Pediatr Res $\underline{54}, 353-357$

Leppert, D, Leib SL, Grygar C, Miller KM, Schaad UB, Holländer GA (2000): Matrix metalloproteinase (MMP)-8 and MMP-9 in cerebrospinal fluid during bacterial meningitis: association with blood-brain barrier damage and neurological sequelae. Clin Infect Dis $\underline{31}, 80-84$

Linseisen J, Bechthold A, Bischoff-Ferrari HA, Hintzpeter B, Leschik-Bonnet E, Reichrath J, Stehle P, Volkert D, Wolfram G, Zittermann A (2011): Vitamin D und Prävention ausgewählter chronischer Krankheiten. Deutsche Gesellschaft Für Ernährung E. V., 1-47

Liu C, Lu M, Xia X, Wang J, Wan Y, He L, Li M (2015): Correlation of serum vitamin D level with type 1 diabetes mellitus in children: a meta-analysis. Nutr Hosp $\underline{32}, 1591-1594$

Liu PT, Krutzik SR, Modlin RL (2007): Therapeutic implications of the TLR and VDR partnership. Trends Mol Med 13,117-124

Lotz M, Ebert S, Esselmann H, Iliev AL, Prinz M, Wiazewicz N, Wiltfang J, Gerber J, Nau R (2005): Amyloidßpeptide 1-40 enhances the action of toll-like receptor-2 and -4 agonists but antagonizes toll-like receptor-9 induced inflammation in primary mouse microglial cell cultures. J. Neurochem 2005 94, 289- 298

Lüllmann-Rauch R: Taschenlehrbuch Histologie. 3. Auflage; Georg Thieme Verlag, Stuttgart 2009

Mandell E, Seedorf G, Gien J, Abman SH (2014): Vitamin D treatment improves survival and infant lung structure after intra-amniotic endotoxin exposure in rats: potential role for the prevention of bronchopulmonary dysplasia. Am J Physiol Lung Cell Mol Physiol $\underline{306}$, L420-L428

Meister T: Beeinflussung des Verlaufs von ZNS-Infektionen in immundefizienten Mäusen durch Immunstimulanzien. Med. Diss. Göttingen 2013

Mildner A, Djukic M, Garbe D, Wellmer A, Kuziel WA, Mack M, Nau R, Prinz M (2008): Ly-6G ${ }^{+}$CCR2 myeloid cells rather than $\mathrm{Ly}-6 \mathrm{C}^{\text {high }} \mathrm{CCR} 2^{+}$monocytes are required for the control of bacterial infection in the central nervous system. J Immunol $\underline{181}$, 2713-2722

Mitchell AJ, Yau B, McQuillan JA, Ball HJ, Too LK, Abtin A, Hertzog P, Leib SL, Jones CA, Gerega SK (2012): Inflammasome-dependent IFN- $\gamma$ drives pathogenesis in Streptococcus pneumoniae meningitis. J Immunol 189, 4970-4980 
Mittal R, Gonzalez-Gomez I, Panigrahy A, Goth K, Bonnet R, Prasadarao NV (2010): IL-10 administration reduces PGE-2 levels and promotes CR3-mediated clearance of Escherichia coli K1 by phagocytes in meningitis. J Exp Med 207, 1307-1319

Mofredj A, Guerin JM, Leibinger F, Mamoudi R (2000): Spontaneous Escherichia coli meningitis in an adult. Scand J Infect Dis $\underline{32}, 699-700$

Møller S, Laigaard F, Olgaard K, Hemmingsen C (2007): Effect of 1,25-dihydroxy-vitamin $D_{3}$ in experimental sepsis. Int J Med Sci 4, 190-195

Mook-Kanamori BB, Geldhoff M, van Der Poll T, van De Beek D (2011): Pathogenesis and pathophysiology of pneumococcal meningitis. Clin Microbiol Rev 24, 557-591

Mora JR, Iwata M, von Andrian UH (2008): Vitamin effects in the immune system: vitamins A and D take centre stage. Nat Rev Immunol $\underline{8}, 685-698$

Munger KL, Zhang SM, O'Reilly E, Hernán MA, Olek MJ, Willett WC, Ascherio A (2004): Vitamin D intake and incidence of multiple sclerosis. Neurology $\underline{62}, 60-65$

Muniz LR, Knosp C, Yeretssian G (2012): Intestinal antimicrobial peptides during homeostasis, infection, and disease. Front Immunol $\underline{3}, 310$

Nau R, Brück W (2002): Neuronal injury in bacterial meningitis: mechanisms and implications for therapy. Trends Neurosci $\underline{25}, 38-45$

Nau R, Soto A, Brück W (1999): Apoptosis of neurons in the dentate gyrus in humans suffering from bacterial meningitis. J Neuropathol Exp Neurol $\underline{58}, 265-274$

Nau R, Ribes S, Djukic M, Eiffert H (2014): Strategies to increase the activity of microglia as efficient protectors of the brain against infections. Front Cell Neurosci $\underline{8}, 138$

Nau R, Djukic M, Spreer A, Ribes S, Eiffert H (2015): Bacterial meningitis: an update of new treatment options. Expert Rev Anti Infect Ther 13, 1401-1423

Niyonsaba F, Hirata M, Ogawa H, Nagaoka I (2003): Epithelial cell-derived antibacterial peptides human $\beta$-defensins and cathelicidin: multifunctional activities on mast cells. Curr Drug Targets Inflamm Allergy 2, 224-231

Orihuela CJ, Fillon S, Smith-Sielicki SH, El Kasmi KC, Gao G, Soulis K, Patil A, Murray PJ, Tuomanen El (2006): Cell wall-mediated neuronal damage in early sepsis. Infect Immun $\underline{74}$, 3783-3789

Özkan B, Hatun S, Bereket A (2012): Vitamin D intoxication. Turk J Pediatr $\underline{54}, 93-98$

Pachter JS, de Vries HE, Fabry Z (2003): The blood-brain barrier and its role in immune privilege in the central nervous system. J Neuropathol Exp Neurol $\underline{62}, 593-604$

Petersen H, Patel M, Ingason EF, Einarsson EJ, Haraldsson Á, Fransson PA (2014): Long-term effects from bacterial meningitis in childhood and adolescence on postural control. PLoS ONE $\underline{9}$, e112016

Pouillot F, Chomton M, Blois H, Courroux C, Noelig J, Bidet P, Bingen E, Bonacorsi S (2012): Efficacy of bacteriophage therapy in experimental sepsis and meningitis caused by a clone O25b:H4-ST131 Escherichia coli strain producing CTX-M-15. Antimicrob Agents Chemother 56, 3568-3575 
Prinz M, Kann O, Draheim HJ, Schumann RR, Kettenmann H, Weber JR, Hanisch UK (1999): Microglial activation by components of gram-positive and - negative bacteria: distinct and common routes to the induction of ion channels and cytokines. J Neuropathol Exp Neurol $\underline{58}, 1078-1089$

Proulx N, Fréchette D, Toye B, Chan J, Kravcik S (2005): Delays in the administration of antibiotics are associated with mortality from adult acute bacterial meningitis. QJ Med $\underline{98}, 291-298$

Ptaszynski AE, Hooten WM, Huntoon MA (2007): The incidence of spontaneous epidural abscess in Olmsted County from 1990 through 2000: a rare cause of spinal pain. Pain Med $2007 \underline{8}$, 338-343

Pulzova L, Bhide MR, Andrej K (2009): Pathogen translocation across the blood-brain barrier. FEMS Immunol Med Microbiol 57, 203-213

Quraishi SA, De Pascale G, Needleman JS, Nakazawa H, Kaneki M, Bajwa EK, Camargo CA, Bhan I (2015): Effect of cholecalciferol supplementation on vitamin D status and cathelicidin levels in sepsis: A randomized, placebo-controlled trial. Crit Care Med $\underline{43}, 1928-1937$

Ramesh G., Maclean AG, Philipp MT (2013): Cytokines and chemokines at the crossroads of neuroinflammation, neurodegeneration, and neuropathic pain. Mediators Inflamm 2013, 480739

Ribes S, Ebert S, Czesnik D, Regen T, Zeug A, Bunkowski S, Mildner A, Eiffert H, Hanisch UK, Hammerschmidt $S$ (2009): Toll-like receptor prestimulation increases phagocytosis of Escherichia coli DH5a and Escherichia coli K1 strains by murine microglial cells. Infect Immun $\underline{77}$, 557-564

Ribes S, Regen T, Meister T, Tauber SC, Schütze S, Mildner A, Mack M, Hanisch UK, Nau R (2013): Resistance of the brain to Escherichia coli K1 infection depends on MyD88 signaling and the contribution of neutrophils and monocytes. Infect Immun $\underline{81}, 1810-1819$

Robert Koch-Institut (2016): Epidemiologisches Bulletin. 29. August 2016/Nr.34 [http://www.rki.de (abgerufen am 23.10.16)]

Rook GA, Steele J, Fraher L, Barker S, Karmali R, O'Riordan J, Stanford J (1986): Vitamin $D_{3}$, Yinterferon, and control of proliferation of Mycobacterium tuberculosis by human monocytes. Immunology $\underline{57}, 159-163$

Russo TA, Johnson JR (2000): Proposal for a new inclusive designation for extraintestinal pathogenic isolates of Escherichia coli: ExPEC. J Infect Dis 181, 1753-1754

Ryynänen J, Carlberg C (2013): Primary 1,25-Dihydroxyvitamin $D_{3}$ response of the interleukin 8 gene cluster in human monocyte- and macrophage-like cells. PLoS ONE $\underline{8}$, e78170

Salahuddin N, Ali F, Hasan Z, Rao N, Aqeel M, Mahmood F (2013): Vitamin D accelerates clinical recovery from tuberculosis: results of the SUCCINCT study [supplementary cholecalciferol in recovery from tuberculosis]. A randomized, placebo-controlled, clinical trial of vitamin D supplementation in patients with pulmonary tuberculosis. BMC Infect Dis $\underline{13}, 22$

Savastio S, Cadario F, Genoni G, Bellomo G, Bagnati M, Secco G, Picchi R, Giglione E, Bona G (2016): Vitamin D deficiency and glycemic status in children and adolescents with type 1 diabetes mellitus. PLoS ONE 11, e0162554

Schlögl M, Holick MF (2014): Vitamin D and neurocognitive function. Clin Interv Aging $\underline{9}$, 559-568

Schmidt H, Heimann B, Djukic M, Mazurek C, Fels C, Wallesch CW, Nau R (2006): Neuropsychological sequelae of bacterial and viral meningitis. Brain $\underline{129}, 333-345$ 
Schuchat A, Robinson K, Wenger JD, Harrison LH, Farley M, Reingold AL, Lefkowitz L, Perkins BA (1997): Bacterial meningitis in the United States in 1995. Active Surveillance Team. N Engl J Med 337, $970-976$

Schütze S, Ribes S, Kaufmann A, Manig A, Scheffel J, Redlich S, Bunkowski S, Hanisch UK, Brück W, Nau R (2014): Higher mortality and impaired elimination of bacteria in aged mice after intracerebral infection with $E$. coli are associated with an age-related decline of microglia and macrophage functions. Oncotarget $\underline{5}, 12573-12592$

Schwalfenberg GK (2008): Vitamin D and diabetes: improvement of glycemic control with vitamin $D_{3}$ repletion. Can Fam Physician 54, 864-866

Schwalfenberg GK (2011): A review of the critical role of vitamin $D$ in the functioning of the immune system and the clinical implications of vitamin D deficiency. Mol Nutr Food Res $\underline{55}$, 96-108

Schwalfenberg GK (2012): Solar radiation and vitamin D: mitigating environmental factors in autoimmune disease. J Environ Public Health 2012, 619381

Schwerk C, Tenenbaum T, Kim KS, Schroten H (2015): The choroid plexus-a multi-role player during infectious diseases of the CNS. Front Cell Neurosci $\underline{9}, 80$

Sellner J, Leib SL (2006): In bacterial meningitis cortical brain damage is associated with changes in parenchymal MMP-9/TIMP-1 ratio and increased collagen type IV degradation. Neurobiol Dis $\underline{21}$, 647-656

Spiro A, Buttriss JL (2014): Vitamin D: an overview of vitamin D status and intake in europe. Nutr Bull 39, 322-350

Stehle P, Junk K, Sack S, Volkert D (2000): Ernährung älterer Menschen. In: Deutsche Gesellschaft für Ernährung (Hrsg.): Ernährungsbericht 2000. Frankfurt am Main, 147-178

Upala S, Sanguankeo A, Permpalung N (2015): Significant association between vitamin D deficiency and sepsis: a systematic review and meta-analysis. BMC Anesthesiol $\underline{15}, 84$

Van de Beek D, de Gans J, Spanjaard L, Weisfelt M, Reitsma J, Vermeulen M (2004): Clinical features and prognostic factors in adults with bacterial meningitis. N Engl J Med $\underline{351}, 1849-59$

Vergnano S, Buttery J, Cailes B, Chandrasekaran R, Chiappini E, Clark E, Cutland C, de Andrade SD, Esteves-Jaramillo A, Guinazu JR (2016): Neonatal infections: case definition and guidelines for data collection, analysis, and presentation of immunisation safety data. Vaccine $\underline{2016}$. [http://dx.doi.org/10.1016/j.vaccine (abgerufen am 23.10.16)]

Wabitsch M, Koletzko B, Schnabel D, Moss A: Vitamin D-Versorgung im Säuglings-, Kindes- und Jugendalter. Ernährungskommission der Deutschen Gesellschaft für Kinder- und Jugendmedizin (DGKJ). Berlin 2011, 1-15.

[http://www.dgkj.de/fileadmin/user_upload/Stellungnahmen/1107_VitaminD_Lang_HP.pdf (abgerufen am 23.10.16)]

Wang X, Maruvada R, Morris AJ, Liu JO, Wolfgang MJ, Baek DJ, Bittman R, Kim KS (2016): Sphingosine 1-phosphate activation of EGFR as a novel target for meningitic Escherichia coli penetration of the blood-brain barrier. PLoS Pathog $\underline{12}$, e1005926

Windaus A, Linserst O, Luttringhaus A, Weidlinch $G$ (1932): Über das krystallisierte Vitamin $D_{2}$. Justus Liebig Ann Chem 492, 226-231 
Xu G, Wang J, Gao GF, Liu CH (2014): Insights into battles between Mycobacterium tuberculosis and macrophages. Protein Cell $\underline{5}, 728-736$

Yuk JM, Shin DM, Lee HM, Yang CS, Jin HS, Kim KK, Lee ZW, Lee SH, Kim JM, Jo EK (2009): Vitamin $D_{3}$ induces autophagy in human monocytes/macrophages via cathelicidin. Cell Host Microbe $\underline{6}, 231-243$

Zeiser R (2015): Activation of innate immunity in graft-versus-host disease: implications for novel targets? Oncol Res Treat $\underline{38}, 239-243$

Zhang Y, Leung DYM, Richers BN, Liu Y, Remigio LK, Riches DW, Goleva E (2012): Vitamin D inhibits monocyte/macrophage proinflammatory cytokine production by targeting mitogen-activated protein kinase phosphatase 1. J Immunol $\underline{188}, 2127-2135$

Zwijnenburg PJG, van der Poll T, Florquin S, Roord JJ, van Furth AM (2003): Interleukin-10 negatively regulates local cytokine and chemokine production but does not influence antibacterial host defense during murine pneumococcal meningitis. Infect Immun $\underline{71}$, 2276-2279

Zwijnenburg PJG, van der Poll T, Roord JJ, van Furth AM (2006): Chemotactic factors in cerebrospinal fluid during bacterial meningitis. Infect Immun $\underline{74}, 1445-1451$

Zysk G, Brück W, Gerber J, Brück Y, Prange HW, Nau R (1996): Anti-inflammatory treatment influences neuronal apoptotic cell death in the dentate gyrus in experimental pneumococcal meningitis. J Neuropathol Exp Neurol $\underline{55}, 722-728$ 


\section{Publikation im Zusammenhang mit dieser Dissertation}

Djukic M, Sostmann N, Bertsch T, Mecke M, Nessler S, Manig A, Nau R (2015): Vitamin $D$ deficiency decreases survival of bacterial meningoencephalitis in mice. J Neuroinflamm 12, 208-218 


\section{Danksagung}

Mein herzlicher Dank gilt meiner Doktormutter Frau PD Dr. med. Marija Djukic für ihre bewundernswerte Unterstützung und ihren unermüdlichen Einsatz bei der Versuchsplanung, der Durchführung und der Auswertung der in-vivo-Experimente!

Mein Dank gilt außerdem Herrn Prof. Dr. med. Roland Nau, der mir mit Rat und Tat zur Seite stand und bei den Laborbesprechungen Probleme jeglicher Art zu lösen wusste.

Frau PD Dr. rer. nat. Sandra Ribes danke ich für ihre kollegiale Unterstützung bei den Versuchen und die entspannte Arbeitsatmosphäre.

Frau Stephanie Bunkowski danke ich für ihre großartige Hilfe bei den ELISAMessungen!

Ein großer Dank gilt auch meinen Mitdoktoranden der Arbeitsgruppe Nau, Frau Marianne Mecke und Frau Dr. med. Anja Manig, für die kollegiale Zusammenarbeit bei in-vivo-Experimenten!

Für die Überlassung der E.-coli-K1-Stammlösung danke ich Herrn Dr. med. Gregor Zysk (Institut für medizinische Mikrobiologie, Düsseldorf).

Herrn Dr. med. Stefan Nessler danke ich für seine ausgezeichnete Unterstützung bei den FACS-Messungen und Auswertungen.

Außerdem möchte ich mich bei Herrn Prof. Dr. med. Thomas Bertsch bedanken, der zusammen mit der klinischen Chemie des Klinikums Nürnberg die Analyse der VitDKonzentrationen im Blut vorgenommen hat. 


\section{Lebenslauf}

Am 12.03.1991 wurde ich als Tochter von Rüdiger Heinrich Sostmann und Sabine Margarete Sostmann in Lingen (Ems) geboren. Meine schulische Laufbahn begann mit dem Besuch der Grundschule Johannesschule Lingen (1997-2001), wurde fortgeführt mit der Orientierungsstufe Friedensschule Lingen (2001-2003) und schließlich erwarb ich am Gymnasium Georgianum Lingen (2003-2010) im Juni 2010 die Allgemeine Hochschulreife.

Im Wintersemester 2010/2011 begann mein Studium der Zahnmedizin an der GeorgAugust-Universität Göttingen. Das Staatsexamen beendete ich am 03.06.2016 und bin seit dem 20.06.2016 approbierte Zahnärztin.

Mit den Arbeiten zur vorliegenden Dissertation begann ich im August 2013. 